\title{
Catchment Streamflow Response to Climate Change Conditioned by Historic Alterations of Land-Use: Forest Harvest, Succession, and Stand Conversion
}

\author{
David Young
}

Follow this and additional works at: https://researchrepository.wvu.edu/etd

\section{Recommended Citation}

Young, David, "Catchment Streamflow Response to Climate Change Conditioned by Historic Alterations of Land-Use: Forest Harvest, Succession, and Stand Conversion" (2014). Graduate Theses, Dissertations, and Problem Reports. 7144.

https://researchrepository.wvu.edu/etd/7144

This Thesis is protected by copyright and/or related rights. It has been brought to you by the The Research Repository @WVU with permission from the rights-holder(s). You are free to use this Thesis in any way that is permitted by the copyright and related rights legislation that applies to your use. For other uses you must obtain permission from the rights-holder(s) directly, unless additional rights are indicated by a Creative Commons license in the record and/ or on the work itself. This Thesis has been accepted for inclusion in WVU Graduate Theses, Dissertations, and Problem Reports collection by an authorized administrator of The Research Repository @ WVU. For more information, please contact researchrepository@mail.wvu.edu. 
Catchment Streamflow Response to Climate Change Conditioned by Historic Alterations of Land-Use: Forest Harvest, Succession, and Stand Conversion

by

David Young

Thesis submitted to the Davis College of Agriculture, Natural Resources, and Design at West Virginia University

in partial fulfillment of the requirements for the degree of

Masters of Science in

Forestry

Approved by

Nicolas Zegre, Ph.D., Committee Chairperson

Pamela Edwards, Ph.D.

Michael Strager, Ph.D.

Division of Forestry and Natural Resources

Morgantown, West Virginia

2014

Keywords: Hydrology, Fernow, Budyko, Climate Change, Forest Disturbance, Copyright 2014 David Young 


\section{ABSTRACT \\ Catchment Streamflow Response to Climate Change Conditioned by Historic Alterations of Land-Use: Forest Harvest, Succession, and Stand Conversion}

\section{by David Young}

Forest management practices and climate change can alter streamflow in headwater catchments by changing the balance between precipitation and factors that control evapotranspiration. To understand how water resources are changing, the impacts of climate change and forest disturbance must be isolated. Toward this end the Budyko decomposition method is applied to quantify the impacts of climate change and forest disturbance on catchments of the Fernow Experimental Forest. The Budyko framework provides the theoretical basis for the methodology and assumes variation in streamflow can be attributed to the principal controls governing climate (precipitation and potential evapotranspiration) and catchment water balance (precipitation and actual evapotranspiration). Although the Budyko framework is intended to model large-scale water balance with long-term data, this study tests the effectiveness of the method at the headwater scale and at both long-term and several fine temporal scales. This was accomplished by applying the decomposition method to planned forest disturbances and comparing the results to those obtained from the paired-catchment method. Data covering a 60 year period from a reference catchment (WS-4) and three disturbed catchments were analyzed. The disturbed watersheds were subject to forest disturbances followed by three different forms of regeneration: natural hardwood forest regrowth (WS-1), herbicide-suppressed regrowth followed by natural hardwood regrowth (WS-7), and herbicide-suppressed regrowth followed by stand conversion to a coniferous forest (WS-6). Based on this analysis forest disturbance, forest regeneration, and climate change differentially impacted streamflow. Using a Mann-Kendall trend analysis positive trends were found in climate variables: annual average and minimum temperature and growing season precipitation. Using long-term averages, the decomposition method showed that all catchments deviated in both the horizontal and vertical directions reflecting the impacts of climate and disturbance driven changes. For all catchments, the direction of change influenced by climate (dryness index) did not produce a shift in the evaporative index according to the Budyko curve. Instead, disturbance-induced changes in streamflow dampened (WS-1) or masked (WS-6, WS-7) the effects of climate change over the study period. For the reference catchment, incremental increases in streamflow are not explained by climate change alone. Analyzing species composition changes over the study period suggest that late forest succession may be causing increases in streamflow. Using linear regression and correlation the application of the Budyko framework at the headwater scale and at inter-annual timescales was supported by the paired catchment method for WS-6 and WS-7. This result was less influenced by the ability of the Budykos curve to predict actual evapotranspiration from the climate dryness index, then the sensitivity of the Budyko decomposition method to the magnitude and duration of disturbance. This study provides guidance for how the Budyko decomposition method can be applied to headwater catchments and at inter-annual time scales. In addition this study provides a starting point for understanding the future impacts of climate change at the Fernow. 


\section{TABLE OF CONTENTS}

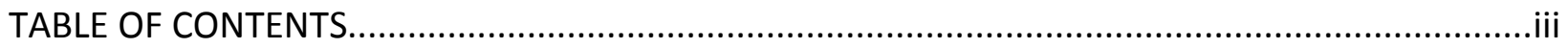

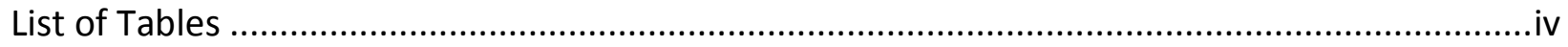

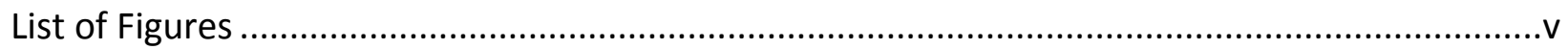

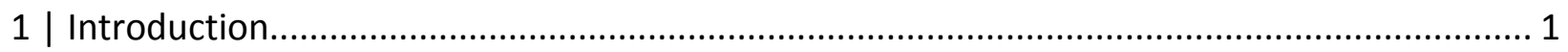

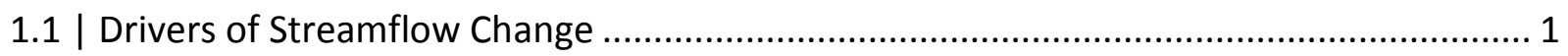

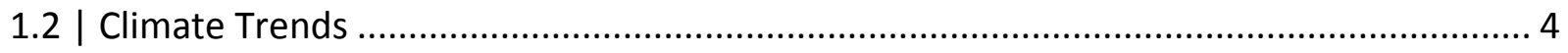

1.3 | Quantifying Past Impacts of Climate and Disturbance on Streamflow ............................ 5

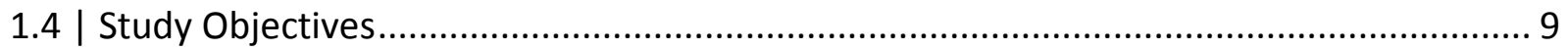

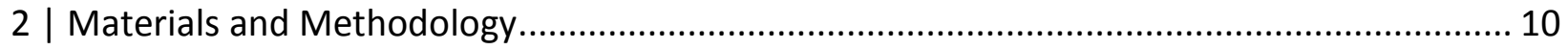

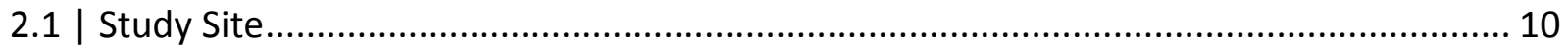

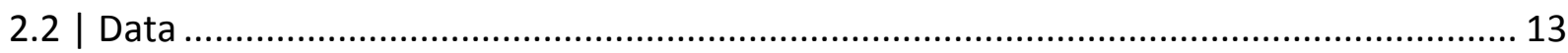

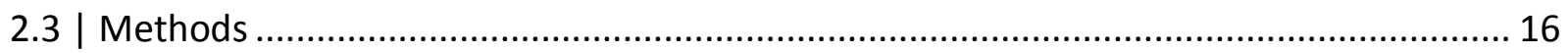

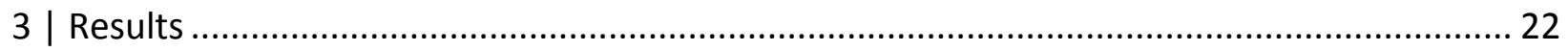

3.1 | Historic Climate Trends and Vegetation Changes...................................................... 22

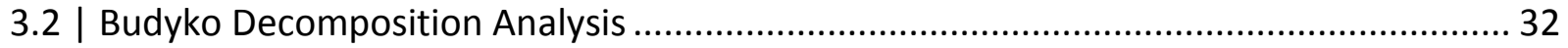

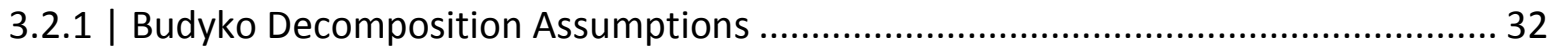

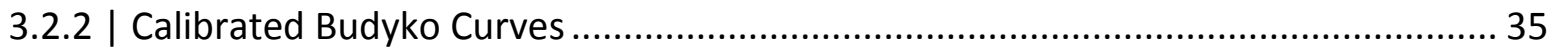

3.2.3 | Effects of Forest Disturbance During Period 1...................................................... 36

3.2.4 | Effects of Forest Disturbance and Climate Change From Period 1 to 2 …............... 37

3.2.4 | Temporal Sensitivity of the Decomposition Method................................................ 40

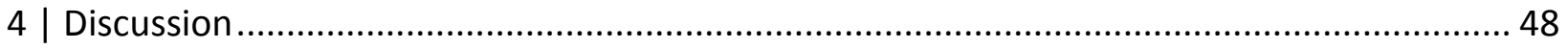

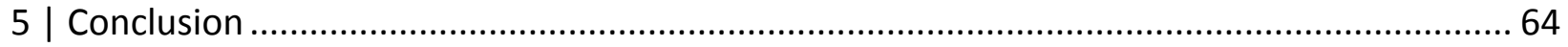

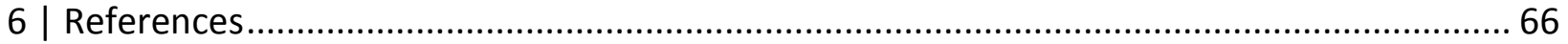




\section{List of Tables}

Table 1. Selected Experimental Catchments and Their Forest Disturbance Histories ................. 12

Table 2. Description of Morphometric. ............................................................................... 14

Table 3. Catchment Morphometric Variables...................................................................... 15

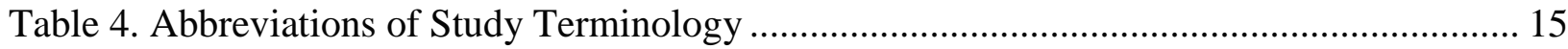

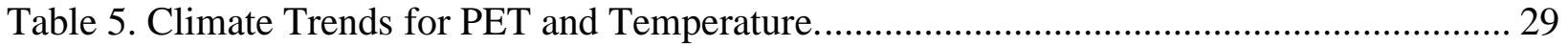

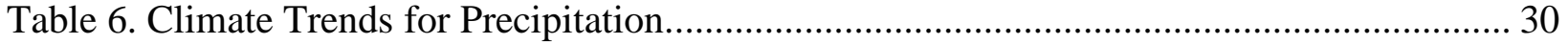

Table 7. Long-Term Averages and Percent Changes for P, Q, AET, PET* .............................. 31 


\section{List of Figures}

Figure 1. Map of The Fernow Experimental Forest. ......................................................... 11

Figure 2. Relative importance of tree species in WS-1. .................................................... 25

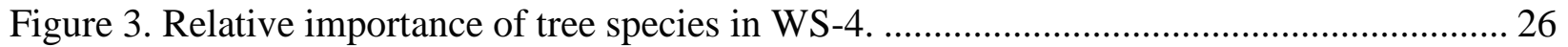

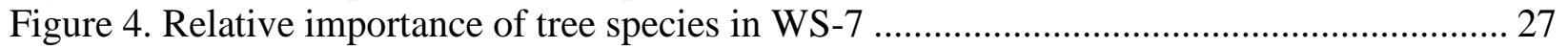

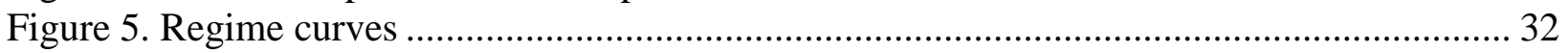

Figure 6. The decomposition assumption ..................................................................... 34

Figure 7. Cumulative precipitation versus cumulative streamflow WS-4 ............................... 35

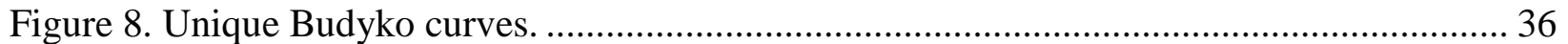

Figure 9. Effects of forest harvest............................................................................... 37

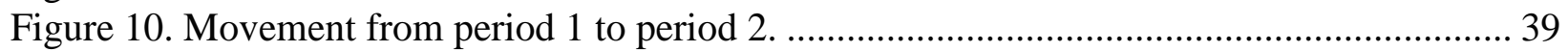

Figure 11. Percentage change in streamflow .................................................................. 40

Figure 12. Validation of change in streamflow due to forest disturbance ( $\Delta$ Qh) for WS-1....... 42

Figure 13. Validation of change in streamflow due to forest disturbance $(\Delta Q \mathrm{Q}$ ) for WS-6....... 43

Figure 14. Validation of change in streamflow due to forest disturbance $(\Delta \mathrm{Q}$ ) for WS-7 ........ 44

Figure 15. Validation of change in streamflow due to climate $(\Delta \mathrm{Qc})$ for WS-1..................... 45

Figure 16. Validation of change in streamflow due to climate $(\Delta \mathrm{Qc})$ for WS-6 ...................... 46

Figure 17. Validation of change in streamflow due to climate $(\Delta \mathrm{Qc})$ for WS-7...................... 47

Figure 18. Percent change in streamflow over 5-year time intervals ..................................... 50

Figure 19. Validation of change in streamflow due to forest disturbance for WS-6 part 2........ 58

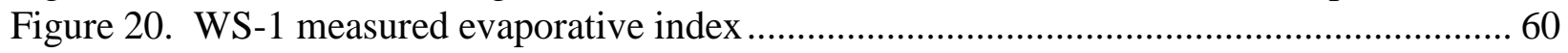

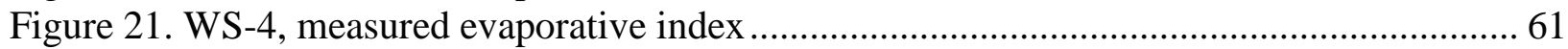

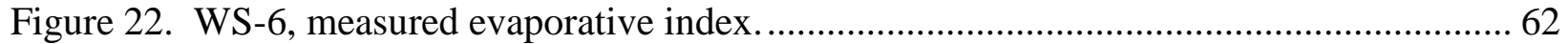

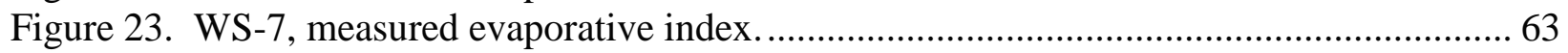




\section{1 | Introduction}

Characterizing and understanding hydrologic variability in space and time, and how this variability will change in the future is fundamental to the study and application of hydrology (Sivapalan 2005). Poff (1997) identified five components of the flow regime that describe the relationship between the range of values streamflow takes through time and the river ecosystem. This holistic description of hydrology suggests streamflow variability is the product of the coevolution of landform, climate, soils, and vegetation (Wagener et al. 2007). In recent decades, anthropogenic modifications of the climate combined with landscape disturbances have caused flow regimes to deviate from equilibrium (Milly 2007). As a consequence, the flow regimes that maintain and limit human water services and other ecosystem services are changing. For streams draining forested headwater catchments, hydrologic changes reflect forest management practices and the balance between precipitation and factors that control evapotranspiration (Campbell et al. 2011).

In established research sites, such as the Fernow Experimental Forest, the history of plant succession across experimental disturbance regimes and precipitation and temperature over those time periods are known. Therefore, streamflow can be used to assess the hydrologic responses to climate change conditioned by historic alterations of land-cover change. This study uses a waterenergy balance model to isolate the impacts of climate and forestry disturbance on streamflow over 60 years.

\section{1 | Drivers of Streamflow Change}

Climate variability and land cover disturbance are commonly recognized as principal drivers in streamflow variability of forested catchments (e.g., Wei et al. 2010). In the eastern United States, forested lands are continuously subjected to natural (e.g., extreme weather, 
invasive insects) and anthropogenic disturbances (e.g., forest harvesting, vegetation conversion). Conceptually the hydrologic impact of forest disturbance follows a general trajectory of disturbance, response, and recovery (Ebel and Mirus 2014). Traditionally, forest hydrology has quantified hydrologic response and recovery through the paired watershed approach (Hewlett and Helvey 1970, Hewlett and Pienaar 1973). The paired watershed method estimates the effect of disturbance by predicting the treated watershed against a control during pretreatment and post treatment periods. The disturbance response phase is differentiated from the recovery phase when deviations (predicted - observed streamflow) are no longer statistically different from the calibration period-defined confidence intervals. Success of paired watershed studies depends upon the strength of the relationship between the catchments during the calibration period (Zhao 2010) and similarity of state and variable conditions (i.e., climate) between the pre-disturbance and post-disturbance periods (Bosch and Hewlett 1981).

The effects of forest disturbances are well documented in published reviews (Bosch and Hewlett 1981, Stednick 1996, Brown et al. 2005). In general these studies provide evidence that forest harvesting increases streamflow due to decreased interception and transpiration, but as vegetation regrows water yield increases decline (Brown et al. 2005). In most Eastern catchments with natural regrowth, streamflow recovers to pre-harvest equilibrium within 10 years (Hornbeck et al. 1993). However, in studies that suppressed natural regrowth over multiple years, such as WS-7 at the Fernow Experimental Forest, WV, recovery was much longer (Hornbeck et al. 1993). In some cases, pre-disturbance equilibrium is never achieved. For example catchments 2 and 4 at Hubbard Brook experienced long term post-treatment change in species composition, which resulted in a forest that transpired more water. Similar changes also occurred where stand conversion from deciduous to conifer species has taken place. With 
permanent conversion, streamflow may never return to pre-treatment conditions, but instead may converge to a new equilibrium as succession progresses (Swank et al. 1988).

Concurrently with disturbance climate is also influencing hydrology and vegetation. Of the many abiotic factors that affect hydrology, temperature (T) and precipitation (P) exert firstorder controls (Mcvicor et al. 2010). Precipitation patterns affect soil moisture and influence vegetation to balance water availability with atmospheric demand. Plants achieve this balance by regulating stomatal conductance and leaf area to limit transpiration rates above water potentials and avoid permanent wilting point.

Because temperature data are readily available and temperature is an essential component of actual evapotranspiration (AET), temperature is regularly used to link vegetative responses to human induced temperature increases. In the short term, annual and seasonal temperature increases have the potential to alter the magnitude and timing of streamflow. In areas that depend on snowpacks for soil moisture recharge, increased temperatures reduce snow fall and snow pack, potentially reducing plant water availability later in the year (Hayhoe et al. 2007). Temperature increases in the spring and fall may reduce streamflow by advancing phenological controls of vegetation and inducing longer growing seasons (Kimball et al. 2004, Jolly et al. 2005, White et al. 2005). In energy-limited systems, higher temperatures are likely to increase stomatal conductance and transpiration, further reducing streamflow (Montieith 1965, Berry and Bjorkman 1980, Kirschbaum 2000). Furthermore, temperature increases likely drive the intensification of the water cycle, including precipitation (Huntington 2006).

Precipitation is also an indicator of climate change. Precipitation is the principal determinant of water availability influencing plant species composition (Emanuel et al. 1985), ecosystem net primary productivity (Boisvenue and Running 2012), and streamflow. Changes in 
vegetation and hydrology have been associated with changes in precipitation intensity (Knapp et al. 2008) and timing (Knapp et al. 2008), and the occurrence of drought (Rind et al. 1990, Allen and Breshears 1998). Vegetation type, size, and age, mediated by rooting depth, leaf area, and hydraulic conductance, differentially respond to water availability (Wullschleger et al. 1998, Binkley et al. 2002, Meinzer et al. 2005). For example, deep roots of large, mature sugar maple (Acer saccharum) trees use two to five times more water and are less sensitive to climate-driven soil moisture fluxes than small or young sugar maples (Dawson 1996). Hence, long-term changes in plant communities may occur if species cannot adapt to changes in catchment water balance and resist pressure of competition from neighboring plant communities (Byers and Norris 2011).

\section{2 | Climate Trends}

In the eastern United States, the effects of increasing global air temperatures and altered precipitation on the catchment water balance are receiving greater amounts of attention. In the mid to high latitudes of the eastern United States, warming winter temperatures are decreasing snow packs, snow-to total precipitation ratios, snow water equivalents, and annual catchment recharge (Hayhoe et al. 2007, Campbell et al. 2011). Rising temperatures in winter and spring are advancing the biological response of vegetation, effectively lengthening the growing season's influence on streamflow (Huntington 2006, Hayhoe et al. 2007, Hatcher 2011). Precipitation is stochastic and geographically heterogeneous, making it difficult to generalize trends through time and space (Zhang et al. 2007). Increasing trends in mean precipitation and precipitation intensity have been found over the Mid-Atlantic Highlands (Pitchford et al. 2012). In West Virginia, precipitation normals (30-year averages) for all physiographic divisions except for the central highlands have increased from 1931 to 2000. In the central climate division, fall 
precipitation has increased by $12.5 \%$, decreased by $8 \%$ in the summer, and decreased $1.5 \%$ in winter and spring (Leonard and Law 2012). Leonard and Law (2012) also sought to understand how tropical cyclone patterns affected precipitation depth between two time periods (1931 1960 and 1971 - 2000). Using data from the U.S. Historical Climate Network station located in Parsons, WV they found precipitation increased by 32\% for tropical cyclone tracks that passed within $600 \mathrm{~km}$ of the state.

Several studies recently have analyzed climate trends that include the Fernow Experimental Forest located near Parsons, WV. These studies reported that annual minimum and average temperatures increased significantly over the period of record (Jones et al. 2012, Vose et al. 2012, Hatcher 2011).The year 1966 was identified as the point at which positive temperature trends began (Vose et al. 2012). This date corresponds with regional and global studies that have reported accelerated increases in temperature over the last 50 years (Stocker et al. 2013).

\subsection{Quantifying Past Impacts of Climate and Disturbance on Streamflow}

Streamflow is sensitive to changes in the ratio of water supply (precipitation $(\mathrm{P})$ ) to atmospheric demand (energy) and to changes in the ratio of evapotranspiration to precipitation. Methods linking these ratios in a coupled water-energy balance model have been developed to quantify the impacts of climate change and human disturbances on streamflow (Zhang et al. 2001, Roderick and Farquhar 2011, Wang and Hiejazi 2011). The Budyko hypothesis (Budyko 1974) provides the theoretical basis for these methods and assumes long-term (AET) is controlled by precipitation and the evaporative demands of energy (potential evapotranspiration (PET)), so that catchment water balance is limited by either water (PET $>$ P) or by energy (PET $<\mathrm{P}$ ). The graphical representation of these controls is known as the Budyko framework and is depicted by plotting the dryness index (PET/P) on the $\mathrm{x}$-axis and the evaporative index (AET/P) 
on the y-axis. Using large catchments (1,000 - 10,000 km) Budyko (1974) found that long-term data plot in a curvilinear fashion, permitting AET to be approximated from PET and P. The resulting curve is known as the Budyko curve. Subsequent studies observed that measured AET deviates from the curve due to catchment characteristics (Donhue et al. 2007). To account for catchment differences, equations were developed with an adjustable parameter (Fu 1981, Choudhury 1999, Zhang et al. 2001) that integrates effects of catchment characteristics, such as vegetation cover, soil properties, and catchment topography (Zhang et al. 2004). Parameter values control the shape of the curve and can be calibrated to individual catchments (Wang and Hiejazi 2011). The supply-demand framework has been associated with physical characteristics, such as vegetation cover (Yang et al. 2009, Donohue et al. 2010), vegetation change (Wang and Hiejazi 2011), soil moisture (Milly 1994, Potter et al. 2005, Yang et al. 2007), and topography (Zhang et al. 2004, Yang et al. 2007). For example, Zhang et al. (2004) employed Fu’s (1981) equation to vegetated catchments globally and found that catchments with forested land cover have a higher parameter value $(w=2.84)$ than grasslands $(w=2.55)$. Plant soil moisture dynamics also have been associated with the Budyko framework. The evaporative index increases with increases in rooting depth, and Budyko's original curve corresponds to an effective rooting depth of $53 \mathrm{~mm}$ (Porporato et al. 2004).

Two methods have extended the Budyko curve for the use of quantifying the impacts of climate change and anthropogenic disturbance on streamflow. The first method, the sensitivity approach, quantifies the effect of streamflow (Q) due to perturbations in P and PET between two or more time periods (Milly and Dunne 2002, Li et al. 2007, Zhang et al. 2001, Roderick and Farquhar 2011). Zhao et al. (2010) compared a sensitivity approach to the paired watershed approach (Hewlett and Pienaar 1973) in catchments ranging in size of 0.18 to $3.5 \mathrm{~km}^{2}$ and 
determined that the sensitivity method provided comparable estimates of streamflow change from forest harvest and climate variability. The second method, the decomposition method, provides a formal way of assessing deviation in the Budyko framework between two or more time periods (Wang and Hiejazi 2011). Patterson et al. (2013) applied this method to 38 basins draining to the south Atlantic. They found that decomposition identified changes in climate that corroborated streamflow increases due to climate reported in previous studies. Human impacts on streamflow, such as land cover change and reservoir construction and operation were greatest for small catchments, but results were inconsistent among catchments. Patterson et al. (2013) also extended the decomposition method from a two-period analysis to a 5-year interval. However, at this latter temporal scale no signal of reservoir construction or operation was consistently detected. Recently a study that compared the sensitivity and hydrological modeling approaches to the decomposition method report agreement in causation but differences in magnitude (Sun et al. 2014).

The application of Budyko-based methodologies are guided by assumptions inherent in the water balance approach and the equilibrium concept implicit in the Budyko hypothesis (Dooge et al. 1999). Two assumptions guide the application of the Budyko curve: 1) temporal scales must be sufficiently long to assume steady state catchment conditions; and 2) large spatial scales are necessary to maintain macro-scale climate controls (Donohue et al. 2007). However, in practice numerous studies provide precedent for applying the Budyko framework at short temporal scales (Carmona et al. 2014) and small spatial scales (Zhao et al. 2010, Jones et al. 2012, Vose et al. 2012, Tetzlaff et al. 2013, Creed et al. 2014).

Steady state (change in soil moisture $=0$ ) is a common assumption in catchment hydrology that depends largely on the study site characteristics. Steady state conditions are 
commonly interpreted in the literature to include temporal scales of one year and greater (Roderick and Farquhar 2011). Donohue et al. (2007) noted that steady state conditions are largely dependent on temporal scales, and compromises on spatial scales can be made if temporal scales are adequate, and "the inherent assumptions (of the Budyko framework) can be violated", and incorporating vegetation will likely enhance the framework's predictive capacity.

Gentine et al. (2012) showed that the Budyko curve fits data aggregated to the climatological scale better than the inter-annual scale. Donohue et al. (2010) modeled scatter of observed AET-predicted AET around the Budyko curve to understand principal sources of deviation (i.e., precipitation variability, vegetation) at various temporal and spatial scales. At large spatial scales scatter was attributed to variability in PET, and the original Budyko curve was found to perform optimally. As spatial scales decreased, accounting for short-term precipitation variability and physical catchment characteristics became more important. Across all spatial scales, scatter at inter-annual time scales was attributed to precipitation variability and corresponding soil moisture flux. Consequently, at inter-annual time scales predictive capacity of covariates representing physical catchment characteristics increased as spatial scales decreased. Fu's curve (Fu 1981) with $w$ optimized to physical characteristics accurately predicted AET and runoff at mean annual and inter-annual time scales for 108 non-humid catchments in China (Yang et al. 2007).

The aforementioned studies used statistical validation techniques to assess the performance of the Budyko framework at mean-annual and inter-annual time scales across catchment areas of 272 to $95,000 \mathrm{~km}^{2}$. Only a few studies applied the Budyko framework to the headwater scale $(<1 \mathrm{~km})$ and none of them statistically evaluated model performance. Jones et al. (2012) plotted average and inter-annual data over 10 years for 30 sites ranging in drainage 
area of 0.001 to $10,000 \mathrm{~km}^{2}$ (17 site were less than $1 \mathrm{~km}^{2}$ ). Using a 10-year average, 7 of the 30 sites ( 4 sites $<1 \mathrm{~km}^{2}$ ) plotted on the curve. At inter-annual time scales, variation of AET relative to PET varied according to biome. Vose et al. (2012), Tetzlaff et al. (2013), and Creed et al. (2014) used the Budyko framework to assess deviation between two time periods to determine the effects of climate change and/or forest disturbance. In each case the results were compared qualitatively to past studies, but no attempt was made to validate the performance of the model or discuss its effectiveness. Therefore, it is unclear whether the Budyko framework's capability of predicting AET is indicative of its effectiveness to assess relative changes between time periods.

\section{4 | Study Objectives}

The Wang and Hiejazi (2011) decomposition method is applied in this study at the headwater scale to quantify the impacts of climate change relative to forest disturbancesuccession on streamflow. Results are determined at different temporal scales and validated with results obtained from the paired watershed method to help determine the effectiveness of the Budyko framework. Three central questions are examined:

Question 1. How does the magnitude of anthropogenic disturbance affect streamflow compared to change in climate?

Question 2. Can the Budyko framework be used at a headwater scale?

Question 3. Can the Budyko framework be used at fine temporal scales? 


\section{2 | Materials and Methodology}

\section{1 | Study Site}

This study analyzes long-term data from headwater catchments in the Fernow Experimental Forest (Figure 1). The Fernow is positioned at temperate latitudes on the windward side of the Allegheny Mountains near Parsons, West Virginia. Elevation, topography, and prevailing winds, combined with air masses originating from the north (polar continental) or the south (Gulf maritime), produce frequent storm events and variable temperatures (Weedfall and Dickerson 1965). In the winter, frontal storm systems bring cold temperatures and frequent rain and snowfall, resulting in limited snowpack duration. Summers are warm and humid and are dominated by local and regional convective storms. Rainfall averages of 1,450 mm annually and is distributed relatively evenly over winter, spring, and summer. Precipitation in fall is less than in other seasons, but it is highly variable because of tropical storms. The growing season of the Fernow is considered to extend from May through October (Kochenderfer et al. 1990).

The four catchments used in this study are WS-1, WS-4, WS-6, and WS-7. They have well-drained soils that tend to be less than 1-m thick, steep slopes (mean of 15\% slope, max 57\% of slope). Average elevation ranges from $706 \mathrm{~m}$ to $843 \mathrm{~m}$. 


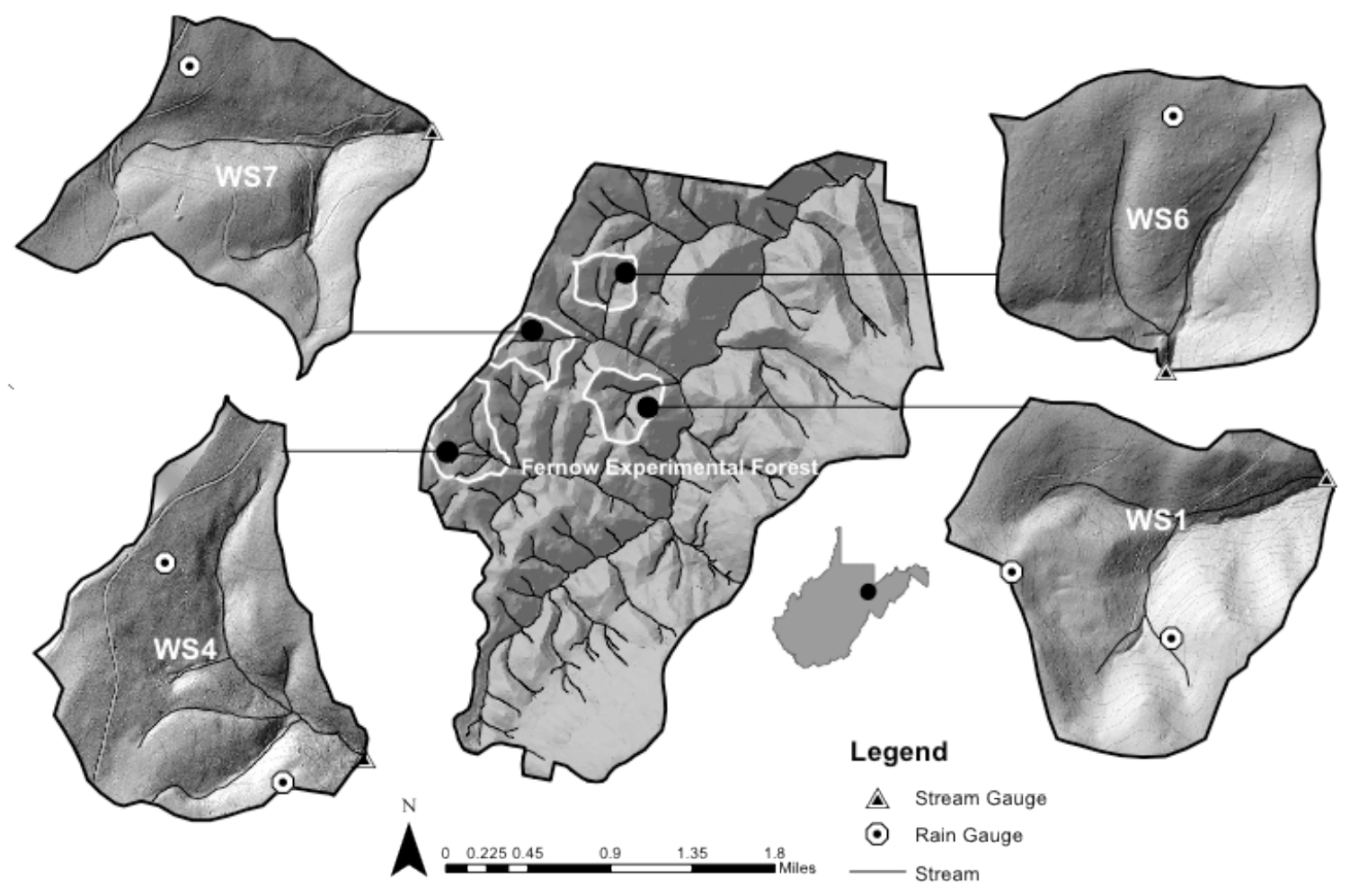

Figure 1. Map of The Fernow Experimental Forest, located near Parsons, West Virginia, showing the catchments used in this study; reference catchment WS-4, and disturbed catchments WS-1, WS-6, and WS-7.

The catchments used for this study were chosen in part for their continuity of data and for the range of vegetative disturbance to which each has been subjected. After an initial calibration period, these experimental catchments (except the control, WS-4) were subject to different forest treatments (Table 1). In WS-1, 74\% of basal area was harvested without implementing best management practices (BMPs), and the watershed was then left to recover naturally (Reinhart and Eschner 1962). WS-6 and WS-7 were deforested in two phases of all vegetation greater than 25.4-mm diameter at breast height. In the first phase, the lower half of WS-6 and the upper half of WS-7 were clearcut and maintained barren with herbicides. Three years later, the remaining 
half of the catchment was harvested and both halves were treated with herbicides for another 3 years (Patric and Reinhart 1971). After that time WS-7 was allowed to naturally recover, while WS-6 was converted to Norway spruce (Picea abies) in 1973. Although the vegetation disturbances were extreme, except for skid roads, haul roads, and landings mechanical disturbance of the forest floor was minimal (Reinhart and Eschner 1962).

Table 1. Selected Experimental Catchments and Their Forest Disturbance Histories

\begin{tabular}{|c|c|c|}
\hline Watershed & Treatment & Treatment Date \\
\hline \multirow[t]{4}{*}{ WS-1 } & Pretreatment period & $7 / 1951-4 / 1957$ \\
\hline & $\begin{array}{l}\text { Clearcut trees } 152.4 \mathrm{~mm} \text { in diameter and } \\
\text { greater except culls. Removed } 74 \% \text { of the } \\
\text { basal area }\end{array}$ & $5 / 1957-9 / 1958$ \\
\hline & $\begin{array}{l}\text { Aerial application of urea fertilizer (560 } \mathrm{kg} \mathrm{ha}^{-} \\
{ }^{1} \text { ) }\end{array}$ & $5 / 1971$ \\
\hline & Aerial application of Dimilin (0.03 $\mathrm{kg} \mathrm{ha}^{-1}$ a.e.) & $5 / 1992$ \\
\hline \multirow[t]{3}{*}{ WS-4 } & Installation & $5 / 1951$ \\
\hline & Control (no treatment) & \\
\hline & Last known harvesting in the watershed & $1905-1910$ \\
\hline \multirow[t]{10}{*}{ WS-6 } & Pretreatment period & $11 / 1956-2 / 1964$ \\
\hline & Clearcut lower half (phase 1, $11.17 \mathrm{ha}$ ) & 3/1964 - 10/1964 \\
\hline & Removed $51 \%$ of original basal area & \\
\hline & Maintained lower half barren with herbicides & $5 / 1965-10 / 1969$ \\
\hline & Clearcut upper half (phase 2, $11.17 \mathrm{ha}$ ) & 10/1967 - 2/1967 \\
\hline & Removed $49 \%$ of original basal area & \\
\hline & Maintained upper half barren with herbicides & $5 / 1968-10 / 1969$ \\
\hline & Planted Norway spruce (Picea abies) & 3/1973-4/1973 \\
\hline & $\begin{array}{l}\text { Aerial application of broad-leafed plant } \\
\text { defoliant }\end{array}$ & 8/1975 \\
\hline & $\begin{array}{l}\text { Aerial application of broad-leafed plant } \\
\text { defoliant }\end{array}$ & 9/1980 \\
\hline \multirow[t]{7}{*}{ WS-7 } & Pretreatment period & $11 / 1956-10 / 1963$ \\
\hline & Clearcut upper half (phase 1, $12.14 \mathrm{ha}$ ) & $11 / 1963-3 / 1964$ \\
\hline & Removed $49 \%$ of original basal area & \\
\hline & Maintained upper half barren with herbicides & $5 / 1964-10 / 1969$ \\
\hline & Clearcut lower half (phase 2, 12.14 ha) & 10/1966 - 3/1967 \\
\hline & Removed $51 \%$ of original basal area & \\
\hline & Maintained lower half barren with herbicides & $5 / 1967-10 / 1969$ \\
\hline
\end{tabular}




\section{2 | Data}

Hydro-climate data measured at the Fernow Experimental Forest are used in this analysis. Data include daily streamflow, daily precipitation, daily temperature (T) for WS-1 and WS-4 from 1952-2012 and WS-6 and WS-7 from 1957-2012 (obtained from Edwards and Wood 2011). Discharge measured from each watershed using $120^{\circ} \mathrm{V}$-notch weirs is expressed on a per unit area basis (mm/day). Daily watershed-weighted precipitation for each watershed was calculated by the Thiessen polygon method using data from two tipping bucket rain gauges, corrected when necessary, using weekly recorded standard gauge data (Edwards and Wood 2011).

Actual evapotranspiration was determined using an annual water balance, where AET = P - Q. To uphold the assumption of steady state conditions (net flux of water storage is negligible) data were analyzed over the Fernow water year (May through April) (Troendle 1970). In addition, all analyses (except annual time intervals) are at time scales that equal or exceed estimates of groundwater residence times for WS-4 ( $\leq 5$ years) determined by DeWalle et al.'s (1997). Therefore, all temporal scales of 5 years or greater are assumed to be at steady state conditions.

Annual PET was estimated using a temperature-based Priestly-Taylor model (Archibald and Walter 2014, Rao et al. 2011). The model requires minimum and maximum temperatures and an estimate of albedo for forest covers; 0.15 was used for all watersheds (Barry and Chorley 2009). Due to missing temperature data 7\% of the record between 1989 and 2010 were estimated. For three or less successive missing values a cubic spline interpolation method was used (Fritsch and Carlson 1980). When more than three successive observations were missing, the missing values were predicted from temperature collected at the NOAA National Climate 
Data Center station in Parsons using linear regression. Regression was performed using a window of 20 observations before and after missing values (Stoy et al. 2006).

Catchment structure was defined and compared using morphometric variables calculated from a $1 \mathrm{~m} \times 1 \mathrm{~m}$ LIDAR derived DEM at its original resolution (Table 2 and 3). Abbreviations for all terminology used in this study can be found in Table 4 .

Table 2. Description of Morphometric Variables used to Describe Topographical Study Site Characteristics.

\begin{tabular}{|c|c|c|c|}
\hline $\begin{array}{l}\text { Morphometric } \\
\text { Variable }\end{array}$ & Metric & Abbreviation & Definition \\
\hline Heat Load Index & Mean & HLI & $\begin{array}{l}\text { An analytical index of solar radiation } \\
\text { based on latitude, slope, and aspect. } \\
\text { [McCune 2002] }\end{array}$ \\
\hline Slope & Mean & SLP & Slope in degrees \\
\hline Aspect & Mean & ASP & Linear Aspect \\
\hline Curvature & Mean & CVX & $\begin{array}{l}\text { Upwardly convex surfaces. Note: the } \\
\text { inverse equals area with concave surface. } \\
\text { (Cushman 2012) }\end{array}$ \\
\hline Distance to Stream & Mean & DTS & $\begin{array}{l}\text { The distance downslope to the stream. } \\
\text { (Tarboton and Ames 2001) }\end{array}$ \\
\hline $\begin{array}{l}\text { Compound } \\
\text { Topographical } \\
\text { Wetness Index }\end{array}$ & Mean & CTWI & $\begin{array}{l}\text { Steady State Wetness Index. Calculated as } \\
\text { the mean of all cells with CTWI }>12 \\
\text { [Cushman et al. 2012] }\end{array}$ \\
\hline Drainage Density & Mean & DD & $\begin{array}{l}\text { Total stream line length divided by basin } \\
\text { area. }\end{array}$ \\
\hline Elevation & Mean & ELEV & Elevation \\
\hline $\begin{array}{l}\text { Elevation of } \\
\text { Precipitation } \\
\text { Instrument }\end{array}$ & $\begin{array}{l}\text { Actual } \\
\text { Value }\end{array}$ & ELEVP & $\begin{array}{l}\text { Elevation of precipitation instrument } \\
\text { nearest the study site catchments. }\end{array}$ \\
\hline Area & $\begin{array}{l}\text { Actual } \\
\text { Value }\end{array}$ & AREA & Area is presented in hectares. \\
\hline
\end{tabular}


Table 3. Catchment Morphometric Variables.

\begin{tabular}{lccccc}
\hline & $\begin{array}{c}\text { Heat Load } \\
\text { Index }\end{array}$ & $\begin{array}{c}\text { Elevation } \\
(\mathrm{m})\end{array}$ & $\begin{array}{c}\text { Elevation of Precip. } \\
\text { Instrument }(\mathrm{m})\end{array}$ & $\begin{array}{c}\text { Compound } \\
\text { Topographic Index }\end{array}$ & $\begin{array}{c}\text { Distance to } \\
\text { Stream (m) }\end{array}$ \\
\hline WS-1 & 122.1 & 738.57 & 659.4 & 0.012 & 122.1 \\
WS-4 & 117.23 & 819.1 & 842.2 & 0.023 & 117.23 \\
WS-6 & 136.57 & 781.45 & 733.7 & 0.016 & 136.57 \\
WS-7 & 125.41 & 803.62 & 824.5 & 0.024 & 125.41 \\
\hline & Slope & Density & Area (ha.) & Aspect & Curvature \\
& (deg.) & & 30.11 & 145.82 & 0.56 \\
\hline WS-1 & 22.04 & 0.0025 & 38.73 & 129 & 0.65 \\
WS-4 & 12.6 & 0.0045 & 22.34 & 177.61 & 0.63 \\
WS-6 & 14.1 & 0.0022 & 24.22 & 116.55 & 0.63 \\
WS-7 & 12.98 & 0.0039 &
\end{tabular}

All variables are mean values except the Elevation of Precip. Instrument and Area which are the actual values.

Table 4. Abbreviations of Study Terminology

\begin{tabular}{lr}
\hline Term & Abbreviation \\
\hline Actual Evapotranspiration (mm) & $\mathrm{AET}$ \\
Best Management Practices & $\mathrm{BMP}$ \\
Catchment 1 & $\mathrm{WS}-1$ \\
Catchment 4 & $\mathrm{WS}-4$ \\
Catchment 6 & $\mathrm{WS}-6$ \\
Catchment 7 & $\mathrm{WS}-7$ \\
Climate Caused Change in Streamflow & $\Delta \mathrm{Q}_{\mathrm{c}}$ \\
Climate Change Component & $\mathrm{AET}_{2} / \mathrm{P}_{2}$ \\
Diameter Breast Height & $\mathrm{DBH}$ \\
Disturbance Caused Change in Streamflow & $\Delta \mathrm{Q}_{\mathrm{h}}$ \\
Double Cumulative Curve & $\mathrm{DCC}$ \\
Dryness Index & $\mathrm{PET}^{\mathrm{P}}$ \\
Evaporative Index & $\mathrm{AET} / \mathrm{P}$ \\
Hydrologic Recovery (mm) & $\Delta \mathrm{Q}_{\mathrm{R}}$ \\
Palmer Drought Severity Index & $\mathrm{PDSI}$ \\
Percent Change in Streamflow Due to Climate & $\% \mathrm{Q}_{\mathrm{c}}$ \\
Percent Change in Streamflow Due to & $\% \mathrm{Q}_{\mathrm{h}}$ \\
Disturbance & \\
Potential Evapotranspiration (mm) & $\mathrm{PET}_{\text {Precipitation (mm) }}$ \\
Predicted Actual Evapotranspiration & $\mathrm{P}$ \\
Predicted Streamflow & $\mathrm{AET}_{\mathrm{p}}$ \\
Streamflow (mm) & $\mathrm{Q}_{\mathrm{p}}$ \\
Streamflow of the previous time interval (mm) & $\mathrm{Q}$ \\
Temperature ( ${ }^{\circ}$ C) & $\mathrm{Q}_{1}$ \\
& $\mathrm{~T}$ \\
\hline
\end{tabular}




\section{3 | Methods}

This study uses a combination of graphical methods and hydrometric analysis to quantify variability and identify patterns in climate, evapotranspiration, and streamflow across multiple time scales. These analyses requires three components: (1) identify climate trends through the historical period of record, (2) quantify the relative contribution of climate and land cover disturbance to streamflow, (3) validate component 2 with results obtained from the paired catchment method.

\section{Changes in Climate and Vegetation}

Trend analyses were performed on total precipitation, temperature (mean, minimum, and maximum), and total PET annually, seasonally, for winter (Dec.-Feb.), spring (March-May), summer (June-Aug.), and fall (Sept.-Nov.), and for growing (May-Oct.) and dormant (Nov.April) seasons. Trends were determined using the Mann-Kendall trend test (Mann 1945) for noncorrelated data. When data were serially correlated the modified Mann-Kendall trend test was used (Hirsch and Slack 1984, Hamed and Ramachandra 1998). Serial correlation was detected using the auto-correlation function and partial-auto correlation function in the statistical program R (R Core Team 2013). Trends were considered significant at the 0.05 level.

In addition to characterizing changes in climate, watershed-scale forest species composition was characterized to identify changes over the study period for WS-1, WS-4, and WS-7. Stand structure was determined from either a 100 percent inventory of all trees greater than 127-mm diameter-at-breast-height (DBH) or extrapolated from growth plot measurements. For the 100 percent inventory, each tree was tallied by species and 2-inch diameter class. To determine stand structure from growth plot data, each tree was assigned to a 2-inch diameter class and tallied by species for every plot. An area factor was calculated from the total area in all 
growth plots and total watershed area, and used to extrapolate the tally from the sampled area to the total stand area. A relative importance value in this study was determined for each species by adding relative density and relative dominance and dividing by 2 (Peet 1974). Relative density is the number of individuals divided by total number of all individuals. Relative dominance is determined by dividing species basal area by total basal area. Trees with the greatest importance values are thought to have the greatest influence on the ecosystem.

\section{Budyko Decomposition Method}

In the graphical depiction of the Budyko curve the supply-demand framework is represented by the climatic dryness index (PET/P) on the $\mathrm{x}$-axis and the evaporative index (AET/P) along the y-axis. The position of the catchment plotted within this non-dimensional framework identifies the relative control of energy and climate on streamflow. The analytical equation developed by Fu (1981) was used. It incorporates a single parameter to accommodate catchments that plot off of Budyko's original curve.

As a preliminary step, an average ratio of AET/P to PET/P for the period of record was plotted for each catchment and compared to the curve fitted to forested catchments globally, employing a value of 2.84 for $w$ (Zhang et al. 2004). Zhang et al.'s (2004) curve is the forest counterpart to Budyko's general model and provides a theoretical relationship between the dryness index and the evaporative index. Deviations from the curve are attributed to endogenous and exogenous factors affecting the catchment water balance. In a similar manner, deviations among time periods can be assessed to identify temporal changes in catchment properties and climate-forcing variables (Jones et al. 2012, Tetzlaff et al. 2013).

In this study the decomposition method is used to quantify the deviations between time periods plotted with in the Budyko framework. The direction and distance of deviation indicate 
causes of streamflow variability and quantify the magnitude of change. Vertical deviation is attributed to direct anthropogenic disturbances, in this case forest disturbance, and horizontal deviation along the curve is attributed to climate change (Wang and Hejazi 2011).

The decomposition method is applied at 7 different time intervals and to catchments with different study periods. For WS-1 and WS-4 the study period of analysis were: 1-, 5-, 10-, 12-, 15-, and 30-year intervals. For WS-6 and WS-7 the study period of analysis were: 1-, 5-, 9-, 11-, 14-, and 27-year intervals. The 30-year and 27-year time intervals equal the midpoint of the study period, and are referred to as period 1 for the first half of the study period and period 2 for the second half of the study period. In 1959 the National Weather Bureau adopted 30-year climate normals as a standard to compare two or more time periods (Guttman and Quayle 1996). As a result, long term averages calculated for this analysis are an indicator of how precipitation, AET, PET and streamflow are changing overtime.

The decomposition method consists of the following steps. First, the ratio of AET/P to PET/P for period 1 is calculated and plotted. A unique Budyko curve then is calibrated to the initial point using Fu’s (1981) equation.

$$
\frac{\mathrm{AET}}{\mathrm{P}}=1+\frac{\mathrm{PET}}{\mathrm{P}}-\left[1+\left(\frac{\mathrm{PET}}{\mathrm{P}}\right)^{\mathrm{w}}\right]^{1 / \mathrm{w}}
$$

The average ratio of AET/P to PET/P is plotted for period 2. From this ratio the climate change component of period 2 is determined, $\left(\frac{A E T_{2}{ }^{\prime}}{P_{2}}, \frac{\mathrm{PET}_{2}}{\mathrm{P}_{2}}\right)$,

$$
\frac{A E T_{2}^{\prime}}{P_{2}}=1+\frac{P E T_{2}}{P_{2}}-\left[1+\left(\frac{P E T_{2}}{P_{2}}\right)^{w}\right]^{1 / w},
$$

which is the reference point from which the magnitudes of direct human-induced change in streamflow $\left(\Delta \mathrm{Q}_{\mathrm{h}}\right)$ and climate-induced change in streamflow $\left(\Delta \mathrm{Q}_{\mathrm{c}}\right)$ are quantified: 


$$
\begin{gathered}
\Delta \mathrm{Q}_{\mathrm{h}}=\mathrm{P}_{2}\left(\frac{A E T_{2}{ }^{\prime}}{P_{2}}-\frac{A E T_{2}}{\mathrm{P}_{2}}\right), \\
\Delta \mathrm{Q}_{\mathrm{c}}=\mathrm{Q}_{2}-\mathrm{Q}_{1}-\Delta \mathrm{Q}_{\mathrm{h}}
\end{gathered}
$$

Finally, the percent changes in streamflow attributable to $\Delta \mathrm{Q}_{\mathrm{h}}$ and $\Delta \mathrm{Q}_{\mathrm{c}}$ are calculated as:

$$
\begin{aligned}
& \% \mathrm{Q}_{\mathrm{h}}=100\left(\frac{\Delta \mathrm{Qh}}{\mathrm{Q}_{1}}\right), \\
& \% \mathrm{Q}_{\mathrm{c}}=100\left(\frac{\Delta \mathrm{Qc}}{\mathrm{Q}_{1}}\right)
\end{aligned}
$$

\section{Predicted Streamflow}

The decomposition method for separating climate- and human-induced changes in streamflow in the current study differs slightly from previous studies. It is customary to first identify the analytical periods based on a change in one or more variables, such as streamflow, climate inputs, and disturbance. This is often accomplished using a change point detection method, such as double cumulative curve (DCC), Pettit test, sequential Mann-Kendall test, or moving t-test (Wang 2014). The pre-change period is considered the baseline period with negligible human alteration to streamflow, and the post-change period is considered the period where influences of human disturbance become apparent (Wang 2014). In this study, however, the majority of each forest treatment took place during the first half of the study period. To utilize the long-term hydro-climate record and historic forest management studies of the Fernow, an adaptive approach was necessary. Therefore, the paired watershed approach is used to predict streamflow $\left(Q_{p}\right)$ in absence of forest disturbance, and hencefourth is referred to as predicted streamflow. The predicted streamflow datasets are used in conjunction with the Budyko decomposition method to accomplish the following: (1) reconstruct baseline curves for disturbed catchments and determine the effects of forest harvest in period 1, (2) assess the hydrologic recovery of forest disturbance, and (3) validate the decomposition method results. 
Using a simple linear regression equation during the historic calibration period (Table 1), streamflow data from each treated catchment were regressed against the corresponding data from the reference catchment (WS-4) to predict annual streamflow in absence of forest disturbance. The regressions during the calibration period resulted in R-square values of $0.99,0.87$, and 0.93 , respectively, WS-1, WS-6, and WS-7, (Hornbeck et al. 1993). This approach assumes that the regression relationship between catchments is consistent over the study period.

Predicted actual evapotranspiration $\left(\mathrm{AET}_{\mathrm{p}}\right)$ was estimated using an annual water balance by subtracting predicted streamflow from precipitation. Given $\mathrm{AET}_{\mathrm{p}}$, the Budyko model parameters $\mathrm{AET}_{\mathrm{p}} / \mathrm{P}$ and PET/P are used in equation 1 to calibrate the predicted baseline curve. It is important to note that the predicted points and predicted Budyko curve represent the position of the catchment in the absence of forest disturbance. This curve is used to determine the effects of forest disturbance in period 1 and assess the hydrologic recovery of forest disturbance. To quantify the effects of forest disturbance in period 1 , observed data were compared to the predicted baseline. Because the predicted and observed data share a similar time period and dryness index (PET/P), the change in streamflow due to forest harvest was calculated from:

$$
\Delta \mathrm{Q}_{\mathrm{h}} \text { of Period } 1=\mathrm{P}_{1}\left(\frac{\mathrm{AET}_{\mathrm{P} 1}}{\mathrm{P}_{1}}-\frac{\mathrm{AET}_{1}}{\mathrm{P}_{1}}\right) .
$$

To assess the influence of disturbance and climate change on hydrologic recovery, the decomposition results for the two periods analysis for WS-1, WS-6, and WS-7 are compared to the predicted Budyko curve. Recovery is quantified in terms of mean annual streamflow (MAS) and is the vertical distance between the observed plot of period 2 and the predicted Budyko curve. It is solved for by:

$$
\Delta \mathrm{Q}_{\mathrm{R}}=\mathrm{P}_{2}\left(\frac{\mathrm{AET}_{\mathrm{P} 2}}{\mathrm{P}_{2}}-\frac{\mathrm{AET}_{2}}{\mathrm{P}_{2}}\right) .
$$


In this study, a hydrologic system has recovered from disturbance if plotted position of period 2 returns (recovers) to the predicted Budyko curve. This definition of recovery accounts for the dynamism of climate change and assumes that climate change moves horizontally along the curve.

The paired catchment method is also used to validate the decomposition method results. The effects of forest disturbance (Predicted $\Delta \mathrm{Q}_{\mathrm{H}}$ ) on the treated catchment are isolated by subtracting predicted streamflow from observed streamflow. The change in climate between two time periods can also be determined using the paired catchment method, and is referred to as Predicted $\Delta \mathrm{Q}_{\mathrm{c}}$. Predicted $\Delta \mathrm{Q}_{\mathrm{c}}$ was calculated by subtracting average predicted streamflow for one interval $\left(Q_{p} i\right)$ from average predicted streamflow of the following interval $\left(Q_{p} i+1\right)$.

\section{Temporal Sensitivity of Decomposition Method and Validation}

To test the performance of the decomposition model at fine temporal resolutions, it was applied at 1-, 5-, 10-, 12-, and 15-year intervals for WS-1. Intervals of 1-, 5-, 9-, 11-, and 14years were used for WS-6 and WS-7. This method follows the procedure outlined above and employs the value of $w$ calibrated to the first half of the study period, following Patterson et al. (2012). For disturbed catchments, $\Delta \mathrm{Q}_{\mathrm{h}}$ modeled by the decomposition method was validated with the paired catchment model results using simple linear regression and correlation coefficients for each time interval. For disturbed catchments, $\Delta \mathrm{Q}_{\mathrm{c}}$ modeled by the decomposition method was validated with Predicted $\Delta \mathrm{Q}_{\mathrm{c}}$ using simple linear regression and correlation coefficients for each time interval. Because the decomposition method quantifies the effect of climate and disturbance based on comparing two periods, the first interval of the time step was omitted from validation. 


\section{Assumptions of the Decomposition Method}

Besides the assumptions inherent in the Budyko framework the decomposition method is contingent on two assumptions. Direct human disturbance results in only a vertical change from the curve, and a catchment unaltered by direct human disturbance will respond to climate change by moving horizontally along the curve. To test these assumptions the points of predicted and observed period 1 , period 2, and the predicted baseline curve are plotted. If the predicted dataset successfully removes the effects of forest disturbance and climate change occurs, the movement from predicted point 1 to point 2 will move along the curve, thus, providing evidence that climate influences movement horizontally along the curve. If observed and predicted points are different from one another in only a vertical direction, then the assumption that forest disturbance causes only a vertical shift is supported. In addition, the assumptions are further examined by using the guidelines of Wang (2014) and displaying the relationship between P and Q under un-disturbed conditions using a double cumulative curve (DCC). If climate change causes only horizontal movement, than no major inflection points will be present in the DCC plot of reference WS-4.

\section{3 | Results}

\section{1 | Historic Climate Trends and Vegetation Changes}

Forest species composition was determined multiple times over the period of record for species over 152.4 mm (6 in) DBH for WS-1, WS-4, WS-7 (Figures 3, 4, 5, respectively). These Figures depict species composition for nearly sixty years and include measurements before and after disturbance, and across different successional phases.

WS-1 was clearcut down to a diameter of $152.4 \mathrm{~mm} \mathrm{DBH,} \mathrm{so} \mathrm{that} 36 \%$ of the total basal area remained in the watershed after harvesting. The number of stems per hectare between pre- 
harvest (1957) and post-harvest (1963) decreased from 498 to 207. Between those periods, species composition was largely maintained, albeit at smaller diameter classes (Figure 2). At the most recent measurement (1997) yellow-poplar (Liriodendron tulipifera) and sugar maple were the most important species with the total of the two species making up 33\% of the dominance. Six species had importance values that range from $5 \%$ to $10 \%$ which included northern red oak (Quercus rubra), chestnut oak (Quercus prinus), red maple (Acer rubrum), black locust (Robinia pseudoacacia), American basswood (Tilia americana), and sweet birch (Betula lenta). Species composition differed between pre-harvest and post-harvest periods, resulting in a $20 \%$ increase in the number of stems per hectare, dominance being shared by fewer species, and the importance value of oaks decreasing more than other species.

Species composition changes for WS-4 are shown in Figure 3. At the first measurement in 1959 there were 372 stems per hectare and 30 woody species present. In 2009 the number declined steadily to 322 stems per hectare and 26 woody species. In 1959, the five most important tree-species were northern red oak, sugar maple, red maple, chestnut oak, and black cherry (Prunus serotina). After 1959, maple and oak dominance increased and black cherry dominance plateaued. Importance for all other species generally increased modestly or declined.

Figure 4 shows WS-7 species composition from pre-disturbance (1957) through 2009. Before disturbance there were on average 371 stems per hectare and 33 different tree species. In 2009 there were 1211 stems per hectare and 19 species. In 1991, 22 years following disturbance, species importance was led by yellow-poplar, sweet birch, pin cherry (Prunus pensylvanica), black cherry, and black locust. Over subsequent measurements pin cherry and black locust declined in importance and yellow-poplar, sweet birch, and black cherry increased in importance. Shade-tolerant species red maple and sugar maple are also increasing in importance. 
The forest in 2009 was dominated by different species than the pre-disturbance forest, and fewer species are important. 


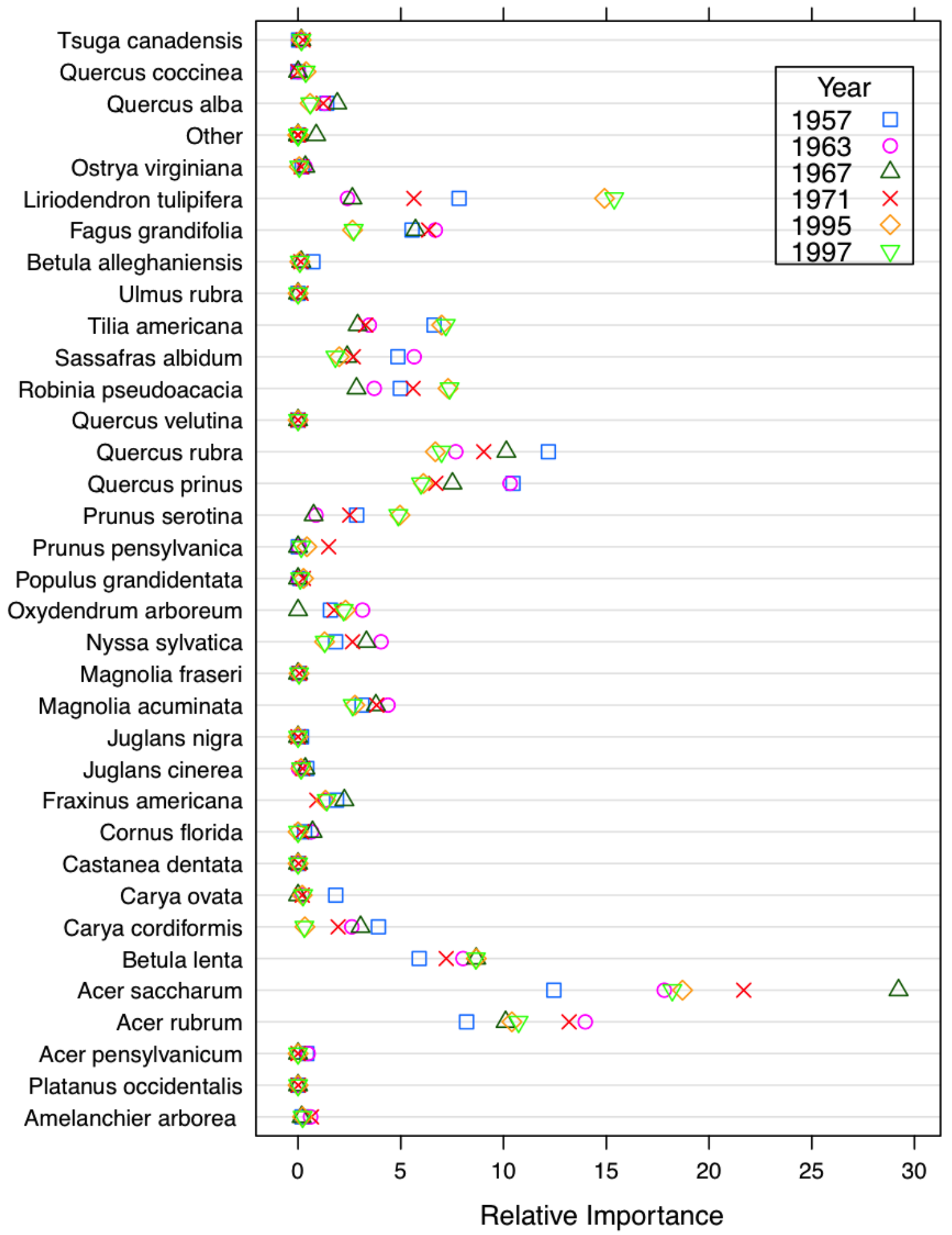

Figure 2. Relative importance of tree species in WS-1 through time. Relative importance captures species' contribution to the total stand in terms of basal area and density of stems. Forest disturbance occurred in 1957 after the first species inventory. 


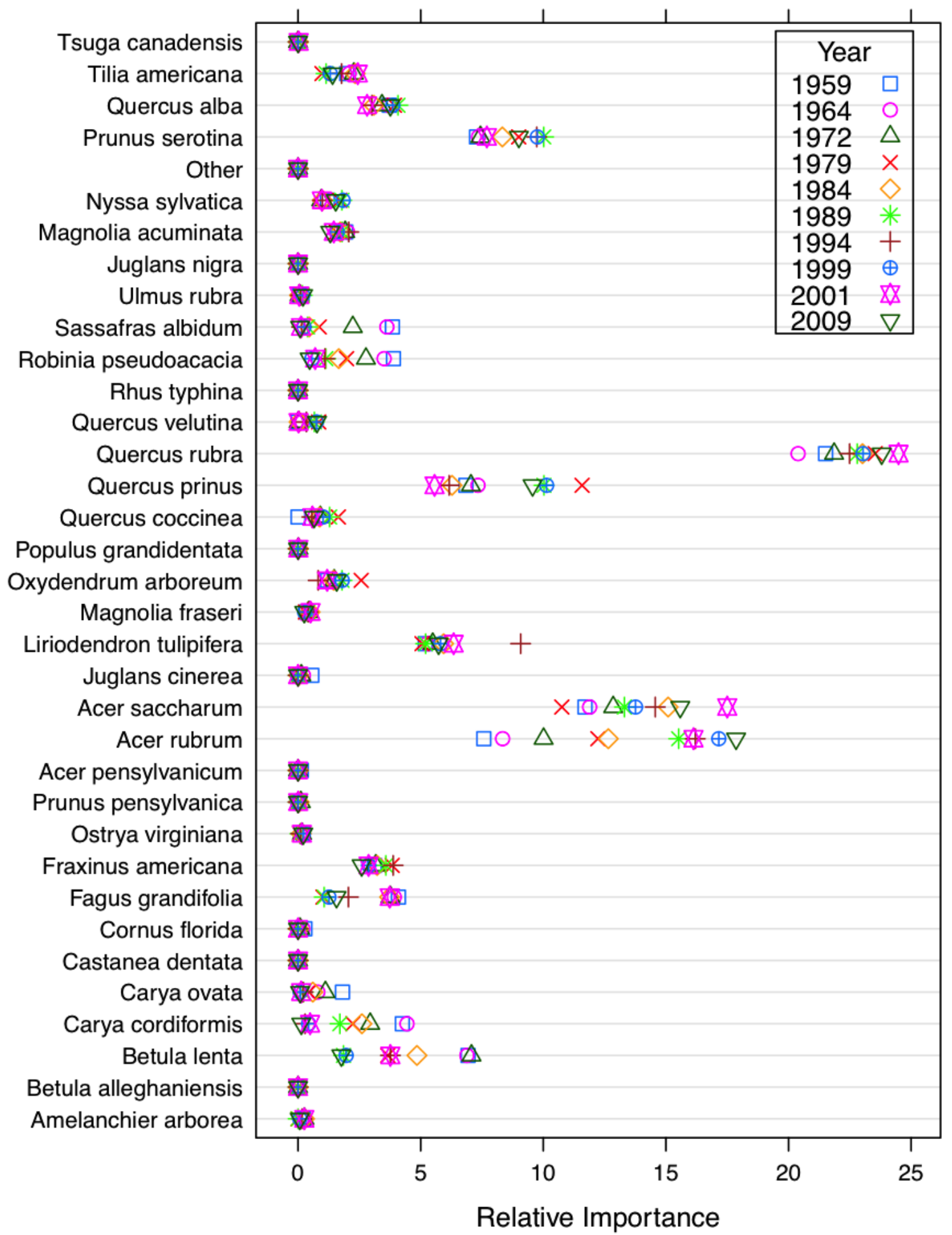

Figure 3. Relative importance of tree species in WS-4 through time. Relative importance captures species' contribution to the total stand in terms of basal area and density of stems. The last forest harvesting on WS-4 occurred about 1905 - 1910. 


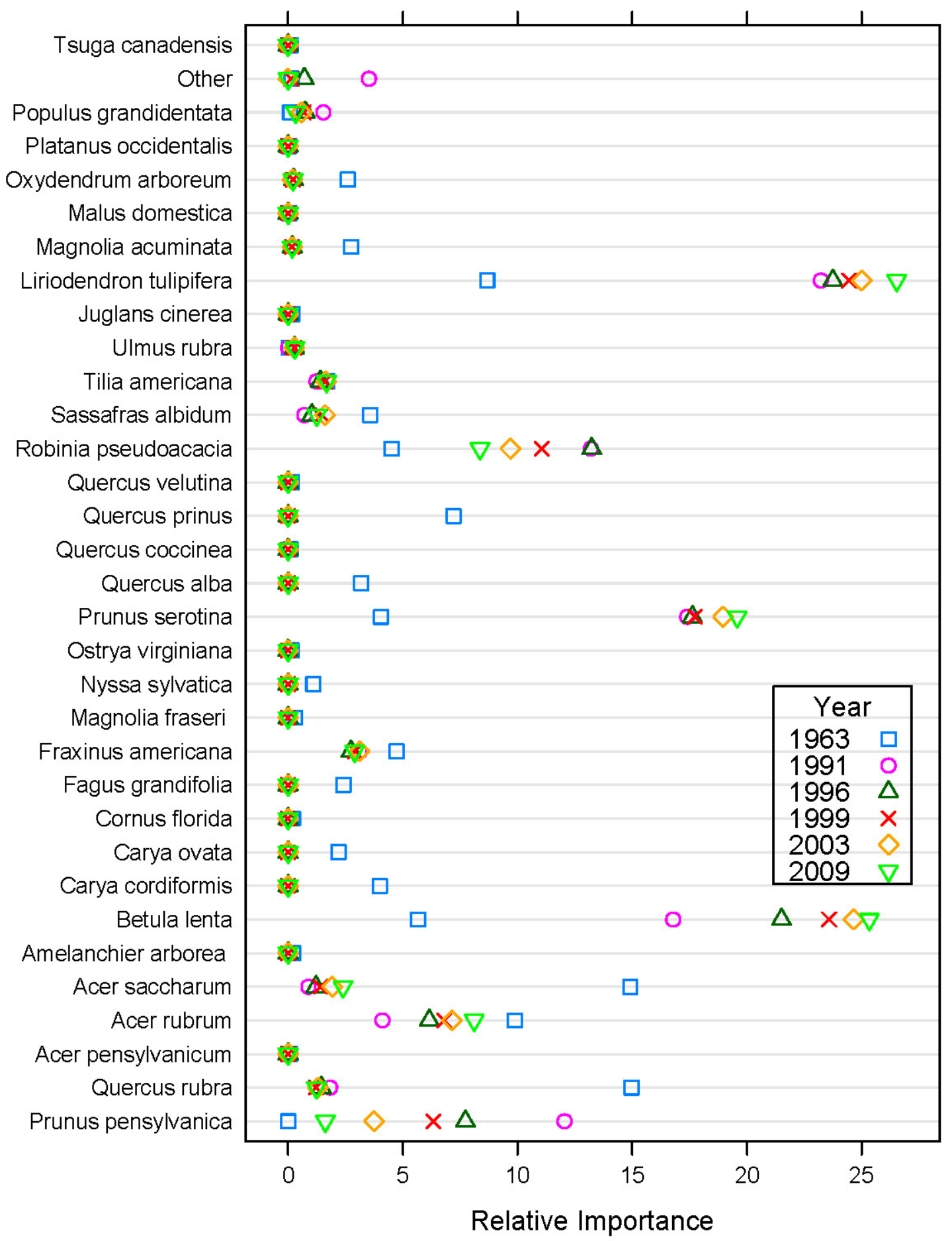

Figure 4. Relative importance of tree species in WS-7 through time. Relative importance captures species' contribution to the total stand in terms of basal area and density of stems. The watershed was clearcut in halves in 1964 and 1967, removing 51\% and 49\% of basal area, respectively. Both halves maintained barren with herbicide following their respective harvests through 1969. 
Trends in P, T, and PET using Mann-Kendall and modified Mann-Kendall trend tests are reported in Tables 5 and 6. Over the period of record (1952 to 2012) significant positive trends were found in average temperatures for annual, growing season, spring, and summer time periods. Slopes for positive trends in average temperatures ranged between 0.0143 and 0.0253 $\left({ }^{\circ} \mathrm{C} /\right.$ year) corresponding to an average increase of $1.1^{\circ} \mathrm{C}$ over the study period. Positive trends were also detected for minimum temperatures during the growing, spring, summer, and fall seasons. Slopes for positive trends in minimum temperatures ranged between 0.0152 and 0.0340 $\left({ }^{\circ} \mathrm{C} /\right.$ year) and average temperature increased $1.5^{\circ} \mathrm{C}$ over the study period. However no trends were detected for maximum temperature or PET. There also were no trends for precipitation for any of the time scales except for the growing season. Growing season increases correspond to an average slope of 0.0133 (mm/year). 
Table 5. Climate Trends for PET and Temperature for Annual, and Winter, Spring, Summer, Fall, Growing, and Dormant Seasons, using Mann-Kendall or Modified Mann-Kendall Trend Tests.

\begin{tabular}{|c|c|c|c|c|c|}
\hline Variable & Time Step & Slope & tau & $\mathrm{P}$ & Auto-Cor \\
\hline \multirow[t]{7}{*}{ PET } & Annual & 0.0658 & 0.0384 & 0.6691 & $\mathrm{NO}$ \\
\hline & Winter & -0.0476 & -0.0536 & 0.5461 & $\mathrm{NO}$ \\
\hline & Spring & 0.0925 & 0.0820 & 0.3538 & $\mathrm{NO}$ \\
\hline & Summer & -0.0185 & 0.0109 & 0.9059 & $\mathrm{NO}$ \\
\hline & Fall & 0.0140 & 0.0098 & 0.9157 & $\mathrm{NO}$ \\
\hline & Growing & 0.8451 & 0.0874 & 0.3224 & $\mathrm{NO}$ \\
\hline & Dormant & 0.0544 & -0.0033 & 0.9752 & $\mathrm{NO}$ \\
\hline \multirow{7}{*}{$\begin{array}{l}\text { Temp. } \\
\text { Avg. }\end{array}$} & Annual & 0.0119 & 0.1797 & 0.0432 & $\mathrm{NO}$ \\
\hline & Winter & -0.0016 & -0.0066 & 0.9454 & $\mathrm{NO}$ \\
\hline & Spring & 0.0152 & 0.1776 & 0.0438 & $\mathrm{NO}$ \\
\hline & Summer & 0.0253 & 0.3104 & 0.0004 & YES \\
\hline & Fall & 0.0102 & 0.1191 & 0.1769 & $\mathrm{NO}$ \\
\hline & Growing & 0.0143 & 0.2240 & 0.0356 & YES \\
\hline & Dormant & 0.0104 & 0.1071 & 0.2250 & $\mathrm{NO}$ \\
\hline \multirow{7}{*}{$\begin{array}{l}\text { Temp. } \\
\text { Min. }\end{array}$} & Annual & 0.0192 & 0.2712 & 0.0748 & YES \\
\hline & Winter & 0.0044 & 0.0284 & 0.7510 & $\mathrm{NO}$ \\
\hline & Spring & 0.0299 & 0.2721 & 0.0020 & $\mathrm{NO}$ \\
\hline & Summer & 0.0340 & 0.4443 & 0.0001 & YES \\
\hline & Fall & 0.0152 & 0.1940 & 0.0276 & $\mathrm{NO}$ \\
\hline & Growing & 0.0246 & 0.3710 & 0.0000 & YES \\
\hline & Dormant & 0.0182 & 0.1683 & 0.0561 & $\mathrm{NO}$ \\
\hline \multirow{7}{*}{$\begin{array}{l}\text { Temp. } \\
\text { Max }\end{array}$} & Annual & 0.0008 & 0.0345 & 0.7020 & NO \\
\hline & Winter & -0.0096 & -0.0617 & 0.4858 & $\mathrm{NO}$ \\
\hline & Spring & 0.0017 & 0.0443 & 0.6186 & $\mathrm{NO}$ \\
\hline & Summer & 0.0081 & 0.0902 & 0.4682 & YES \\
\hline & Fall & 0.0040 & 0.0328 & 0.7135 & $\mathrm{NO}$ \\
\hline & Growing & -0.0023 & -0.0016 & 0.9931 & YES \\
\hline & Dormant & -0.0004 & 0.0115 & 0.9010 & NO \\
\hline
\end{tabular}

If Auto-Cor. category is "YES" then the modified Mann-Kendall trend test was used for determining significance of the trend. Significance was determined at a level of 0.05. 
Table 6. Climate Trends for Precipitation for Annual, and Winter, Spring, Summer, Fall, Growing, and Dormant Seasons, using Mann-Kendall or Modified Mann-Kendall Trend Tests.

\begin{tabular}{|c|c|c|c|c|c|}
\hline Variable & Time Step & Slope & Tau & $\mathrm{P}$ & Auto-Cor. \\
\hline \multirow[t]{7}{*}{ WS-1 } & Annual & 1.1732 & 0.1051 & 0.2380 & $\mathrm{NO}$ \\
\hline & Winter & -0.0052 & -0.0809 & 0.3603 & $\mathrm{NO}$ \\
\hline & Spring & 0.0019 & 0.0055 & 0.9553 & NO \\
\hline & Summer & 0.0096 & 0.1093 & 0.2156 & $\mathrm{NO}$ \\
\hline & Fall & 0.0088 & 0.1093 & 0.2156 & $\mathrm{NO}$ \\
\hline & Growing & 0.0143 & 0.2364 & 0.0067 & $\mathrm{NO}$ \\
\hline & Dormant & -0.0034 & -0.0904 & 0.2489 & YES \\
\hline \multirow[t]{7}{*}{ WS-4 } & Annual & -0.3656 & -0.0011 & 0.9949 & $\mathrm{NO}$ \\
\hline & Winter & -0.0111 & -0.1661 & 0.0594 & NO \\
\hline & Spring & -0.0011 & -0.0295 & 0.7415 & NO \\
\hline & Summer & 0.0055 & 0.0508 & 0.5670 & NO \\
\hline & Fall & 0.0068 & 0.0885 & 0.3164 & $\mathrm{NO}$ \\
\hline & Growing & 0.0116 & 0.1888 & 0.0306 & $\mathrm{NO}$ \\
\hline & Dormant & -0.0079 & -0.1586 & 0.0996 & YES \\
\hline \multirow[t]{7}{*}{ WS-6 } & Annual & 0.6140 & 0.0335 & 0.7379 & $\mathrm{NO}$ \\
\hline & Winter & -0.0043 & -0.0610 & 0.5110 & $\mathrm{NO}$ \\
\hline & Spring & 0.0019 & 0.0195 & 0.8376 & $\mathrm{NO}$ \\
\hline & Summer & 0.0160 & 0.1468 & 0.1118 & NO \\
\hline & Fall & 0.0010 & 0.0195 & 0.8376 & NO \\
\hline & Growing & 0.0136 & 0.2260 & 0.0142 & NO \\
\hline & Dormant & -0.0066 & -0.1169 & 0.1673 & YES \\
\hline \multirow[t]{7}{*}{ WS-7 } & Annual & 1.7306 & 0.1118 & 0.2553 & $\mathrm{NO}$ \\
\hline & Winter & -0.0002 & -0.0182 & 0.8487 & NO \\
\hline & Spring & 0.0047 & 0.0403 & 0.6664 & $\mathrm{NO}$ \\
\hline & Summer & 0.0170 & 0.1474 & 0.1102 & $\mathrm{NO}$ \\
\hline & Fall & 0.0031 & 0.0403 & 0.6664 & $\mathrm{NO}$ \\
\hline & Growing & 0.0135 & 0.2416 & 0.0087 & $\mathrm{NO}$ \\
\hline & Dormant & -0.0034 & -0.0636 & 0.4918 & YES \\
\hline
\end{tabular}

If Auto-Cor. category is "YES" then the modified Mann-Kendall trend test was used for determining significance of the trend. Significance was determined at a level of 0.05 .

Table 7 provides 30-year averages for WS-1 and WS-4 and 27-year averages for WS-6 and WS-7 for precipitation, streamflow, AET, and PET. Between the first and second halves of the study period, precipitation increased by 3.03\%, 0.215\%, $1.9 \%$, and $4.01 \%$, respectively for WS-1, WS-4, WS-6, and WS-7. PET data are similar for all watersheds but differ slightly because different lengths of analyses were employed. Between the two halves, PET changed $0.87 \%$ for WS- 1 and WS-4 and $0.48 \%$ for WS-6 and WS-7. Changes in total annual AET and 
discharge varied greatly among catchments. AET changed 3.1 \%, -3.54\%, 25.88\%, and 20.78\%, respectively, for WS-1, WS-4, WS-6, and WS-7 between time periods. Streamflow between time periods changed 2.81\%, 4.94\%, $-28.80 \%$, and $-5.78 \%$ for WS-1, WS-4, WS-6, and WS-7, respectively. These long-term averages serve as the foundation for this study and provide the metrics against which the decomposition method assigns and measures change.

Table 7. Long-Term Averages and Percent Changes for P, Q, AET, PET*.

\begin{tabular}{|l|c|c|c|c|c|c|}
\hline & \multicolumn{3}{|c|}{ WS-1 } & \multicolumn{3}{c|}{ WS-4 } \\
\hline & $1952-1981$ & $1982-2012$ & \% Change & $1952-1981$ & $1982-2012$ & \% Change \\
\hline Precipitation & 1483 & 1528 & 3.03 & 1448 & 1451 & 0.21 \\
\hline Runoff & 605 & 622 & 2.81 & 628 & 659 & 4.94 \\
\hline AET & 878 & 906 & 3.19 & 820 & 791 & -3.54 \\
\hline PET & 1036 & 1045 & 0.87 & 1036 & 1045 & 0.87 \\
\hline & \multicolumn{7}{|c|}{ WS-6 } & \multicolumn{5}{|c|}{ WS-7 } \\
\hline & $1957-1985$ & $1986-2012$ & \% Change & $1957-1985$ & $1986-2012$ & \% Change \\
\hline Precipitation & 1410 & 1437 & 1.91 & 1398 & 1454 & 4.01 \\
\hline Discharge & 618 & 440 & -28.80 & 882 & 831 & -5.78 \\
\hline AET & 792 & 997 & 25.88 & 515 & 622 & 20.78 \\
\hline PET & 1041 & 1046 & 0.48 & 1041 & 1046 & 0.48 \\
\hline
\end{tabular}

* Averages correspond to 30-year averages for WS-1 and WS-4, and 27-year averages for WS-6 and WS-7. All variables have units of $\mathrm{mm} /$ year.

Regime curves (Figure 5) show the combined effects of climate change and forest disturbance-succession on the timing and magnitude of MAS for periods 1 and 2. Annual seasonality of streamflow is also depicted. During the dormant season when evaporative demands on streamflow are low, MAS is highest. In the growing season the opposite is true and MAS is reduced. Two patterns are present in the regime curves. First, the difference between period 1 and period 2 are similar for WS- 1 and WS-4, while both WS-6 and WS-7 show unique differences from period 1 to period 2. 

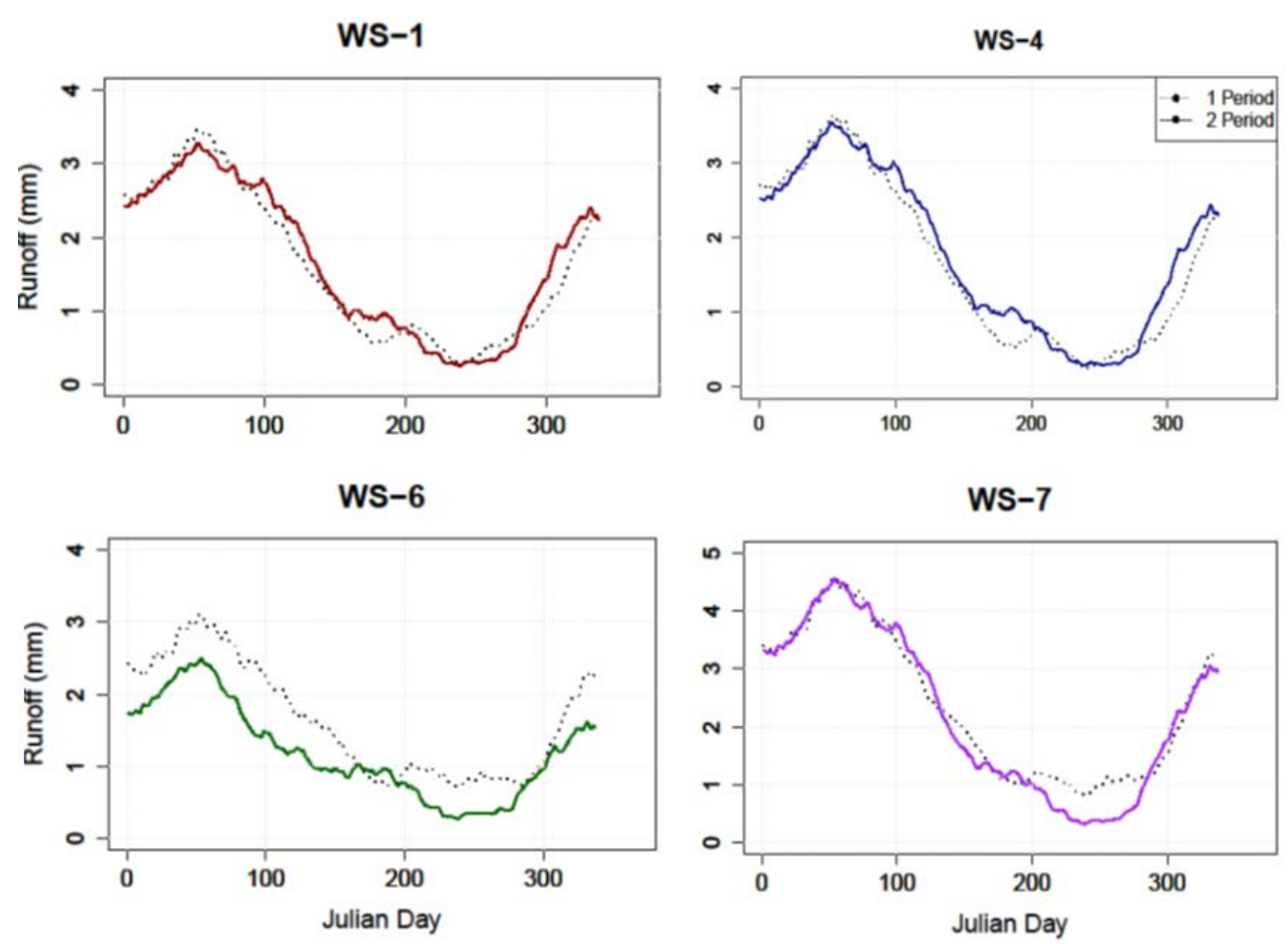

Figure 5. Regime curves show changes of intra-annual variability of streamflow between periods 1 and period 2. Regime curves are calculated by averaging mean daily streamflow by Julian day over period 1 (dotted line) and period 2 (solid line) for each watershed.

\section{2 | Budyko Decomposition Analysis}

This section presents the results of the decomposition method across multiple time periods. It is organized in the following order: (1) decomposition assumptions, (2) the position of the Fernow points and calibrated curves within the framework, (3) forest disturbance effects during period 1 based on a predicted baseline curve, (4) the effects of forest disturbance and climate change from period 1 and period 2, and (5) analysis of the decomposition method at shorter time scales to examine its sensitivity.

\subsection{1 | Budyko Decomposition Assumptions}

The assumptions of the Budyko decomposition method define how the movement of a watershed response between time periods is attributed to climate and/or direct anthropogenic 
disturbance. The first assumption is that direct anthropogenic disturbances will result only in vertical movement of the catchment's position relative to the Budyko curve. The second assumption limits movement of a catchment response to climate change to horizontal movement along the curve. As described previously in the Methodology section, these assumptions are tested by plotting both observed and predicted data. The 'predicted' lines in Figures 6 show climate influences because predicted point 2 has shifted horizontally along the same curve on which point 1 occurs. The slight vertical deviation in predicted point 2 of WS-7 is likely due to the high sensitivity of small $w$ parameters on evaporative index (Zhang et al. 2004) or slight deviation in the regression relationship with WS-4 over the study period. The DCC for WS-4 has no major inflection points (Figure 7), additionally supporting the assumption that climate causes horizontal movement. Figure 6, also show that forest disturbance causes changes only in the vertical direction because observed and predicted points for a given time period (i.e. 1 or 2 ) are different only in a vertical direction. Because WS-4 is a reference catchment any inflection in the line is attributed to changes in the relationship between precipitation and runoff. A major inflection point could be evidence that climate can cause a watershed to move vertically and violate the assumptions of the method. 

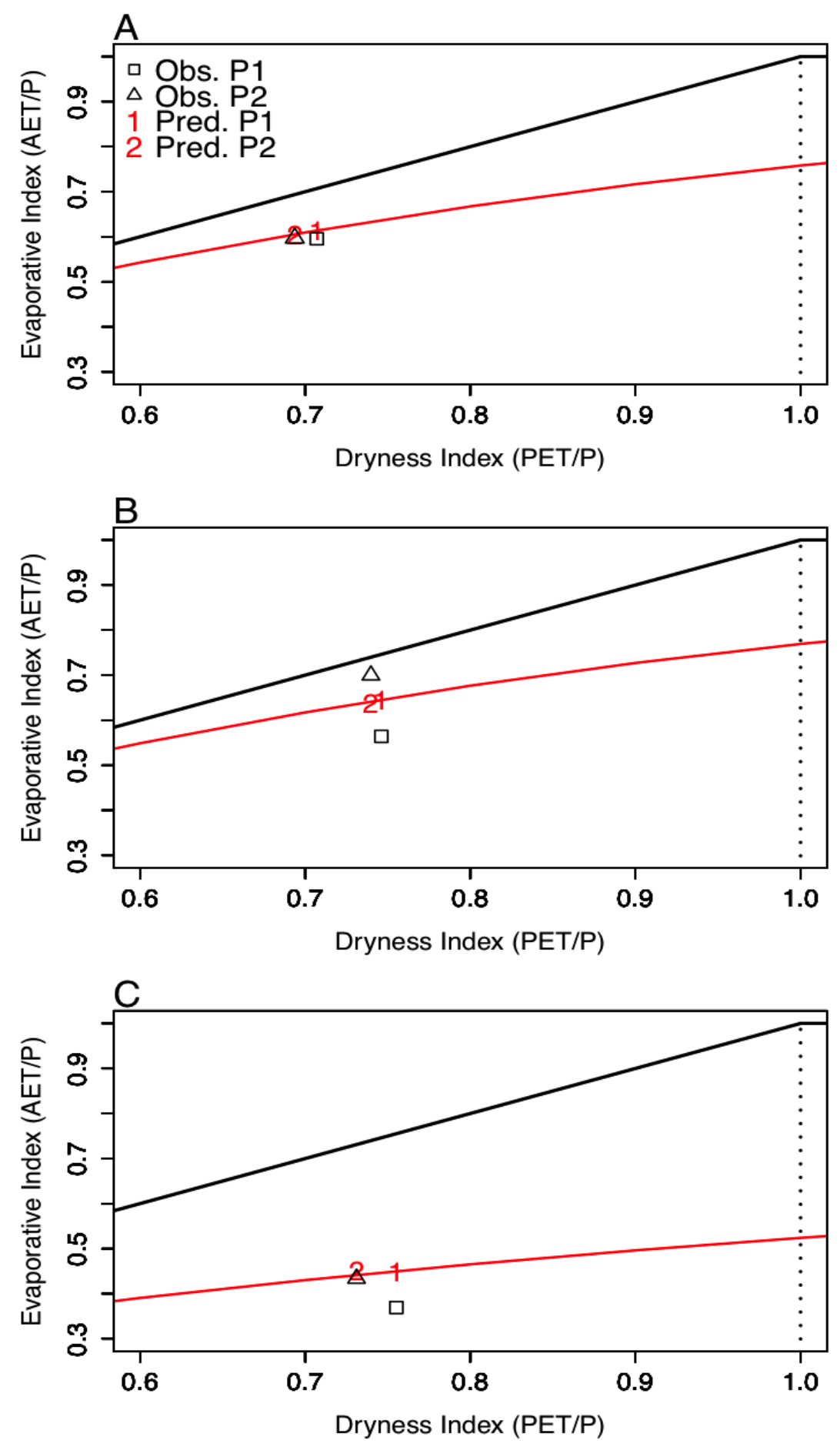

Figure 6. WS-1: The decomposition assumption that climate causes only vertical movement is supported because predicted point 2 moves along the predicted curve. The second assumption, that forest disturbance will move in a vertical direction is also supported because the observed and predicted points are different in a vertical direction. Predicted points and curve represent conditions in absence of forest harvesting, whereas observational points are influenced by forest disturbance. 


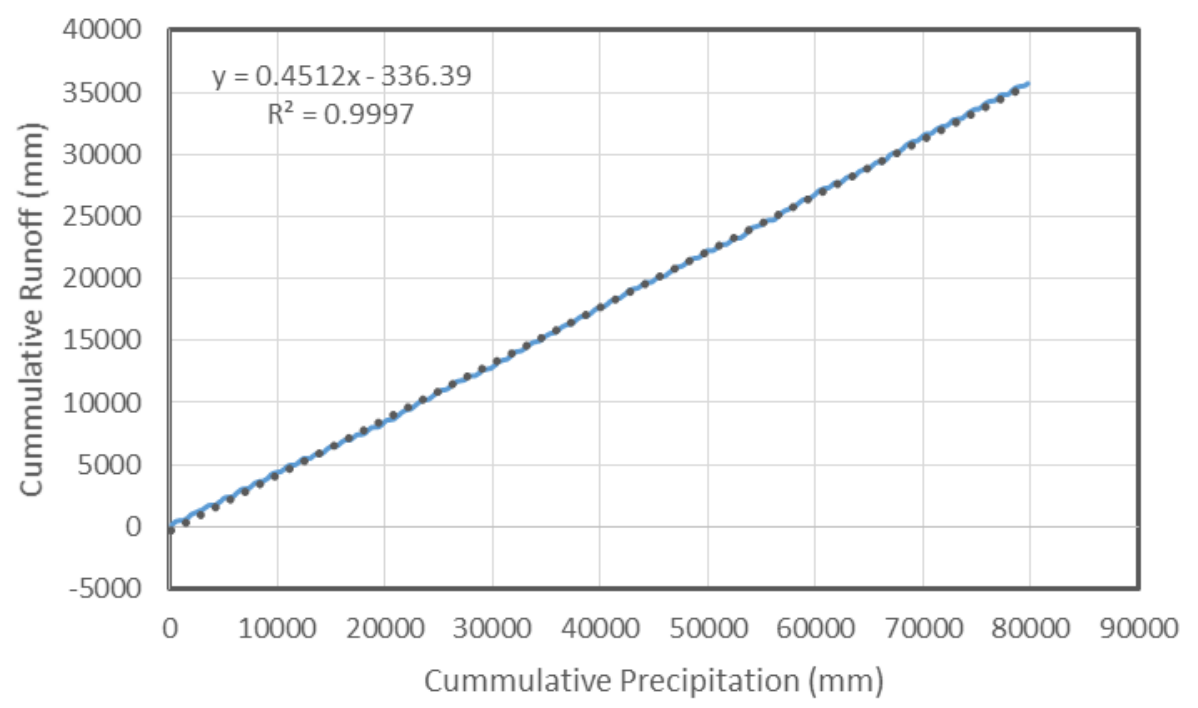

Figure 7. Cumulative precipitation versus cumulative streamflow (Double Cumulative Curve) over the study period (1952 - 2012) for WS-4. The lack of inflection points in the line are evidence that runoff ratios are influenced more by catchment characteristics than climate

\subsection{2 | Calibrated Budyko Curves}

Using Fu’s (1981) equation, a unique Budyko curve was calibrated for each catchment over period 1 (Figure 8). The calibration parameter $w$ was 2.92, 2.54, 2.40, and 1.53, respectively, for WS-1, WS-4, WS-6, and WS7. The Fernow catchment positions on the x-axis (PET/P) of the Budyko framework are all less than 1, indicating that all are energy limited rather than water limited (Figure 8). Dryness index for the four catchments ranged from $0.71-0.76$.

Zhang et al.'s (2004) curve developed with the calibration parameter $w=2.4$ provides a basis to compare variations in catchment water balance. In terms of $w$, vertical deviation from the theoretical curve ranged from -0.07 to 1.31 . Catchments WS-4, WS-6, and WS-7 plot below the curve, and thus, have a lower evaporative index and higher discharge than theoretically expected. By contrast, WS-1 plots slightly above the curve which corresponds to a higher evaporative index and less discharge than expected. 


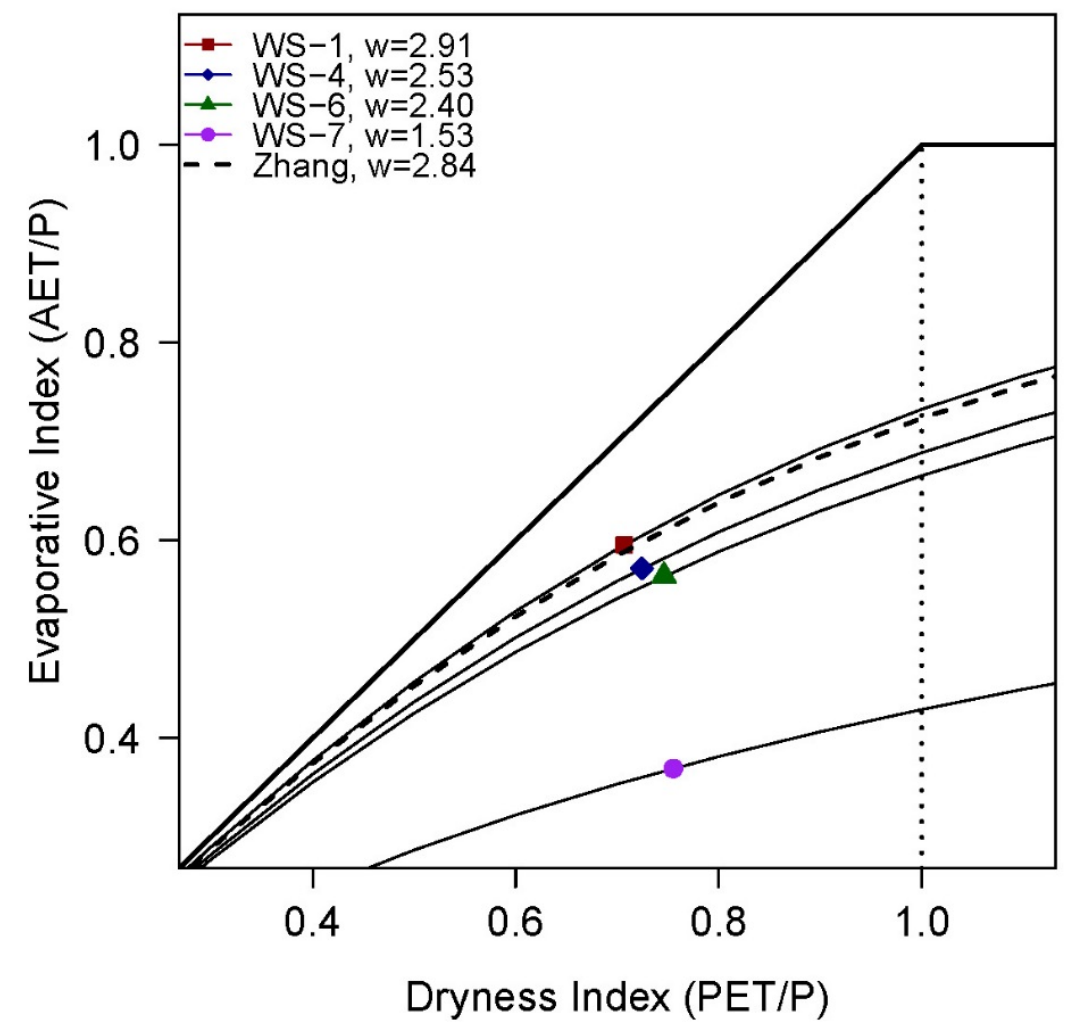

Figure 8. Unique Budyko curves calibrated to the long-term water balance (AET = P - Q) of period 1 for each Fernow catchment, compared to curve representing forested catchments globally with a calibration parameter of $w=2.84$ (Zhang et al. 2004).

\subsubsection{Effects of Forest Disturbance During Period 1}

The results of the paired catchment model provide a prediction of streamflow for the disturbed catchments if treatments had not been applied. These results are aggregated over the first period and plotted within the Budyko framework to allow comparison (Figure 9). By calibrating a unique Budyko curve to the predicted evaporative index using the paired catchment model, the decomposition method can be applied to quantify the effects of forest disturbance on streamflow in period 1. Respectively, the calibration parameter $w$ for the predicted WS-1, WS-6, WS-7 is curves equal 3.20, 3.33, and 1.78 for WS-1, WS-6, and WS7, respectively. In this analysis, points also deviate above and below the theoretical curve by -0.49 to .97 Relative to 
predicted points, observed points shifted to a lower evaporative index (Figure 9), due to the forest disturbances, resulting in the MAS increases during period 1 of $4.71 \%, 22.85 \%$, and 14.58\% for WS-1, WS-6, and WS-7, respectively.

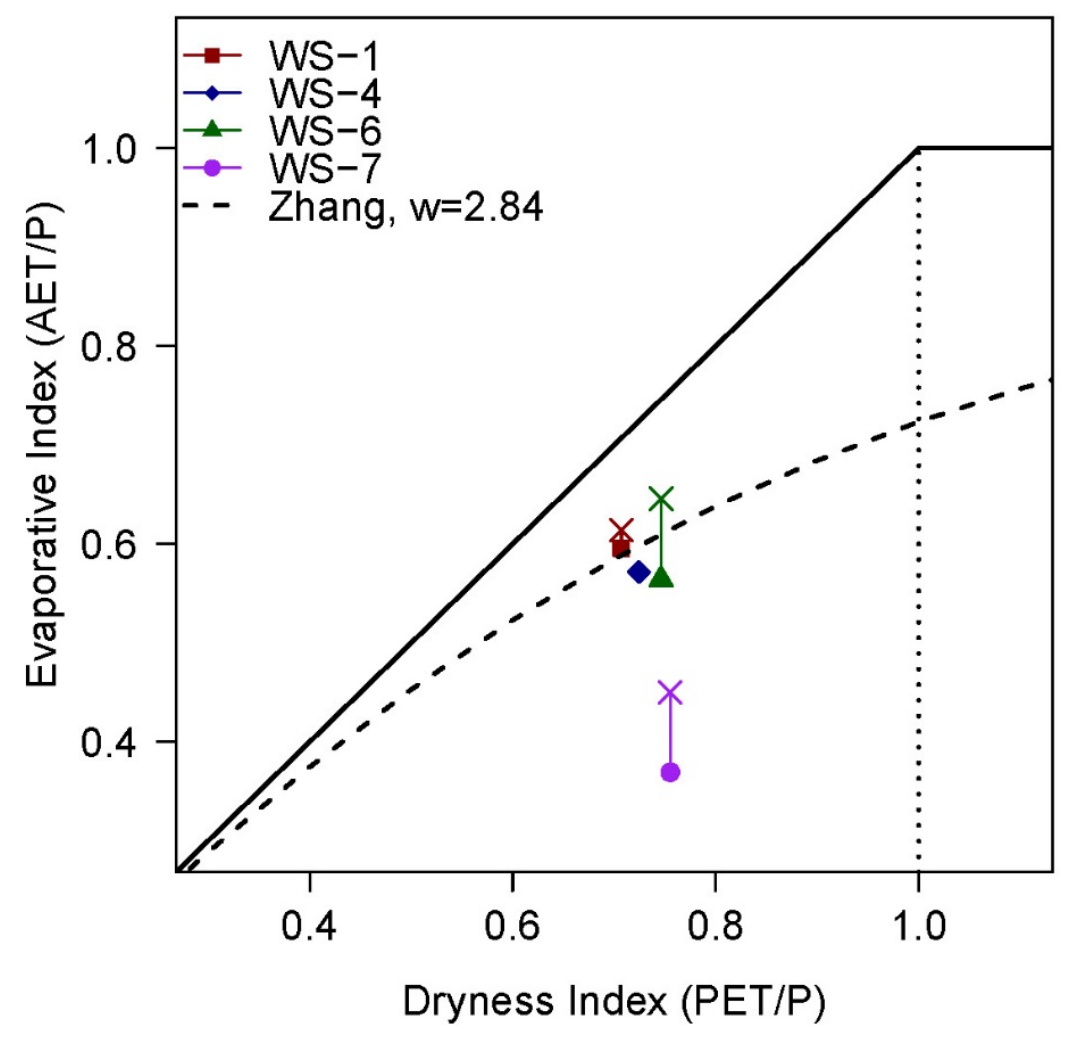

Figure 9. Effects of forest harvest on evaporative index during period 1 is equal to the vertical deviation between observed (watershed symbol) and predicted points (X symbol).

\subsubsection{Effects of Forest Disturbance and Climate Change From Period 1 to 2}

Figure 10 shows the deviation of observed data from period 1 to period 2. For all catchments, period 2 results deviated from period 1 in both the vertical and horizontal directions, respectively reflecting impacts of human and climate-driven changes. The effects of forest disturbance and climate change on streamflow for the two periods are quantified using the decomposition method. Climate-driven changes resulted in a change in MAS of 5.15\%, 
$-0.67 \%$, 3.50\%, and 5.91\% for WS-1, WS-4, WS-6, and WS-7, respectively (Figure 11). The reference watershed (WS-4) was not treated during either the first or second periods of data collection. However, a horizontal shift to the right was observed that did not move along the curve (Fig. 12). The shift was lower than the WS-4 curve, which indicates a lower evaporative index, corresponding to a 5.75\% increase in MAS during the second 30-year period (Figure 10). Forest disturbance-induced changes caused vertical shifts to a higher evaporative indices in the disturbed catchments, resulting in changes in MAS of $-2.41 \%,-32.28 \%$, and $-11.74 \%$ for WS-1, WS-6, and WS-7, respectively (Figure 11). 


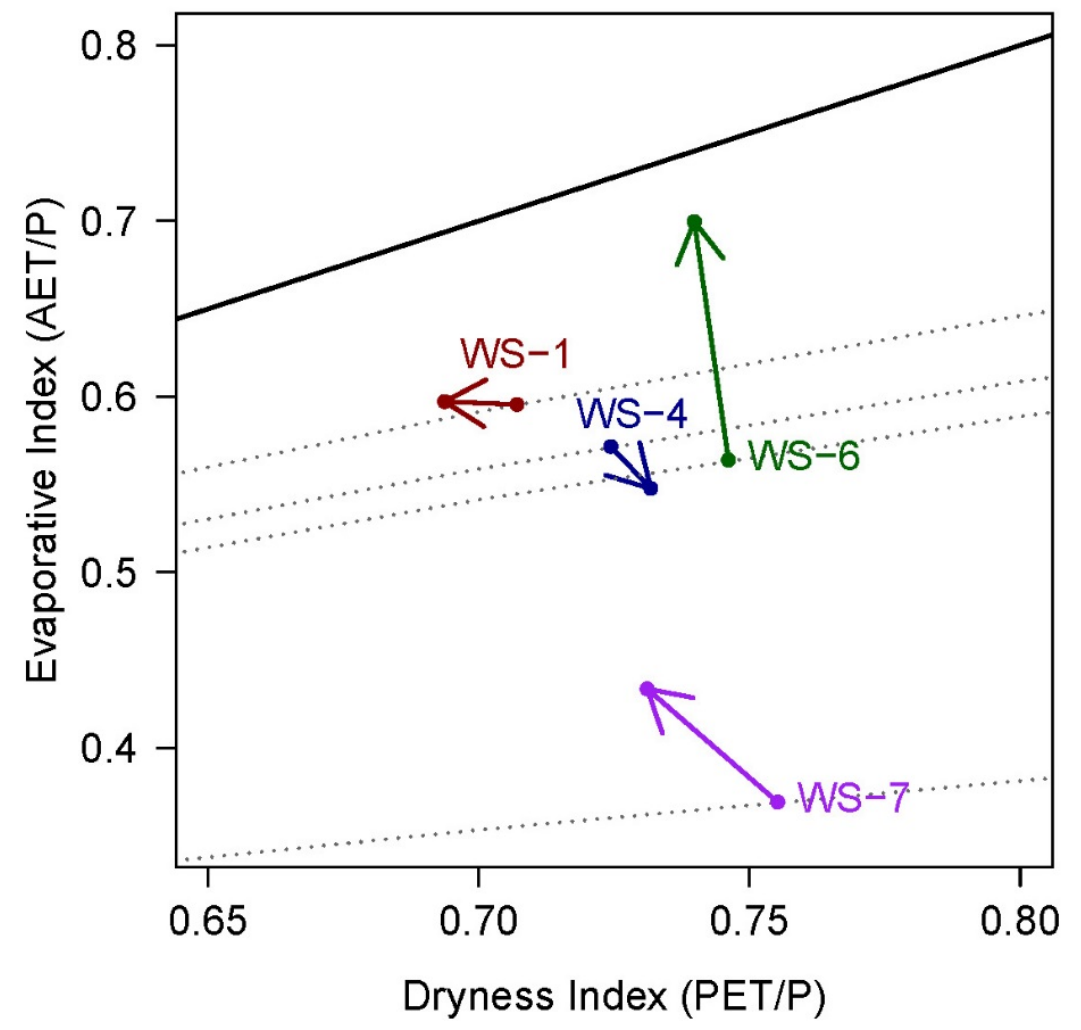

Figure 10. Movement from period 1 (tail of arrow) to period 2 (head of arrow) shows results are moving in both a vertical and horizontal direction. Vertical movement is attributed to forest disturbance and horizontal movement is attributed to climate. 


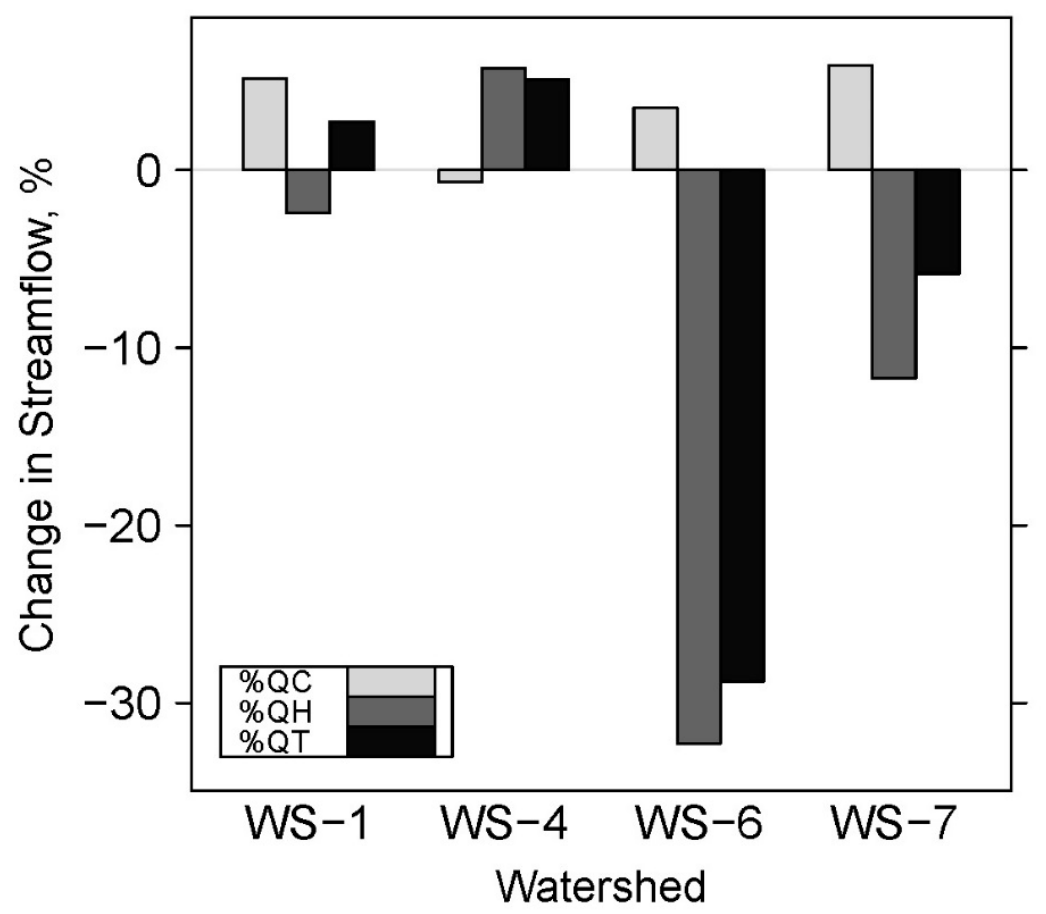

Figure 11. Percentage change in streamflow from period 1 to period 2 attributable to forest disturbance $(\% \mathrm{QH})$, climate $(\% \mathrm{QC})$, and the combined effect of both disturbance and climate change (\%QT).

\subsection{4 | Temporal Sensitivity of the Decomposition Method}

The decomposition method was applied to annual and 5-, 10-, 12-, and 15-year intervals for WS-1 and at annual, 5-, 9-, 11-, 14-year intervals for WS-6 and WS-7 to examine the applicability of the method for describing the effects of disturbances and climate on streamflow at shorter time scales. To examine sensitivity relative to forest disturbance, this analysis was accomplished by predicting paired catchment results (Predicted $\Delta \mathrm{Q}_{\mathrm{h}}$ ) from the decomposition method results $\left(\Delta \mathrm{Q}_{\mathrm{h}}\right)$ using linear regression for each of these shortened time periods. To examine sensitivity relative to climate effects, Predicted $\Delta \mathrm{Q}_{\mathrm{c}}$ was predicted from the decomposition method results $\left(\Delta \mathrm{Q}_{\mathrm{c}}\right)$ using linear regression.

For WS-6 and WS-7, the regression equation results showed that the decomposition 
method underestimated Predicted $\Delta \mathrm{Q}_{\mathrm{h}}$. However, the underestimation was uniform in magnitude and consistent across time scales, resulting in strong linear relationships (Figures 13 and 14); coefficients of determination $\left(\mathrm{R}^{2}\right)$ over each time interval were: annually $=0.92,5$ years $=0.98,9$ years $=0.98,11$ years $=0.99$, and 14 years $=0.99$. Similarly, $\mathrm{R}^{2}$ values for WS- 7 were: annual $=0.77$, 5 year $=0.92$, 9 year $=0.96,11$ year $=0.96$, and 14 year $=0.99$.

The decomposition method did a much poorer job of determining Predicted $\Delta \mathrm{Q}_{\mathrm{h}}$ for WS1 (Figure 12). This result is reflected in the $\mathrm{R}^{2}$ values, which were annual $=0.28,5$ year $=0.42,10$ year $=0.25,12$ year $=0.66$, and 15 year $=0.85$. The 15 -year period prediction performed fairly well, but only because there were only 3 points involved in the regression equation.

The decomposition method showed mixed results for determining Predicted $\Delta \mathrm{Q}_{\mathrm{c}}$ from the decomposition model-derived $\Delta \mathrm{Q}_{\mathrm{c}}$ (Figures 15 - 17). Of the three disturbed catchments, the decomposition model provided the best prediction for WS-1, resulting in $\mathrm{R}^{2}$ values of annual= 0.88 , 5 -year $=0.85,10$-year $=0.77,12$-year $=0.60$, and 15 -year $=0.89$. For WS- 6 , the decomposition method modeled Predicted $\Delta \mathrm{Q}_{\mathrm{c}}$ poorly for all time intervals: annual $=0.48,5$ year $=0.14,9$ year $=0.12,11$ year $=0.23$, and 14 year $=0.18$, and WS-7: annual $=0.77,5$-year $=0.37,9-$ year $=0.15$, 11 -year $=0.18$, and 14 -year $=0.54$. 

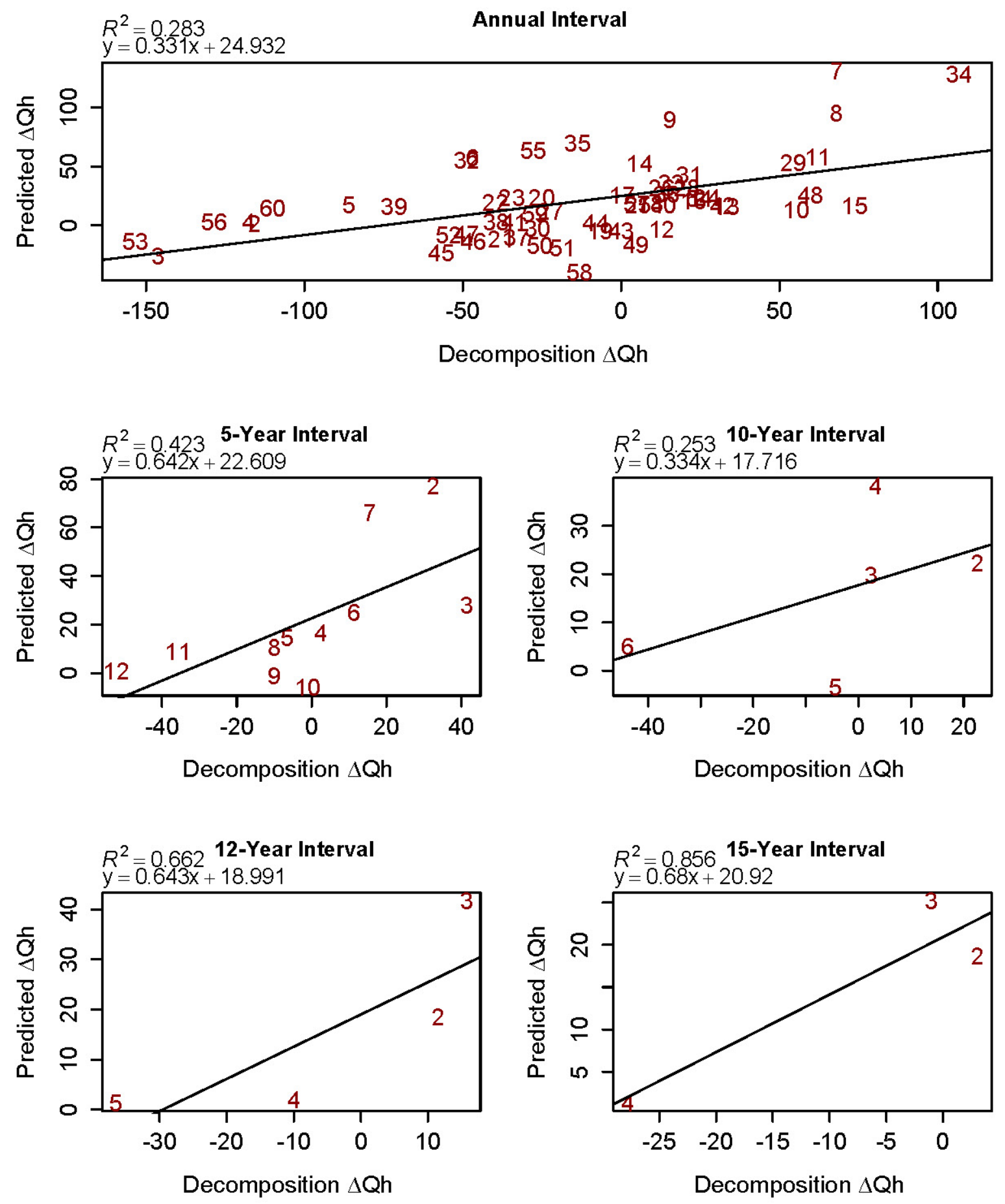

Figure 12. Validation of change in streamflow due to forest disturbance ( $\Delta \mathrm{Qh})$ for WS-1, modeled by the decomposition method (Decomposition $\Delta \mathrm{Qh}$ ) and the paired watershed method (Predicted $\Delta \mathrm{Qh}$ ) for annual, 5-year, 10-year, 12-year, and 15-year time intervals. 

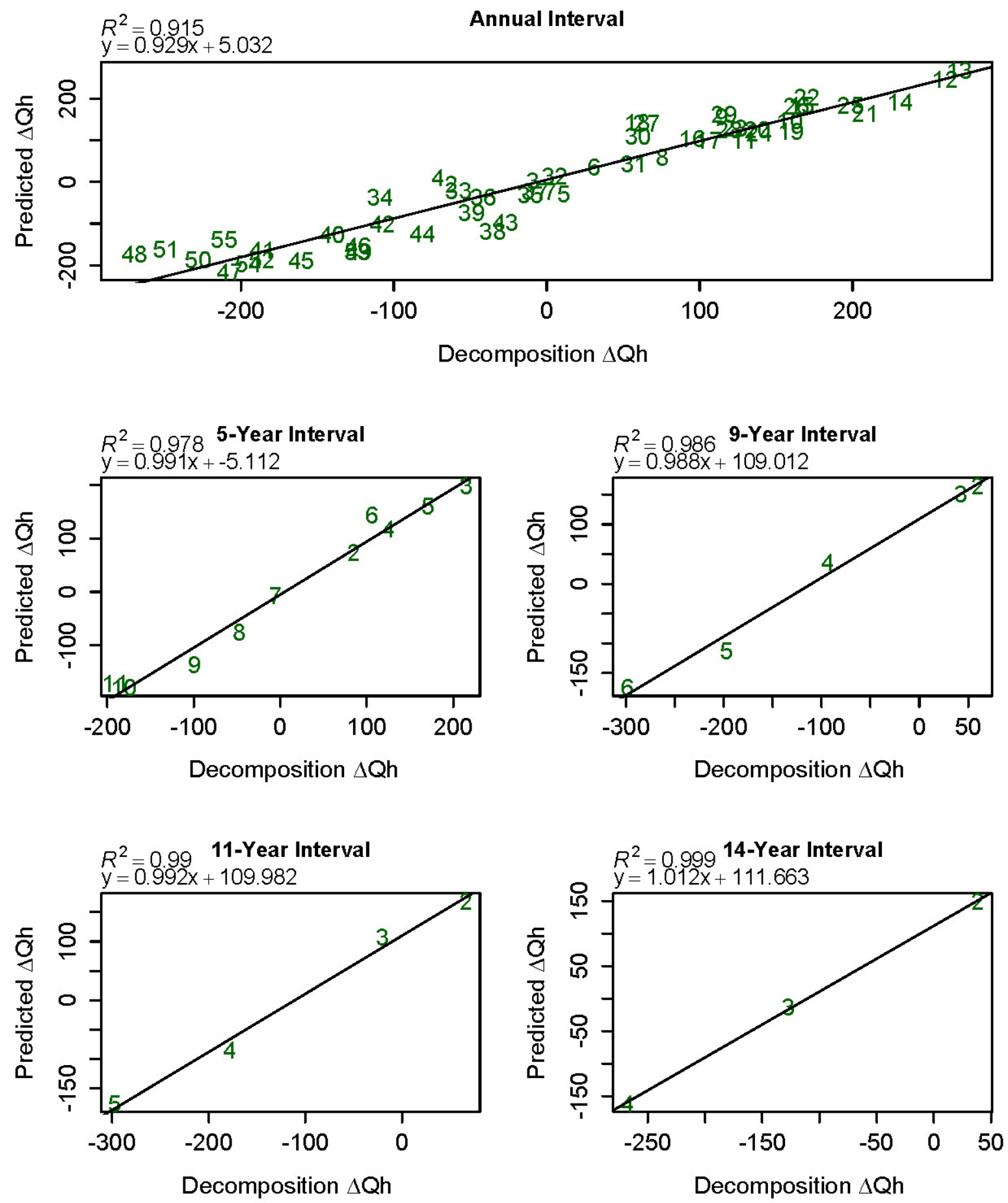

Figure 13. Validation of change in streamflow due to forest disturbance ( $\Delta \mathrm{Qh}$ ) for WS-6, modeled by the decomposition method (Decomposition $\Delta \mathrm{Qh}$ ) and the paired watershed method (Predicted $\Delta \mathrm{Qh}$ ) for annual, 5-year, 9-year, 11-year, and 14-year time intervals. 

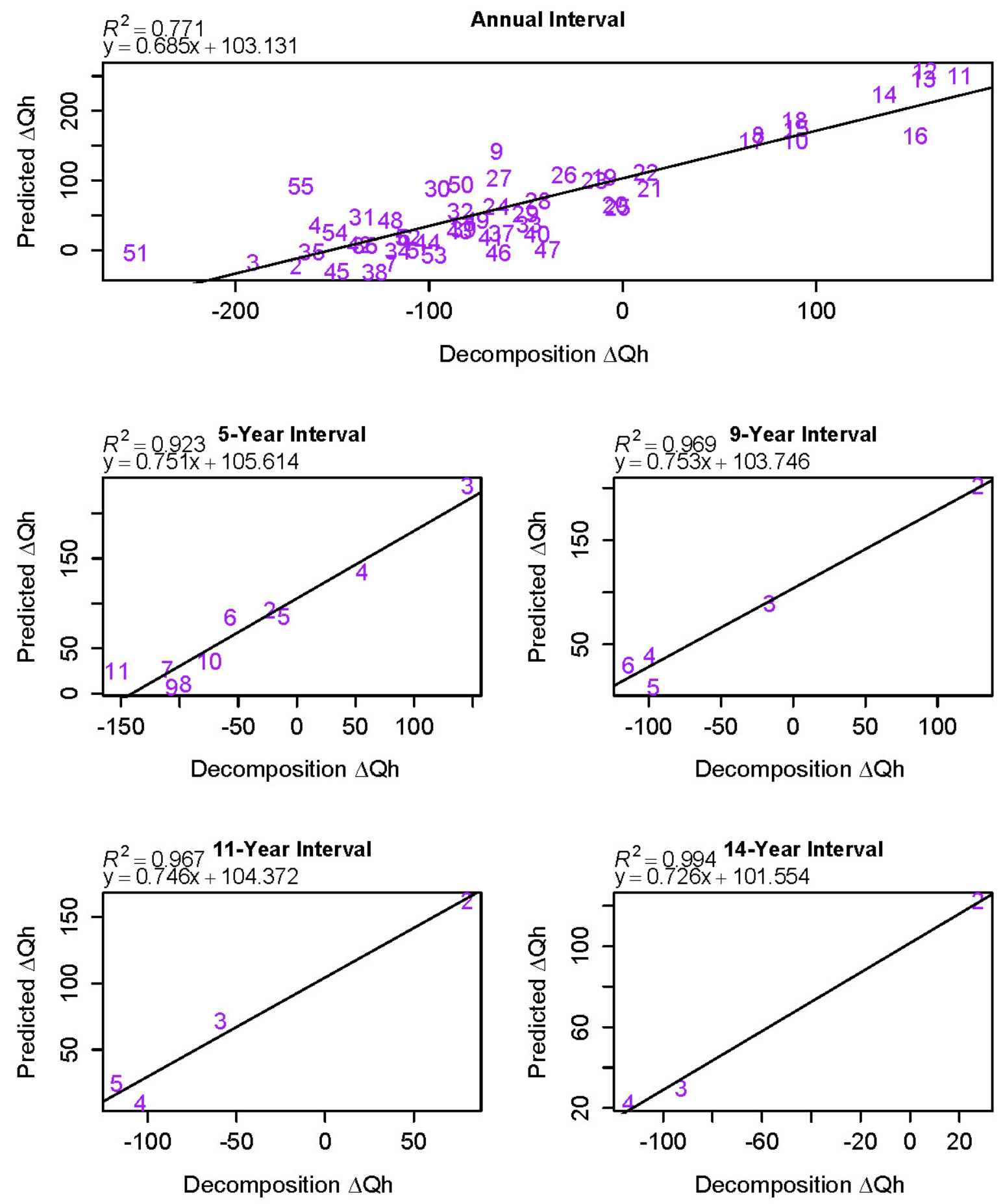

Figure 14. Validation of change in streamflow due to forest disturbance ( $\Delta \mathrm{Qh})$ for WS-7, modeled by the decomposition method (Decomposition $\Delta \mathrm{Qh}$ ) and the paired watershed method (Predicted $\Delta \mathrm{Qh}$ ) for annual, 5-year, 9-year, 11-year, and 14-year time intervals. 

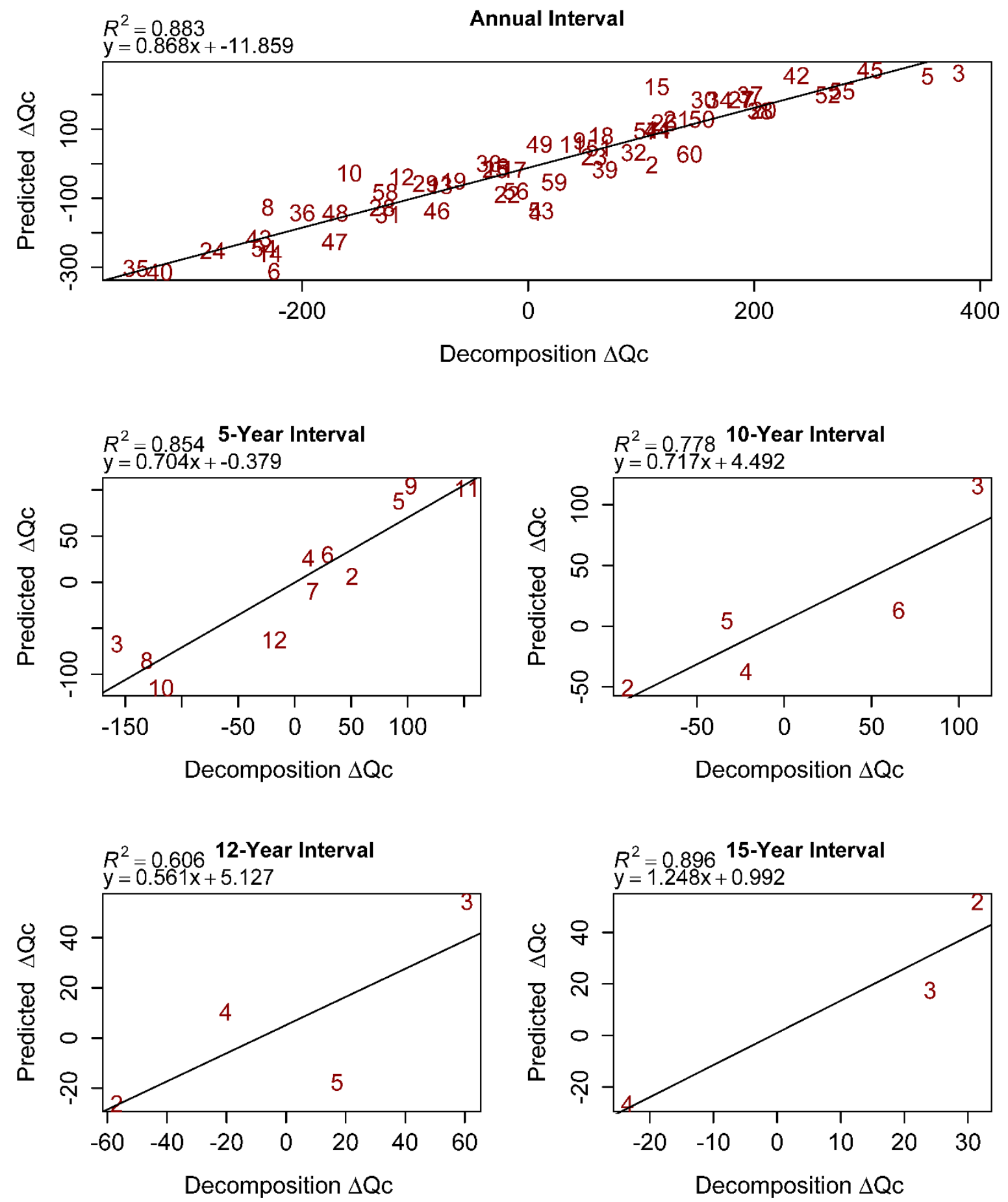

Figure 15. Validation of change in streamflow due to climate ( $\Delta \mathrm{Qc})$ for WS-1, modeled by the decomposition method (Decomposition $\Delta \mathrm{Qc}$ ) and the paired watershed method (Predicted $\Delta Q c)$ for annual, 5-year, 10-year, 12-year, and 15-year time intervals. 

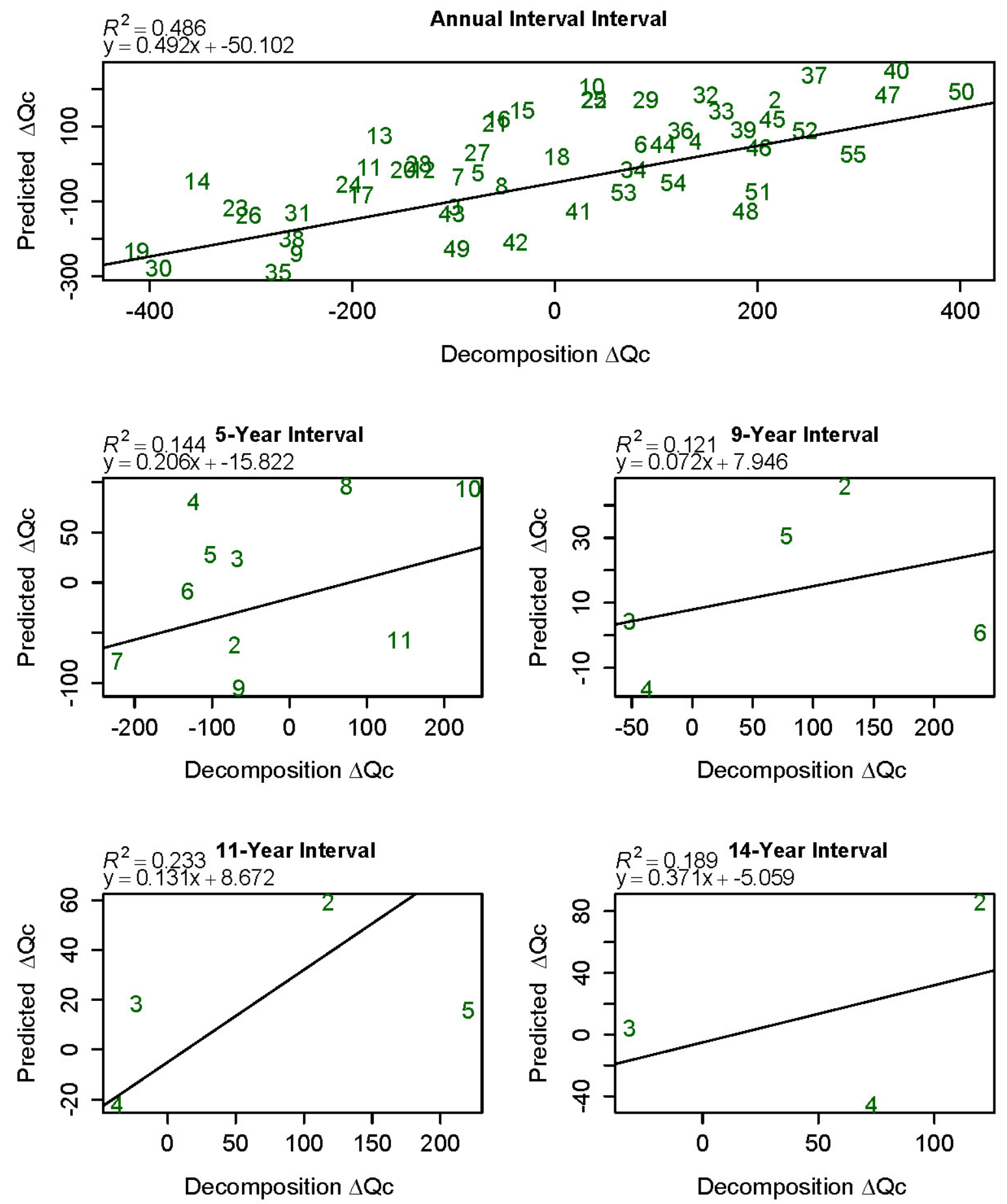

Figure 16. Validation of change in streamflow due to climate ( $\Delta$ Qc) for WS-6, modeled by the decomposition method (Decomposition $\Delta \mathrm{Qc}$ ) and the paired watershed method (Predicted $\Delta \mathrm{Qc}$ ) for annual, 5-year, 9-year, 11-year, and 14-year time intervals. 

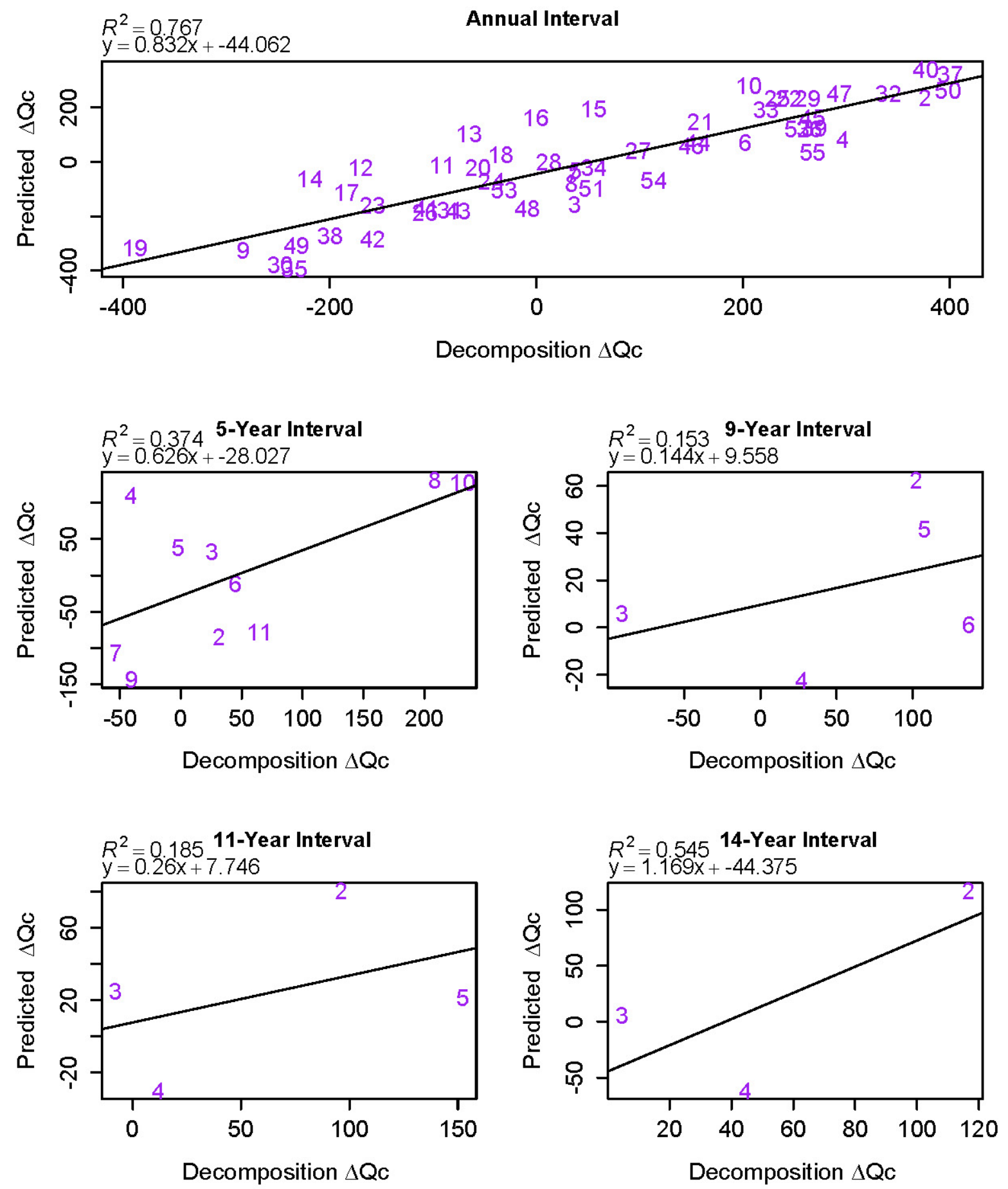

Figure 17. Validation of change in streamflow due to climate ( $\Delta \mathrm{Qc})$ for WS-7, modeled by the decomposition method (Decomposition $\Delta \mathrm{Qc}$ ) and the paired watershed method (Predicted $\Delta \mathrm{Qc}$ ) for annual, 5-year, 9-year, 11-year, and 14-year time intervals. 


\section{4 | Discussion}

\section{Trends in Climate}

Over the period of record (1952 to 2012) temperature and precipitation have changed. Trends in mean and maximum temperature at annual and seasonal scales are consistent with previous studies of the Fernow (Vose et al. 2012, Jones et al. 2012, Hatcher 2011). However, unlike studies by Jones et al. (2012) and Hatcher (2011), statistically positive trends in annual minimum temperature were not found when auto correlation was considered. The temperature increase of $1.5^{\circ} \mathrm{C}$ over the study period is similar to temperature increases reported for the northern U.S. of $0.25^{\circ} \mathrm{C}$ per decade (Hayhoe et al. 2006). The lack of trends in PET likely reflects the lower sensitivity of Priestly-Taylor PET model to temperature (Archiblad and Walter 2014).

No trends in annual precipitation were detected, similar to the findings of Jones et al. (2012) and Hatcher (2011). The significant increases in growing season precipitation increases may be associated with increasing temperatures (Karl and Knight 1998), since temperaturedriven intensification of the water cycle (Huntington 2006) is expected to increase storm intensity, particularly during the summer (Karl and Knight 1998). Changes in climate during the growing season are particularly important to ecosystems because summer is likely to have the greatest impact on vegetation (Knapp et al. 2008). Precipitation pattern data from regional studies are limited and results are variable. Pitchford et al. (2012) found that precipitation intensity increased in the mid-Atlantic region from 1890 - 2009; however, for the stations closest to the Fernow both decreasing and increasing trends were found. Variability is likely attributable to complex topography. Leonard and Law (2012) reported that precipitation normals decreased annually by $-0.7 \%$ and during the summer by $-8.0 \%$ for West Virginia’s central climate division. 


\section{Effects of Forest Disturbance and Climate on Streamflow}

Decomposing the deviation from period 1 to 2 indicates movement in both vertical and horizontal directions, suggesting that each catchment is responding to climate change as well as forest disturbance and succession (Figure 10). For all catchments, the direction of change influenced by climate (dryness index) did not produce a shift in the evaporative index according to the Budyko curve. As a result, climate impacts were secondary to changes in catchment water balance caused by forest disturbance and succession. For disturbed catchments, disturbanceinduced increases in streamflow during period 1 followed by regrowth that dampened (WS-1) or masked (WS-6, WS-7) the effects of climate change during period 2. Direct human disturbance has been found to mimic, exacerbate, counteract, or mask the effects of climate change on streamflow (Jones et al. 2012).

Studies show that the dominance of either climate or direct human disturbance on streamflow depends on magnitude of disturbance, geographic context, and temporal scale of analysis. For example, a recent study of 103 stream stations in Arizona, Georgia, Indiana, and New York found that human impacts are more influential than climate change on streamflow changes (Ahn and Merwade 2014). Using three methods, including the decomposition method, Sun et al. (2014) found that the Upper Hanjiang River Basin was more influenced by climate variability than direct human disturbance.

Streamflow from WS-4 is changing in ways that climate alone cannot describe. From period 1 to period 2 the dryness index of WS-4 increased slightly due to increases in potential evapotranspiration (Table 4). However, for WS-4 the almost 6\% increase in MAS was attributable to a decrease in the evaporative index. Incremental increases in streamflow through 
time were revealed by the Decomposed $\Delta \mathrm{Q}_{\mathrm{h}}$ at 5-year intervals (Figure 18). Increases in streamflow for WS-4 were also reported by Jones et al. (2012), and Hatcher (2011) found significant positive increases in several hydrometric variables: annual $\mathrm{Q} / \mathrm{P}$, baseflow $\mathrm{Q} / \mathrm{P}$, fall $\mathrm{Q} / \mathrm{P}$, fall baseflow $\mathrm{Q} / \mathrm{P}$, winter $\mathrm{Q} / \mathrm{P}$, winter baseflow $\mathrm{Q} / \mathrm{P}$, and fall baseflow. Jones et al. (2012) speculated streamflow increases were due to late forest succession.

WS-1

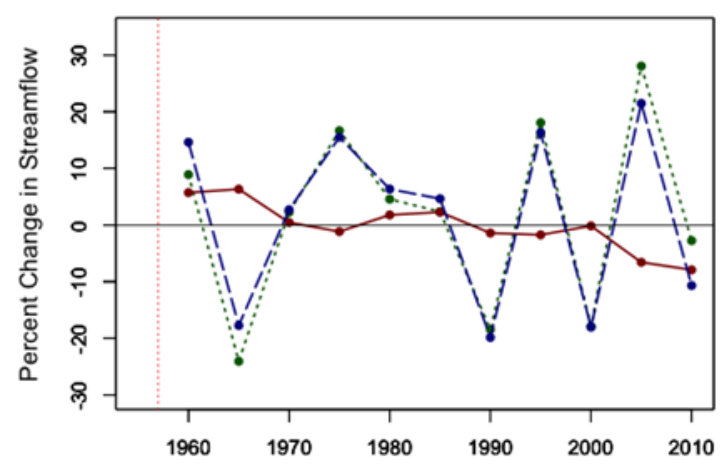

WS-6

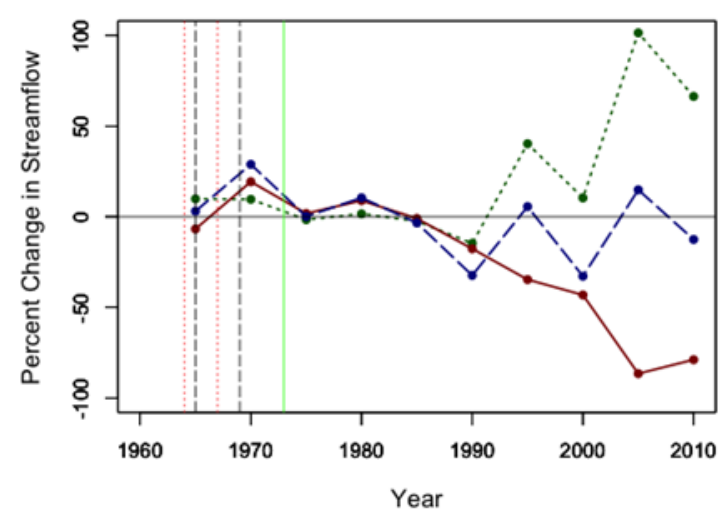

WS-4

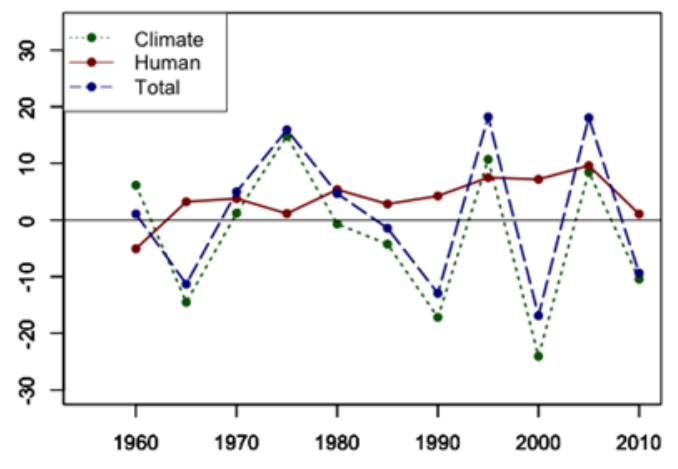

WS-7

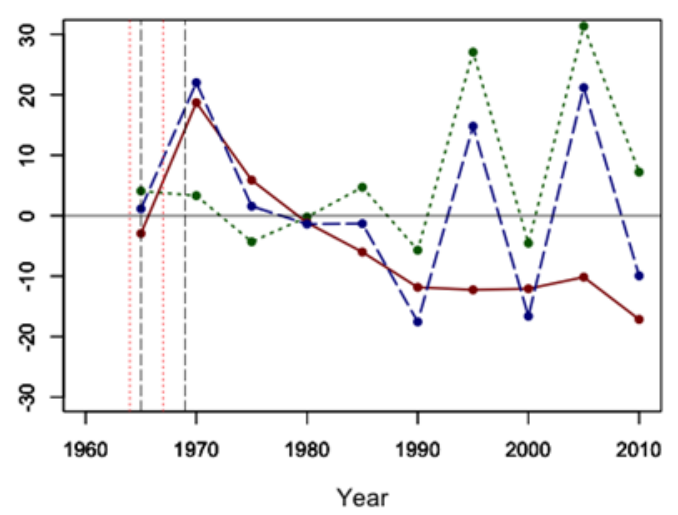

Figure 18. Percent change in streamflow over 5-year time intervals due to climate (horizontal dotted line), forest disturbance (horizontal solid line), and total effects (horizontal dashed line) calculated using the decomposition method. The vertical dotted line indicates the years of forest clear cutting, and the vertical dashed line indicates the years that herbicide application began and ended. The vertical solid line indicates the year WS-6 was planted to Norway spruce.

In WS-4, as one would expect, species importance decreased for early successional species and increased for the most dominant species (Figure 3). Relative to the first sampling 
year in 1959, red maple and sugar maple have increased in importance far more than the other dominant species. Increased maple dominance has been observed across Appalachia (Abrams 1998). In mixed-oak forests, maple increases have been associated with declines in oak species (Brose et al. 2001), attributed to changes in disturbance regimes, including fire suppression, increased deer browsing, and forest harvest practices that cause high intensity, stand initiating disturbances (Abrams and Nowacki 1992). In WS-4 oaks have not experienced the widespread declines other areas have observed, so maple dominance has likely increased due to declines in early successional species (sweet birch, black locust) and decreases in other species (hickories, American beech).

Water use differs by tree species (Wullschleger et al. 2001, Ford et al. 2011) and tree size (Meinzer et al. 2005). For example, mature sugar maples (vs. young sugar maples) have been shown to adapt to dry periods through the process of hydraulic lift, where water is pulled from deeper groundwater (Dawson 1996). In a mature stand of sugar maples this process favors more transpiration, but at the same time hydraulic lift redistributes water to the upper soil profile. In general, mature trees of all species have the ability to extract water held deeply in the soil and reduce the reliance on shallow soil moisture (Sperry 2002). Other studies have quantified transpiration rates by dividing species into ring-porous species (black locust, oaks, and shagbark hickories) and diffuse porous species (American beech, maples, poplar, sweet birch) based on the structure, size, and spatial distribution of xylem conduits. Ring-porous species (3 oaks, 1 hickory) as compared two diffuse-porous species (sugar maple and yellow-poplar) regulate stomata less and exploit water resources over broader ranges of soil water availability and atmospheric dryness (Meinzer et al. 2013). During drought conditions, stomata of diffuse-porous species were 2 to 3 times more sensitive to soil drying, effectively reducing transpiration rates. 
As a result, the inter-annual variability of streamflow from forests dominated by ring-porous species will be less than a forest dominated by diffuse-porous species (Ford et al. 2011), if other conditions are the same.

Wullschleger et al. (2001) found that total transpiration is best described by the species with the largest sapwood area rather than by species, basal area, or density. For example, in a stand where red maple occupied only 12 percent of the basal area, it accounted for $26 \%$ of total transpiration of overstory species. By contrast, a stand of chestnut oak that occupied $26 \%$ of the basal area accounted for only $16 \%$ of overstory transpiration. In the same study sapwood area of ring porous species increased with stem diameter, while there was little change in sapwood area with stem diameter for diffuse porous species. For smaller diameter trees, sapwood area was 3-4 times greater for diffuse porous species than ring porous species.

The above studies provide evidence that species composition changes can impact hydrology. Thus, streamflow increases in WS-4 may be due to the early successional species being replaced by late successional development of red and sugar maples. Although maples may use more water per tree than their predecessors, the decrease in the total number of stems (17\%) in the catchment over the study period suggests maples, along with the other species, are more efficient on a per hectare basis. An alternative hypothesis suggests streamflow increases are due to bio-mass accumulation on the forest floor which has increased soil moisture capacity and changed channel morphology. Although supported only by the author's observations through time, such changes are could cause base flow increases in fall and winter (Jones et al. 2012, Hatcher 2011).

The effects of forest disturbance on MAS reflect the magnitude and duration of disturbance as well as the temporal scale at which the analysis is conducted. Although WS-1 was 
clearcut with no BMPs, rapid regrowth limited hydrologic response to the first 5 years (Reinhart and Eschner 1963, Hornbeck et al. 1993). As a result, all time intervals used in this analysis, except annual intervals, are a coarse measure of hydrologic response to forest disturbance. For example, at a 5-year time scale, disturbance response was contained within the first interval (1957-1962), and subsequent intervals captured changes in water balance due to forest succession or no effect at all. Therefore, as temporal scale increases the aggregation of mean annual data dampens the overall effect, possibly effecting decomposition model performance The magnitude and duration of disturbances for WS-6 and WS-7 resulted in measurable increases in streamflow beyond the final herbicide application (1969) and through the end of period one (Hornbeck et al. 1993). In comparison to WS-1, the effectiveness of the 2-period analysis was improved because period 1 contained mostly the disturbance response phase and period 2 contained the recovery phase. The effects of forest treatment in period 1 caused substantial increases in MAS (WS-6 $=22.85 \%$ and WS-7 $=14.58 \%$ ). Differences in percent change in MAS between the watersheds exist because the lower half of WS-6 versus the upper half of WS-7 was clear cut in the first phase, causing instantaneous peak flows for WS-6 to increase by a factor of four during the first phase of experimental treatment (Patrick and Reinhart 1971). In addition to changes in MAS, the low evaporative index and corresponding $w$ value for WS-7 indicate that vegetation plays a less prominent role in partitioning precipitation to streamflow compared to WS-6.

From period 1 to period 2, the evaporative index increased 20\% for WS-6 and 15\% for WS-7, but streamflow decreased disproportionately more for WS-6. Regime curves (Figure 5) show the difference in timing and magnitude in the two periods and provide a comparison of forest disturbance effects. In WS-7 the effect of disturbance was restricted to the growing season, 
which is consistent with results by Hornbeck et al. (1993). Stand conversion from the hardwood to coniferous forest in WS-6 impacted both dormant season and growing season hydrology. Other studies have reported decreases in dormant season yield after conversion to conifers (Swank and Douglass 1974) due to increased dormant season transpiration and interception (Ford et al. 2011).

\section{Hydrologic Recovery}

The disturbances applied to the study sites resulted in different successional outcomes. Clearcutting WS-1 accelerated forest succession through the release of late successional understory vegetation. Prolonged herbicide application in WS-6 and WS-7 removed opportunities for revegetation to occur from coppicing, root sprouts, and seed bank sources. Furthermore, WS-6 was regenerated with planted Norway spruce seedlings. While WS-4's most recent harvest was about a century ago, it also continues to undergo successional changes.

Hydrologic response to disturbance, follows a trajectory of disturbance, response, and recovery (Abel and Mirus 2014). The response period is marked by a rapid change in the hydrologic dynamic equilibrium, as hydrologic connectivity and storage are altered. The resumption of vegetation interception and transpiration are central to restoring hydrologic function in forested catchments. However, interception and transpiration rates differ by tree type, age, and size (Jones and Post 2004); therefore, forest succession influences hydrologic recovery. State variables, such as landform, geology, and soils also influence hydrologic recovery. In each of the study watersheds, forest disturbance initiated forest succession, which resulted in species composition changes (Figures 2 - 4), and disturbed soils through the construction of roads, skid trails, and log landings.

To assess the influences of disturbance and climate change on hydrologic recovery, the 
decomposition results for disturbed catchments WS-1, WS-6, and WS-7 during period 2 were compared to the predicted Budyko curve (Figure 6). Both WS-1 and WS-7 returned to the predicted Budyko curve, indicating that the hydrologic system returned to the pre-disturbance long-term averages. Changes in climate between time periods caused an horizontal shift along the curve. WS-6 did not return to the predicted Budyko curve, but shifted above the curve to a higher evaporative index. The paired watershed method depends upon confidence intervals determined during the calibration period to differentiate hydrologic response from recovery (Hewlett and Pienaar 1973). Hydrologic response for WS-1 returned to within pre-harvest confidence limits within five years of disturbance (Reinhart and Eschner 1963, Hornbeck et al. 1993). Considering the rapid regrowth and similarity in species composition before and after harvesting, largely attributable to coppicing in WS-1, this result is not surprising.

However, for WS-7 the disturbance magnitude was more extreme and prolonged, which required vegetation to regrow primarily from new seed dispersal into the watershed. Despite this, re-vegetation began in 1970 one year after herbicide treatment ended. Grasses established first followed by herbaceous only to be overtaken by woody vegetation by the end of the decade. In 1979, 87\% of growth plots were stocked with commercial timber species (Kochenderfer and Wendel 1983).

Significant increases in annual water yield were observed on WS-7 during the first 6 years after the disturbance (Kochenderfer and Wendel 1983), then streamflow increases of 50 to $100 \mathrm{~mm}$ greater than pre-disturbance conditions persisted for 14 years (Hornbeck et al. 1993). The re-vegetation of WS-7 is an example of the capacity of these catchments's discharges to recover from disturbance, of which vegetation recovery played an important role. However, differences in stand structure and species composition pre- and post-disturbance suggest WS-7 
hydrology is more influenced by the broad functional-processes of vegetation rather than the differences in plant water use and canopy structure. In addition, WS-7's comparatively low evaporative ratios and $w$ values suggests the catchment is less sensitive to vegetation, and catchment structure is a more dominant control of streamflow.

Recovery is a return toward the original dynamic equilibrium conditions that existed prior to disturbance, as pre-disturbance functional-processes that route, store, and release water begin to reestablish, or alternatively recovery can be a change toward a new dynamic equilibrium if the watershed recovers to a new condition. Watershed-wide species conversion on WS-6 is an example of recovery to a new dynamic equilibrium. Figure 18, shows incremental streamflow decreases until 2005 at which point streamflow changes stabilize. Decreases up to 2005 are associated with increased transpiration and interception rates of young conifers progressing through a stand initiation phase (Swank et al. 1988). Stabilization of streamflow is associated with recovery to a new dynamic equilibrium and occurs as the stand canopy closes and self-thins due to light competition.

\section{Calibrated Curves}

The catchment-specific $w$ parameter, differs from the parameter for global forested catchments $(w=2.84)$ (Zhang et al. 2004). The range in $w$ for the Fernow watersheds $(1.53-2.9)$ reflects the variation in how catchments partition precipitation into evapotranspiration and discharge. Compared to the range of $w$ published in other studies, 1.0 - 5.0, that encompass wide varieties of ecosystems from grassland to tropical rain forests (Zhang et al. 2004, Xu et al. 2013), the range of $w$ is relatively large for the Fernow catchments that are very near one another and are topographically, edaphically, geologically, and biologically similar. Such heterogeneity in $w$ for proximate watersheds poses significant challenges for estimating $w$ for ungauged basins. 
The large range of $w$ values is primarily due to WS-7. The $w$ of WS-7 (1.53) is at the lower limit of the known range of $w$, even when the effects of disturbance are removed (predictive curve, $w=1.78$ ). In comparison to the other study sites, WS-7 naturally partitions a greater percentage of precipitation into streamflow. The $w$ values for the other three Fernow watersheds were more consistent among catchments, and within 0.4 of the global forested curve (2.84). Considering the insensitivity of AET to changes in $w$ at large $w$ values (Zhang et al. 2004), the global forested curve value (2.84) could be used to predict WS-1, WS-4, and WS-6 responses relatively accurately.

\section{Temporal Sensitivity of Decomposition Method}

For short time scales, the decomposition model captured the hydrologic response of forest disturbance for WS-6 and WS-7 but uniformly underestimated the scale. In the decomposition method, the curve is used as the basis for quantifying change. In this study, the curve was calibrated to the first half of the study period which contained forest disturbance. The sign ( + / -) of $\Delta \mathrm{Q}_{\mathrm{h}}$, is determined based on the position above (negative) and below (positive) the curve. The Decomposition $\Delta \mathrm{Q}_{\mathrm{h}}$ generally was positive during the hydrologic response phase and negative during the recovery phase. To test whether model underestimation was due to the sign of the Decomposition $\Delta \mathrm{Q}_{\mathrm{h}}$, the decomposition method was reapplied using the predicted baseline curve for WS-6 at 1- and 5-year intervals. In comparison to the curve calibrated to the observed period 1 , this analysis resulted in a $98 \%$ decrease in y-intercept and approximately the same $\mathrm{R}^{2}$ (Figure 19). This finding shows that the w-parameter greatly influences the sign of $\Delta \mathrm{Q}_{\mathrm{h}}$ but does not influence the overall outcome. Logically this result should apply to WS-7 and WS-1 because forest disturbance caused values to deviate below the predicted curve. This result provides evidence that the decomposition method accurately modeled the effects of forest disturbance on 
streamflow for WS-6 and WS-7.
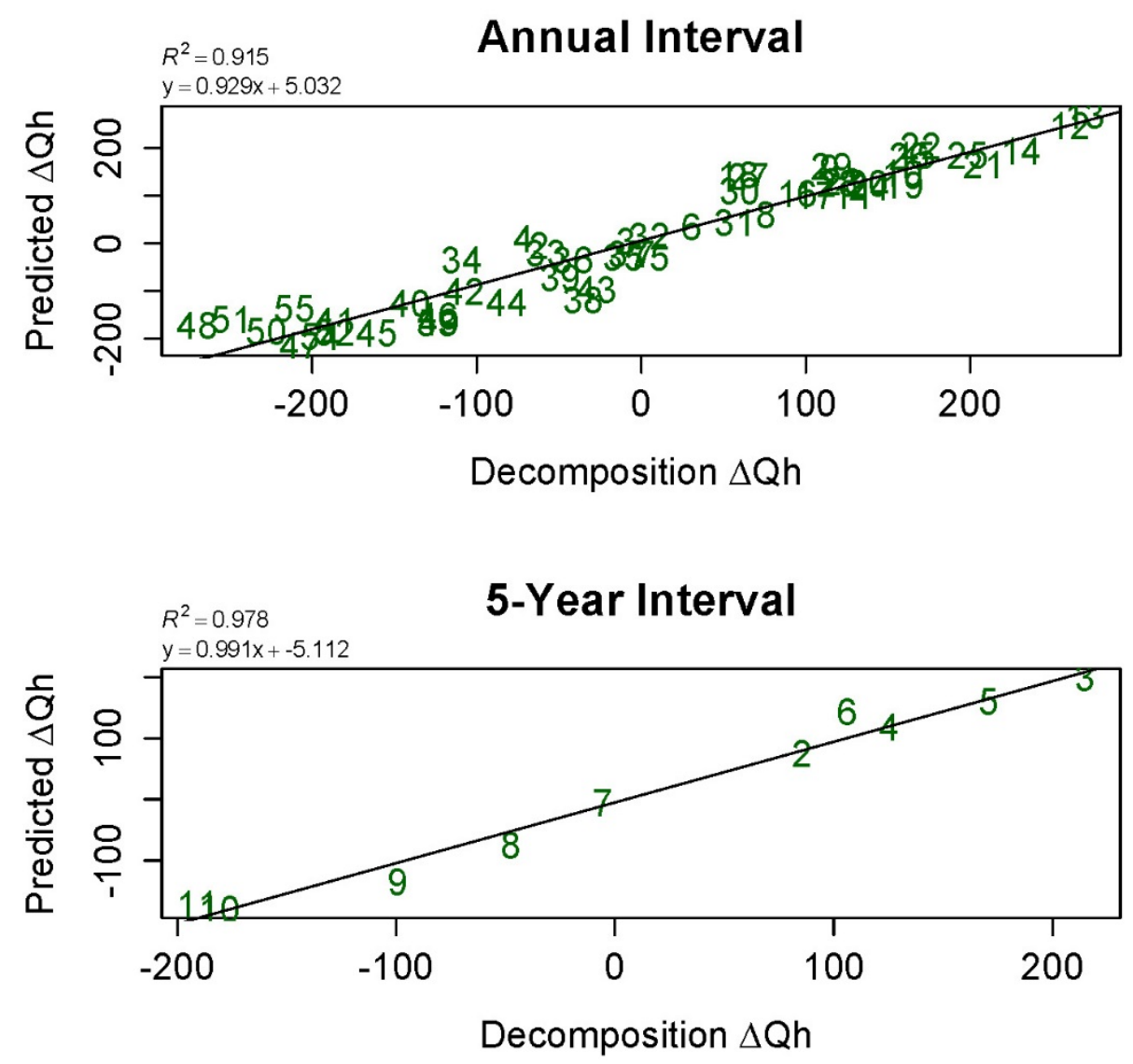

Figure 19. Validation of change in streamflow due to forest disturbance ( $\Delta \mathrm{Qh}$ ) for WS-6, modeled by the decomposition method (Decomposition $\Delta \mathrm{Qh}$ ) after correcting for sign and the paired catchment method (Predicted $\Delta \mathrm{Qh})$ at annual, and 5-year time intervals. The sign $(+/-)$ of decomposition derived $\Delta \mathrm{Q}_{\mathrm{h}}$, is determined based on the position above (negative) and below (positive) the curve. To test whether model underestimation was due to the sign of $\Delta \mathrm{Qh}$, the decomposition method was reapplied using the predicted baseline curve instead of the curve calibrated to long-term water balance data.

In contrast, the decomposition model did not perform well for any of the time scales used in this study for WS-1. One explanation is disturbance response magnitudes were not sustained over a long enough time period. Over the 60 year study period, annual Decomposition $\Delta \mathrm{Q}_{\mathrm{h}}$ at an annual scale did not agree with paired catchment results. However, if only the results of the first 10 years, that include the five years of hydrologic response, are considered, the model performed better $\left(R^{2}=0.64\right)$. As a result the accuracy of the decomposition method may be sensitive to the 
magnitude and duration of disturbance.

In addition, plots of AET/P estimated from calibrated curves vs. measured AET/P for each catchment show patterns that may also help explain the variation in model performance (Figures 20 - 23). In WS-6 and WS-7, Figures 22 and 23 show horizontal relationships between estimated AET/P and measured AET/P, reflecting the limitations of the curve for disturbed catchments. For the less disturbed WS-1 and reference WS-4, points are positioned around the 1:1 line (Figures 20 and 21). In general the annual points for WS-1 and WS-4 are more scattered, which is commonly attributed to variability in precipitation and flux in soil moisture storage (Donohue et al. 2010). In future studies these patterns may help identify catchments that could be modeled using the Budyko decomposition method. 


\section{WS-1, Plot A}

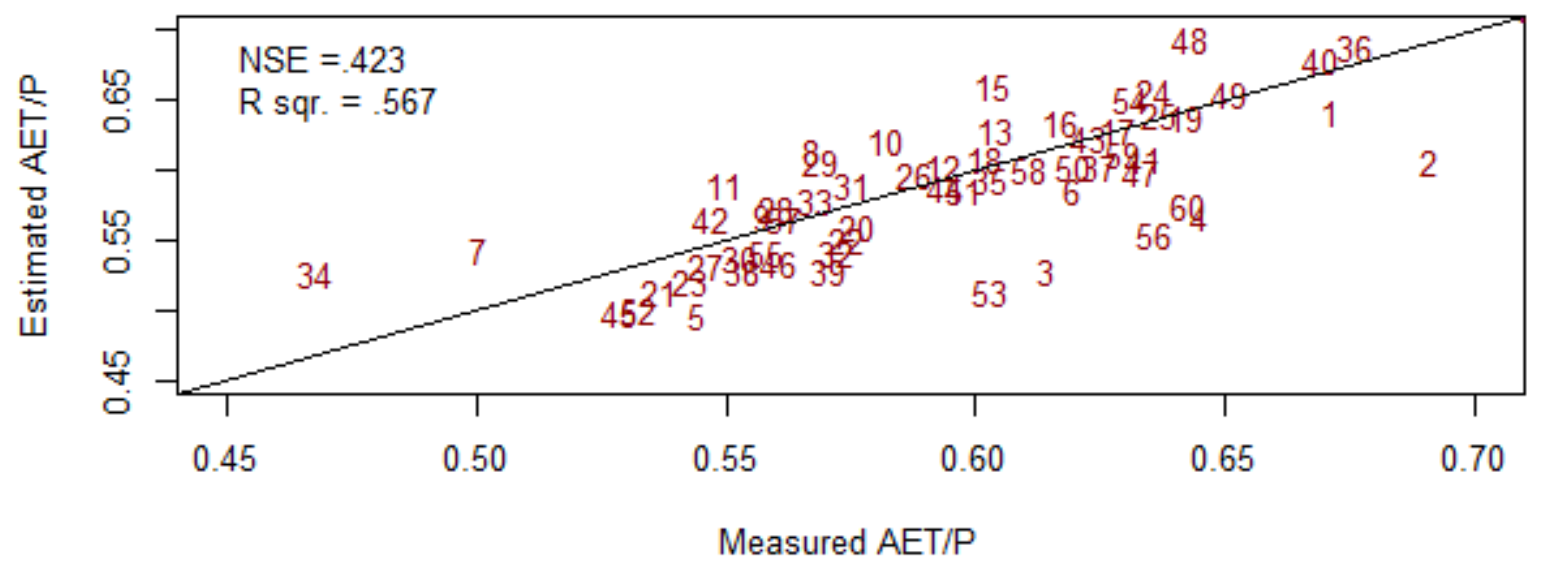

WS-1, Plot B

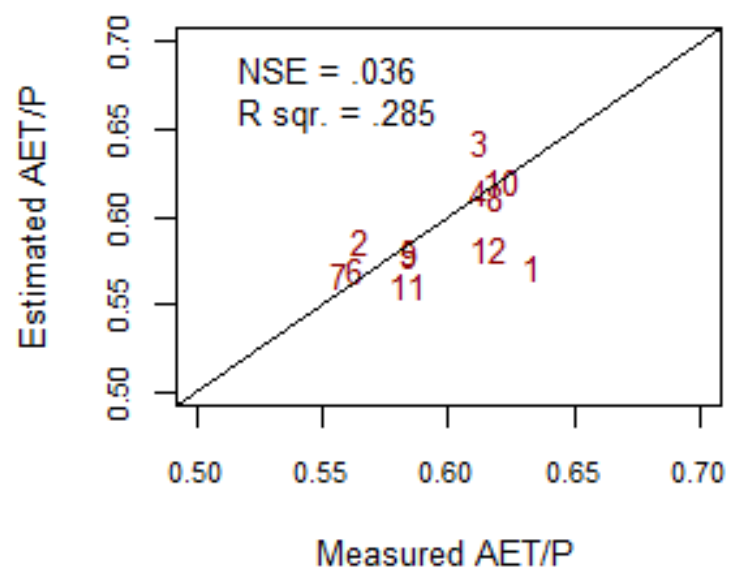

WS-1, Plot C

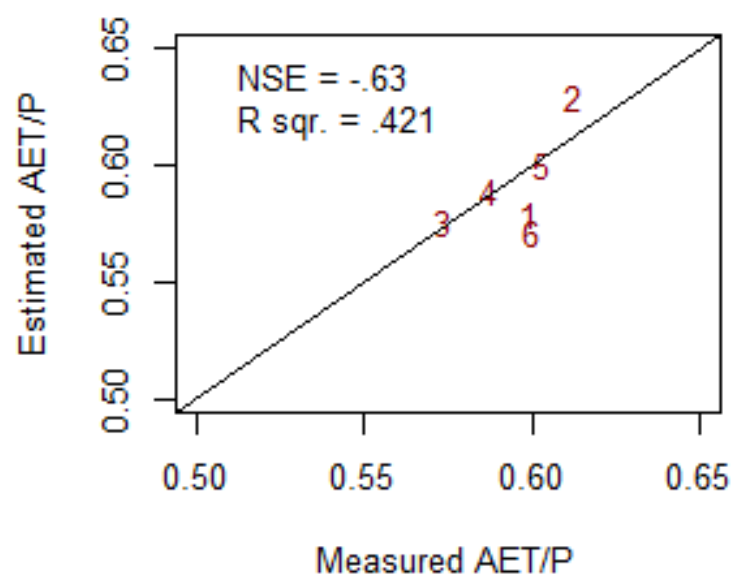

Figure 20. WS-1 measured evaporative index (mm/year) versus estimated evaporative index using Fu's equation calibrated to period 1 . Numbers correspond to chronology of time interval. Plot A: annual AET/P; Plot B: average AET/P over a 5-year interval; Plot C: average AET/P over a 10 -year interval. 


\section{WS-4, Plot A}

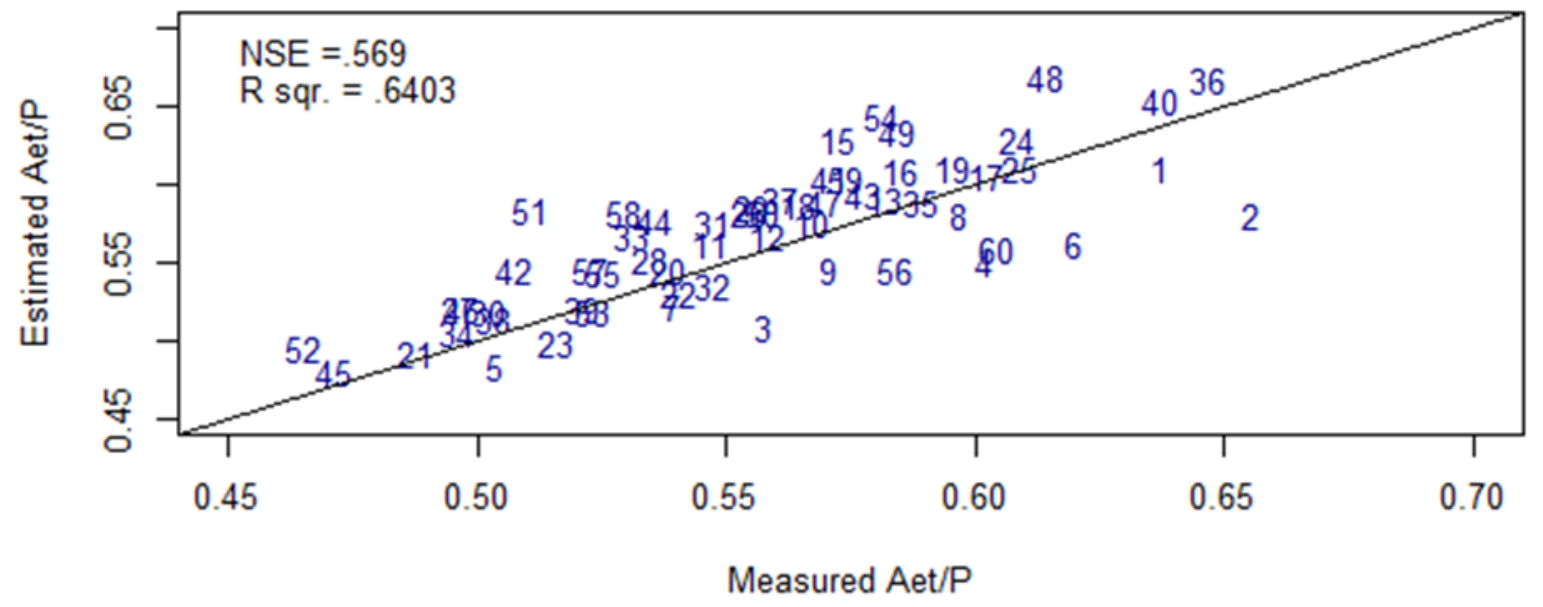

WS-4, Plot B

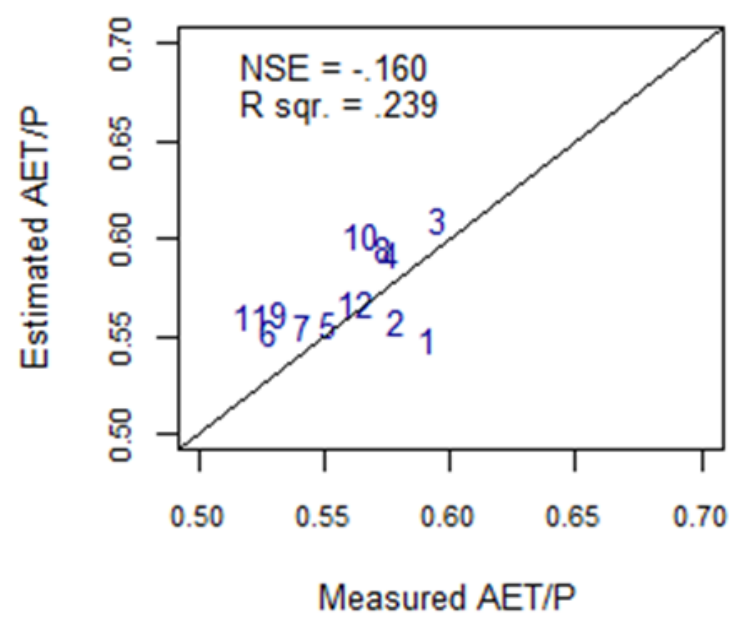

WS-4, Plot C

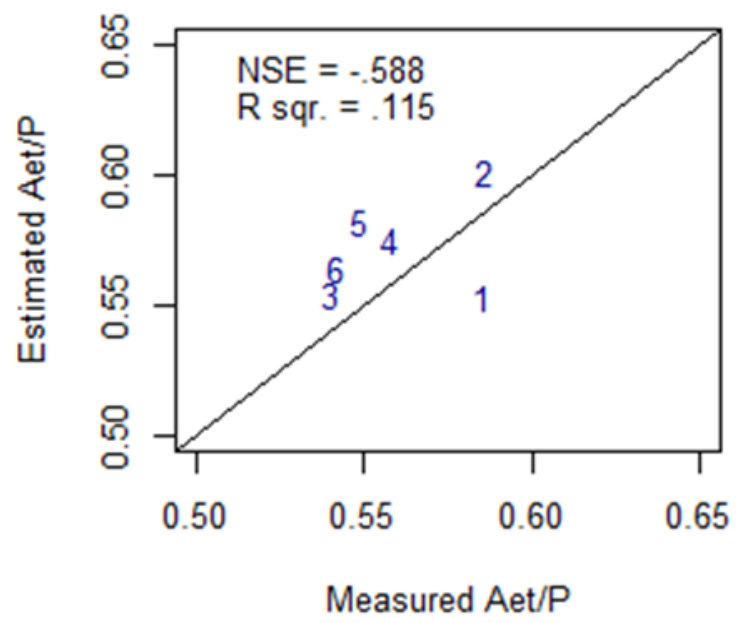

Figure 21. WS-4, measured evaporative index (mm/year) versus estimated evaporative index using Fu's equation calibrated to period 1. Numbers correspond to chronology of time interval. Plot A: annual AET/P, Plot B: Average AET/P over a 5 year interval, Plot C: Average AET/P over a 10 year interval. 


\section{WS-6, Plot A}

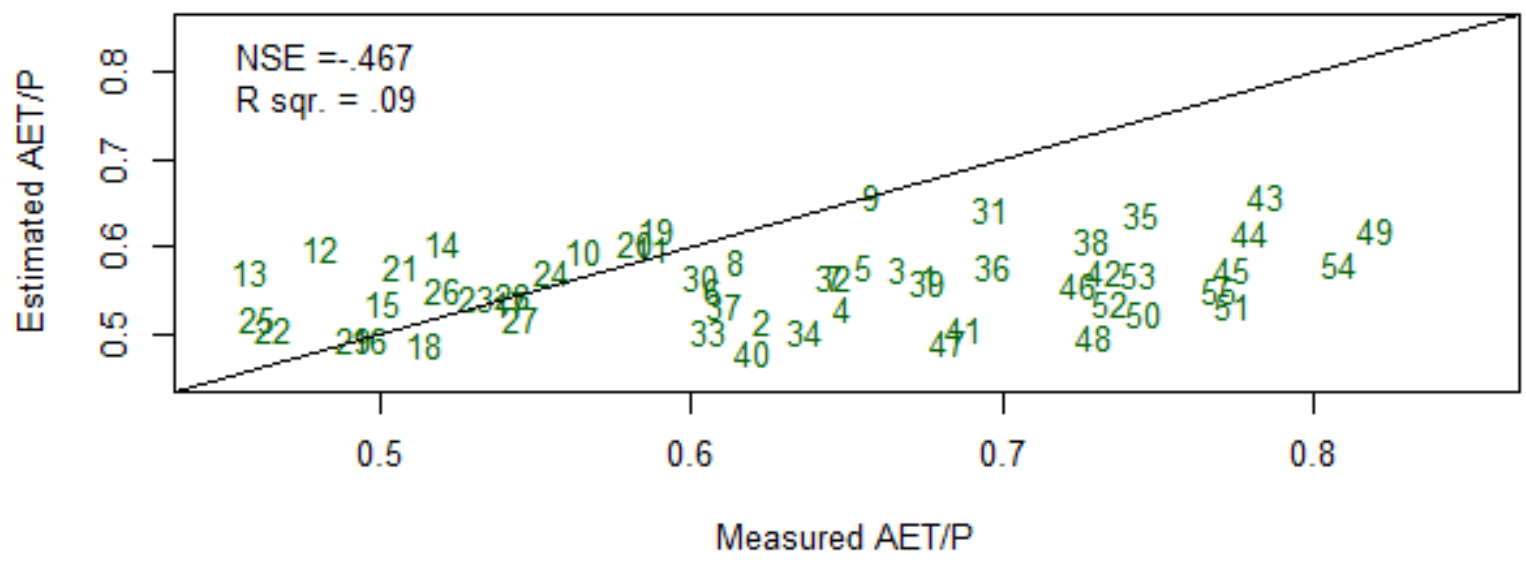

WS-6 Plot B

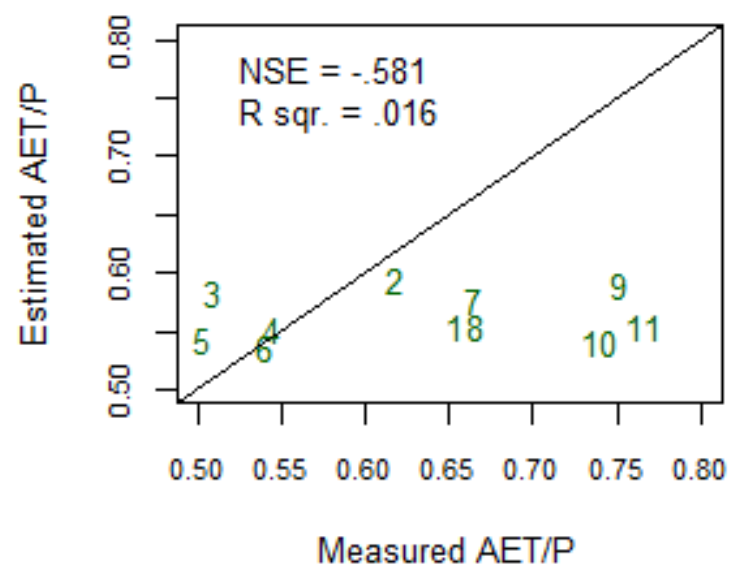

WS-6, Plot C

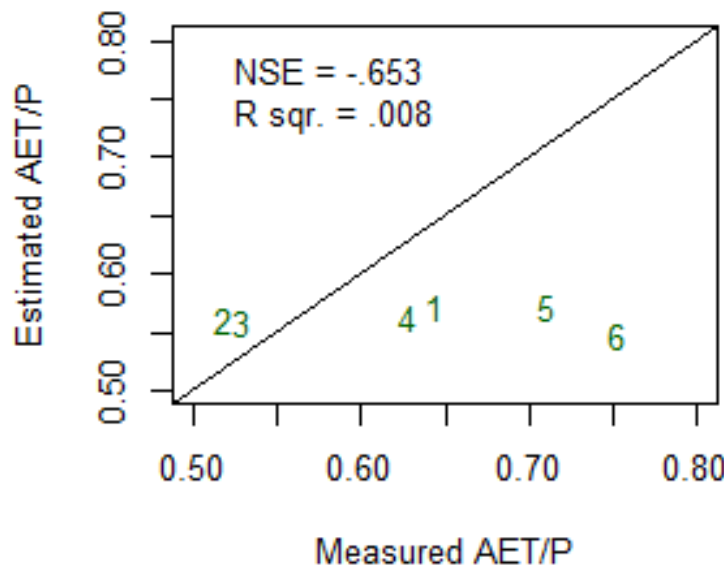

Figure 22. WS-6, measured evaporative index (mm/year) versus estimated evaporative index using Fu's equation calibrated to period 1. Numbers correspond to chronology of time interval. Plot A: annual AET/P, Plot B: Average AET/P over a 5 year interval, Plot C: Average AET/P over a 9 year interval. 


\section{WS-7, Plot A}

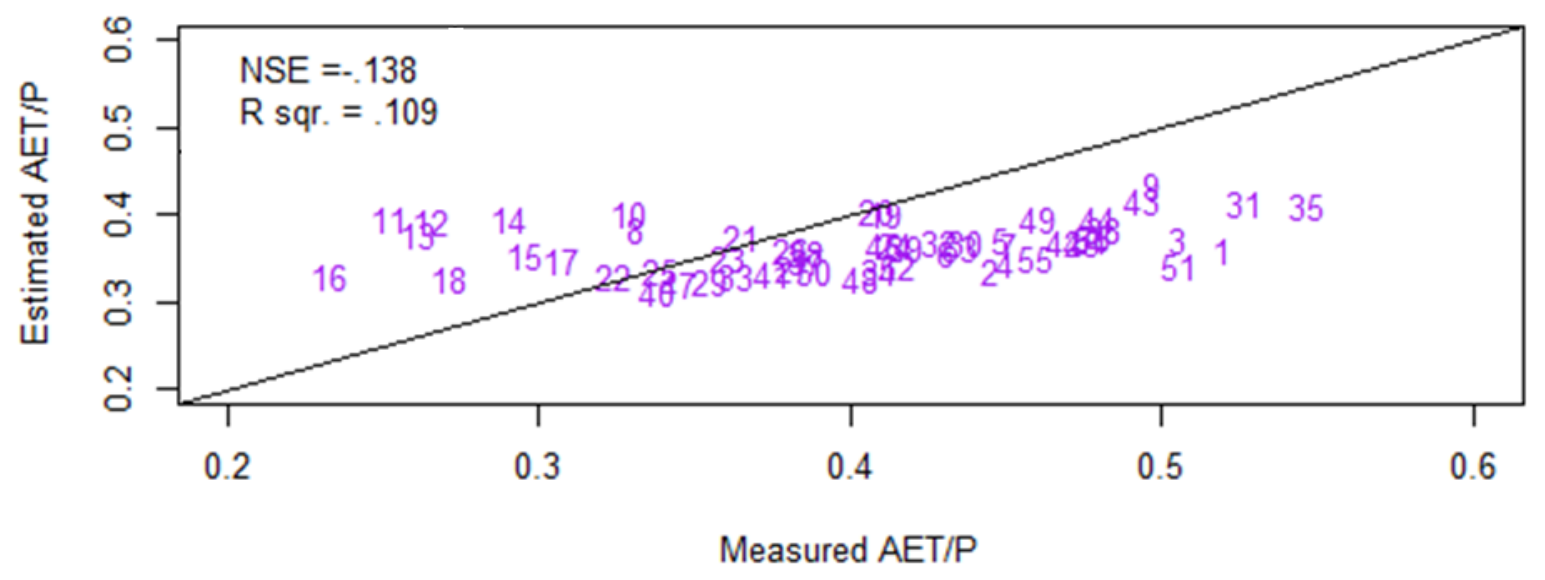

WS-7, Plot B

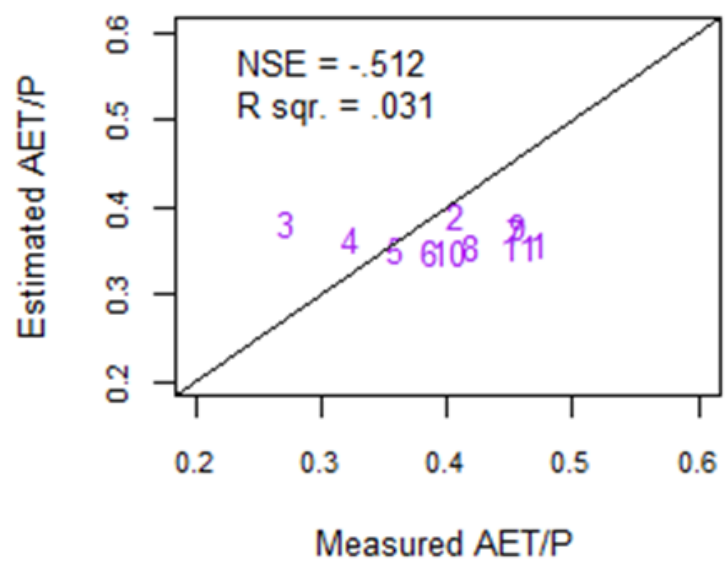

WS-7, Plot C

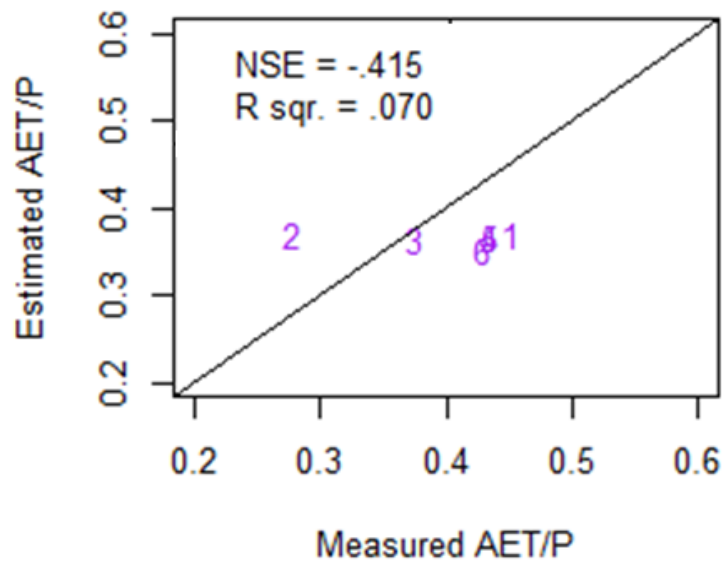

Figure 23. WS-7, measured evaporative index (mm/year) versus estimated evaporative index using Fu's equation calibrated to period 1. Numbers correspond to chronology of time interval. Plot A: annual AET/P, Plot B: Average AET/P over a 5 year interval, Plot C: Average AET/P over a 9 year interval. 


\section{5 | Conclusion}

In this study streamflow, precipitation, and temperature datasets spanning the last 60 years were used to quantify how forest disturbances and changes in climate have impacted streamflow at the Fernow Experimental Forest. The Budyko decomposition method was employed because it provides a formal means to assess temporal changes in streamflow within the Budyko framework; consequently, provides a dimensionless environment to facilitate watershed comparisons. By comparing the results of the decomposition method to the results obtained from the paired catchment method, the efficacy of the decomposition method and Budyko framework at the headwater scale and at fine temporal scales were examined.

Applying the decomposition method to long-term averages, showed the hydrology changed in response to forest disturbance, forest succession, and climate change. The extent of change was different for each catchment because of catchment characteristics, spatial variation in precipitation changes, and differences in the magnitudes of forest disturbances. This study showed that forest disturbances can dampen or mask the effects of climate change. Therefore, it is important to consider the effects of forest disturbance when assessing the effects of climate change on streamflow. At finer time intervals, climate variability greatly influenced streamflow variability. However, during the disturbance-response phase prior to vegetation recovery, disturbance was the dominate driver of streamflow variability.

Based on results of the paired watershed method, the decomposition method accurately quantified the effects of forest disturbance on streamflow for two of the three catchments analyzed. This suggests the Budyko Framework can be used at a headwater scale and at fine temporal scales, but not for all conditions. Decomposition model performance was best for catchments with the greatest disturbances (WS-6, WS-7). When using the calibrated curves and 
PET/P to predict AET/P, AET/P was underestimated for WS-6 and WS-7 compared to WS- 1 and WS-4. These findings can provide guidance for applying the Budyko decomposition method to small spatial and temporal scales. However, further research is needed to identify whether the approach works in other sites, including other physiographic and climatic regions. 


\section{6 | References}

Abrams, Marc D. "The red maple paradox." BioScience (1998): 355-364.

Abrams, Marc D., and Gregory J. Nowacki. "Historical variation in fire, oak recruitment, and post-logging accelerated succession in central Pennsylvania." Bulletin of the Torrey Botanical Club (1992): 19-28.

Ahn, Kuk-Hyun, and Venkatesh Merwade. "Quantifying the relative impact of climate and human activities on streamflow." Journal of Hydrology 515 (2014): 257-266.

Allen, Craig D., and David D. Breshears. "Drought-induced shift of a forest-woodland ecotone: rapid landscape response to climate variation." Proceedings of the National Academy of Sciences 95.25 (1998): 14839-14842.

Archibald, Josephine A., and M. Todd Walter. "Do Energy-Based PET Models Require More Input Data than Temperature-Based Models?-An Evaluation at Four Humid FluxNet Sites." JAWRA Journal of the American Water Resources Association 50.2 (2014): 497-508.

Barry, Roger G., and Richard J. Chorley. Atmosphere, weather and climate. Routledge, 2009.

Berry, Joseph, and Olle Bjorkman. "Photosynthetic response and adaptation to temperature in higher plants." Annual Review of Plant Physiology 31.1 (1980): 491-543.

Binkley, Dan, José L. Stape, Michael G. Ryan, Holly R. Barnard, and James Fownes."Agerelated decline in forest ecosystem growth: an individual-tree, stand-structure hypothesis." Ecosystems 5.1 (2002): 58-67.

Boisvenue, CÉLine, and Steven W. Running. "Impacts of climate change on natural forest productivity-evidence since the middle of the 20th century." Global Change Biology 12.5 (2006): 862-882.

Bosch, J. Mv, and J. D. Hewlett. "A review of catchment experiments to determine the effect of vegetation changes on water yield and evapotranspiration." Journal of hydrology 55.1 (1982): 323.

Brose, Patrick, Thomas Schuler, David Van Lear, and John Berst. "Bringing fire back: the changing regimes of the Appalachian mixed-oak forests." Journal of Forestry 99.11 (2001): 3035 .

Brown, Alice E., Lu Zhang, Thomas A. McMahon, Andrew W. Western, and Robert A. Vertessy. "A review of paired catchment studies for determining changes in water yield resulting from alterations in vegetation." Journal of hydrology 310.1 (2005): 28-61.

Budyko, M. "1., 1974: Climate and Life." International Geophysics Series 18 (1978). 
Byers, Elizabeth, and Sam Norris. "Climate change vulnerability assessment of species of concern in West Virginia." West Virginia Division of Natural Resources, Elkins, WV (2011).

Campbell, John L., Charles T. Driscoll, Afshin Pourmokhtarian, and Katharine Hayhoe. "Streamflow responses to past and projected future changes in climate at the Hubbard Brook Experimental Forest, New Hampshire, United States." Water Resources Research 47.2 (2011).

Carmona, Alejandra M., Murugesu Sivapalan, Mary A. Yaeger, and Germán Poveda. "Regional patterns of interannual variability of catchment water balances across the continental US: A Budyko framework." Water Resources Research (2014).

Choudhury, BhaskarJ. "Evaluation of an empirical equation for annual evaporation using field observations and results from a biophysical model." Journal of Hydrology 216.1 (1999): 99-110.

Creed, I. F., A. T. Spargo, J. A. Jones, J. M. Buttle, M. B. Adams, F. D. Beall, E. Booth et al. "changing forest water yield in response to climate warming: Results from long-term experimental watershed sites across North America.” Global change biology (2014).

Cushman, S.A., Gutzweiler, K., Evans, J.S., McGarigal, K. (2010). The Gradient Paradigm: A conceptual and analytical framework for landscape ecology [chapter 5] In: Cushman, S.A.; Huettmann, F., eds. Spatial complexity, informatics, and wildlife conservation. New York: Springer. p. 83-108.

Dawson, Todd E. "Determining water use by trees and forests from isotopic, energy balance and transpiration analyses: the roles of tree size and hydraulic lift." Tree Physiology 16.1-2 (1996): 263-272.

DeWalle, D. R., P. J. Edwards, B. R. Swistock, R. Aravena, and R. J. Drimmie. "Seasonal isotope hydrology of three Appalachian forest catchments." Hydrological Processes 11.15 (1997): 1895-1906.

Donohue, R. J., M. L. Roderick, and T. R. McVicar. "Can dynamic vegetation information improve the accuracy of Budyko’s hydrological model?." Journal of hydrology 390.1 (2010): 2334.

Donohue, R. J., M. L. Roderick, and T. R. McVicar. "On the importance of including vegetation dynamics in Budyko's hydrological model." Hydrology and Earth System Sciences Discussions 11.2 (2007): 983-995.

Dooge, J. C. I., M. Bruen, and B. Parmentier. "A simple model for estimating the sensitivity of runoff to long-term changes in precipitation without a change in vegetation." Advances in Water Resources 23.2 (1999): 153-163.

Dooge, James CI. "Sensitivity of runoff to climate change: A Hortonian approach." Bulletin of the American Meteorological Society 73.12 (1992): 2013-2024. 
Ebel, Brian A., and Benjamin B. Mirus. "Disturbance hydrology: challenges and opportunities." Hydrological Processes (2014).

Edwards, Pamela J.; Wood, Frederica. 2011. Fernow Experimental Forest daily streamflow. Newtown Square, PA: U.S. Department of Agriculture, Forest Service, Northern Research Station. http://dx.doi.org/10.2737/RDS-2011-0015

Emanuel, William R., Herman H. Shugart, and Mary P. Stevenson. "Climatic change and the broad-scale distribution of terrestrial ecosystem complexes." Climatic change 7.1 (1985): 29-43.

Ford, Chelcy R., Robert M. Hubbard, and James M. Vose. "Quantifying structural and physiological controls on variation in canopy transpiration among planted pine and hardwood species in the southern Appalachians." Ecohydrology 4.2 (2011): 183-195.

Fritsch, F. N. and Carlson, R. E. (1980) Monotone piecewise cubic interpolation, SIAM Journal on Numerical Analysis 17, 238-246.

Fu, B. P. "On the calculation of the evaporation from land surface." Sci. Atmos. Sin 5.1 (1981): 23-31.

Gentine, Pierre, Paolo D'Odorico, Benjamin R. Lintner, Gajan Sivandran, and Guido Salvucci. "Interdependence of climate, soil, and vegetation as constrained by the Budyko curve." Geophysical Research Letters 39.19 (2012).

Guttman, Nathaniel B., and Robert G. Quayle. "A historical perspective of US climate divisions." Bulletin of the American Meteorological Society 77.2 (1996): 293-303.

Hatcher, Kendra L. "Interacting effects of climate, forest dynamics, landforms, and river regulation on streamflow trends since 1950: Examples from the Willamette Basin and forested headwater sites in the US." Master’s thesis. Oregon State University, Corvallis. (2011).

Hamed, Khaled H., and A. Ramachandra Rao. "A modified Mann-Kendall trend test for autocorrelated data." Journal of Hydrology 204.1 (1998): 182-196.

Hayhoe, Katharine, Cameron P. Wake, Thomas G. Huntington, Lifeng Luo, Mark D. Schwartz, Justin Sheffield, Eric Wood et al."Past and future changes in climate and hydrological indicators in the US Northeast." Climate Dynamics 28.4 (2007): 381-407.

Hewlett, John D., and J. D. Helvey. "Effects of forest clear-felling on the storm hydrograph." Water Resources Research 6.3 (1970): 768-782.

Hewlett, John D., and Leon Pienaar. "Design and analysis of the catchment experiment." Symposium on Use of Small Watersheds in Determining Effects of Forest Land Use on Water Quality, Lexington, KY. 1973.

Hirsch, Robert M., and James R. Slack. "A nonparametric trend test for seasonal data with serial dependence." Water Resources Research 20.6 (1984): 727-732. 
Hornbeck, J. W., M. B. Adams, E. S. Corbett, E. S. Verry, and J. A. Lynch. "Long-term impacts of forest treatments on water yield: a summary for northeastern USA." Journal of Hydrology 150.2 (1993): 323-344.

Huntington, Thomas G. "Evidence for intensification of the global water cycle: review and synthesis." Journal of Hydrology 319.1 (2006): 83-95.

Jolly, William M., Ramakrishna Nemani, and Steven W. Running. "A generalized, bioclimatic index to predict foliar phenology in response to climate." Global Change Biology 11.4 (2005): 619-632.

Jones, Julia A., Irena F. Creed, Kendra L. Hatcher, Robert J. Warren, Mary Beth Adams, Melinda $\mathrm{H}$. Benson, Emery Boose et al. "Ecosystem processes and human influences regulate streamflow response to climate change at long-term ecological research sites." BioScience 62.4 (2012): 390404.

Jones, Julia A., and David A. Post. "Seasonal and successional streamflow response to forest cutting and regrowth in the northwest and eastern United States." Water Resources Research 40.5 (2004).

Karl, Thomas R., and Richard W. Knight. "Secular trends of precipitation amount, frequency, and intensity in the United States." Bulletin of the American Meteorological society 79.2 (1998): 231-241.

Kimball, John S., Kyle C. McDonald, Steven W. Running, and Steve E. Frolking."Satellite radar remote sensing of seasonal growing seasons for boreal and subalpine evergreen forests." Remote Sensing of Environment 90.2 (2004): 243-258.

Kirschbaum, Miko UF. "Forest growth and species distribution in a changing climate." Tree physiology 20.5-6 (2000): 309-322.

Knapp, Alan K., Claus Beier, David D. Briske, Aimée T. Classen, Yiqi Luo, Markus Reichstein, Melinda D. Smith et al. "Consequences of more extreme precipitation regimes for terrestrial ecosystems." Bioscience 58.9 (2008): 811-821.

Kochenderfer, J. N., P. J. Edwards, and J. D. Helvey. "Land management and water yield in the Appalachians." Watershed Planning and Analysis in Action. ASCE, 1990.

Kochenderfer, J. N., and G. W. Wendel. "Plant succession and hydrologic recovery on a deforested and herbicided watershed." Forest Science 29.3 (1983): 545-558.

Leonard, James, and Kevin Law. "Spatial and Temporal Variations in West Virginia's Precipitation, 1931-2000." Southeastern Geographer 52.1 (2012): 5-19. 
Li, Li-Juan, Lu Zhang, Hao Wang, Juan Wang, Jun-Wei Yang, De-Juan Jiang, Jiu-Yi Li, and Da-Yong Qin. "Assessing the impact of climate variability and human activities on streamflow from the Wuding River basin in China." Hydrological processes 21.25 (2007): 3485-3491.

Mann, Henry B. "Nonparametric tests against trend." Econometrica: Journal of the Econometric Society (1945): 245-259.

McCune, Bruce, and Dylan Keon. "Equations for potential annual direct incident radiation and heat load." Journal of vegetation science 13.4 (2002): 603-606.

McVicar, Tim R., Randall J. Donohue, Anthony P. O'Grady, and L. T. Li. "The effects of climatic changes on plant physiological and catchment ecohydrological processes in the highrainfall catchments of the Murray-Darling Basin: A scoping study." (2010).

Meinzer, Frederick C., David R. Woodruff, David M. Eissenstat, Henry S. Lin, Thomas S. Adams, and Katherine A. McCulloh. "Above-and belowground controls on water use by trees of different wood types in an eastern US deciduous forest." Tree physiology 33.4 (2013): 345-356.

Meinzer, F. C., B. J. Bond, J. M. Warren, and D. R. Woodruff. "Does water transport scale universally with tree size?." Functional Ecology 19.4 (2005): 558-565.

Milly, P. C. D., B. Julio, F. Malin, M. Robert, W. Zbigniew, P. Dennis, and J. Ronald."Stationarity is dead." Ground Water News \& Views 4.1 (2007): 6-8.

Milly, P. C. D., and K. A. Dunne. "Macroscale water fluxes 2. Water and energy supply control of their interannual variability." Water Resources Research 38.10 (2002): 24-1.

Milly, P. C. D. "Climate, soil water storage, and the average annual water balance." Water Resources Research 30.7 (1994): 2143-2156.

Monteith, J. L. "Evaporation and environment." Symp. Soc. Exp. Biol. Vol. 19. No. 205-23. 1965.

Patric, James H., and Kenneth G. Reinhart, Hydrologic effects of deforesting two mountain watersheds in West Virginia.” Water Resources Research 7.5 (1971):1182-1188.

Patterson, Lauren A., Brian Lutz, and Martin W. Doyle. "Climate and direct human contributions to changes in mean annual streamflow in the South Atlantic, USA." Water Resources Research 49.11 (2013): 7278-7291.

Peet, Robert K. "The measurement of species diversity." Annual review of ecology and systematics (1974): 285-307. 
Pitchford, Jonathan L., Chenjie Wu, LianShin Lin, J. Todd Petty, Richard Thomas, Walter E. Veselka IV, Danny Welsch, Nicolas Zegre, and James T. Anderson. "Climate change effects on hydrology and ecology of wetlands in the Mid-Atlantic highlands." Wetlands 32.1 (2012): 21-33

Poff, N. LeRoy, J. David Allan, Mark B. Bain, James R. Karr, Karen L. Prestegaard, Brian D. Richter, Richard E. Sparks, and Julie C. Stromberg."The natural flow regime." BioScience 47.11 (1997): 769-784.

Porporato, Amilcare, Edoardo Daly, and Ignacio Rodriguez-Iturbe. "Soil water balance and ecosystem response to climate change." The American Naturalist 164.5 (2004): 625-632.

Potter, N. J., L. Zhang, P. C. D. Milly, T. A. McMahon, and A. J. Jakeman. "Effects of rainfall seasonality and soil moisture capacity on mean annual water balance for Australian catchments." Water Resources Research 41.6 (2005).

R Core Team (2013). R: A language and environment for statistical computing. R Foundation for Statistical Computing, Vienna, Austria. ISBN 3-900051-07-0, URL http://www.R-project.org/.

Rao, L. Y., G. Sun, C. R. Ford, and J. M. Vose. "Modeling potential evapotranspiration of two forested watersheds in the southern Appalachians." Transactions of the ASABE 54.6 (2011): 2067-2078.

Reinhart, K.G., and A. R. Eschner. "Effect on streamflow of four different forest practices in the Allegheny Mountains,” Journal of Geophysical Research 67.6 (1962): 2433-2455.

Rind, David, R. Goldberg, J. Hansen, Cynthia Rosenzweig, and R. Ruedy.Potential evapotranspiration and the likelihood of future drought." Journal of Geophysical Research: Atmospheres (1984-2012) 95.D7 (1990): 9983-10004.

Roderick, Michael L., and Graham D. Farquhar. "A simple framework for relating variations in runoff to variations in climatic conditions and catchment properties." Water Resources Research 47.12 (2011).

Sivapalan, Murugesu. "Pattern, process and function: elements of a unified theory of hydrology at the catchment scale." Encyclopedia of hydrological sciences (2005).

Sperry, J. S., U. G. Hacke, R. Oren, and J. P. Comstock. "Water deficits and hydraulic limits to leaf water supply." Plant, Cell \& Environment 25.2 (2002): 251-263.

Stednick, John D. "Monitoring the effects of timber harvest on annual water yield." Journal of hydrology 176.1 (1996): 79-95.

Stocker, Thomas F., et al. "Climate change 2013: The physical science basis." Intergovernmental Panel on Climate Change, Working Group I Contribution to the IPCC Fifth Assessment Report (AR5)(Cambridge Univ Press, New York) (2013). 
Stoy, Paul C., Gabriel G. Katul, Mario Siqueira, Jehn-Yih Juang, Kimberly A. Novick, Heather R. McCarthy, A. Christopher Oishi, Joshua M. Uebelherr, Hyun-Seok Kim, and R. A. M. Oren. "Seperating the effects of climate and vegetation on evapotranspiration along a successional chronosequence in the southeastern US," Global Change Biology 12.11 (2006): 2115-2135.

Sun, Yu, Fuqiang Tian, Long Yang, and Heping Hu. "Exploring the spatial variability of contributions from climate variation and change in catchment properties to streamflow decrease in a mesoscale basin by three different methods." Journal of Hydrology 508 (2014): 170-180.

Swank, W. T., L. W. Swift Jr, and J. E. Douglass. "Streamflow changes associated with forest cutting, species conversions, and natural disturbances." Forest hydrology and ecology at Coweeta. Springer New York, 1988. 297-312.

Swank, Wayne T., and James E. Douglass. "Streamflow greatly reduced by converting deciduous hardwood stands to pine." Science 185.4154 (1974): 857-859.

Tarboton, D. G. and D. P. Ames, (2001), "Advances in the mapping of flow networks from digital elevation data,"World Water and Environmental Resources Congress, Orlando, Florida, May 20 - 24, ASCE, http://www.engineering.usu.edu/dtarb/asce2001.pdf.

Tetzlaff, D., C. Soulsby, J. Buttle, R. Capell, S. K. Carey, H. Laudon, J. McDonnell, K. McGuire, J. Seibert, and J. Shanley. "Catchments on the cusp? Structural and functional change in northern ecohydrology." Hydrological Processes 27.5 (2013): 766-774.

Troendle, Charles A. "A comparison of soil moisture loss from forested and clearcut areas in West Virginia." Research Notes. Northeastern Forest Experiment Station NE-120 (1970).

Vose, James M., Chelcy R. Ford, Stephanie Laseter, Salli Dymond, Ge Sun, Mary Beth Adams, Stephen Sebestyen, John Campbell, Charles Luce, and Devendra Amatya. "Can forest watershed management mitigate climate change effects on water resources?." IAHS-AISH publication (2012): 12-25.

Wagener, Thorsten, Murugesu Sivapalan, Peter Troch, and Ross Woods."Catchment classification and hydrologic similarity." Geography Compass 1.4 (2007): 901-931.

Wang, Dingbao, and Mohamad Hejazi. "Quantifying the relative contribution of the climate and direct human impacts on mean annual streamflow in the contiguous United States." Water Resources Research 47.10 (2011).

Wang, Xixi. "Advances in separating effects of climate variability and human activity on stream discharge: An overview." Advances in Water Resources 71 (2014): 209-218.

Weedfall, Robert O., and Walter Horward Dickerson. 'Climate of the Canaan Valley and Blackwater Falls State Park, West Virginia.” (1965). 
Wei, Xiaohua, and Mingfang Zhang. "Quantifying streamflow change caused by forest disturbance at a large spatial scale: A single watershed study." Water Resources Research 46.12 (2010).

White, Michael A., Forrest Hoffman, William W. Hargrove, and Ramakrishna R. Nemani. "A global framework for monitoring phenological responses to climate change." Geophysical Research Letters 32.4 (2005).

Wullschleger, Stan D., P. J. Hanson, and D. E. Todd. "Transpiration from a multi-species deciduous forest as estimated by xylem sap flow techniques." Forest Ecology and Management 143.1 (2001): 205-213.

WVDEP 2008, “The Importance of Headwater Streams on Annual Water Yield” WVDEP. N.p.,n.d. Web. 08, Apr. .08.

Yang, Dawen, Fubao Sun, Zhiyu Liu, Zhentao Cong, Guangheng Ni, and Zhidong Lei. "Analyzing spatial and temporal variability of annual water-energy balance in nonhumid regions of China using the Budyko hypothesis." Water Resources Research 43.4 (2007).

Yang, Dawen, Weiwei Shao, Pat J-F. Yeh, Hanbo Yang, Shinjiro Kanae, and Taikan Oki. "Impact of vegetation coverage on regional water balance in the nonhumid regions of China." Water Resources Research 45.7 (2009).

Zhang, Lu, W. R. Dawes, and G. R. Walker. "Response of mean annual evapotranspiration to vegetation changes at catchment scale." Water resources research 37.3 (2001): 701-708.

Zhang, Lu, K. Hickel, W. R. Dawes, Francis HS Chiew, A. W. Western, and P. R. Briggs."A rational function approach for estimating mean annual evapotranspiration." Water Resources Research 40.2 (2004).

Zhang, Xuebin, Francis W. Zwiers, Gabriele C. Hegerl, F. Hugo Lambert, Nathan P. Gillett, Susan Solomon, Peter A. Stott, and Toru Nozawa. "Detection of human influence on twentiethcentury precipitation trends." Nature 448.7152 (2007): 461-465.

Zhao, Fangfang, Lu Zhang, Zongxue Xu, and David F. Scott. "Evaluation of methods for estimating the effects of vegetation change and climate variability on streamflow." Water resources research 46.3 (2010). 
